Florida International University FIU Digital Commons

8-13-1997

\title{
Advertising effects on brand search and preference: assessing the mediational role of $\mathrm{Aad}$ and $\mathrm{Ab}$
}

Sandipa Dublish

Florida International University

DOI: $10.25148 /$ etd.FI15101236

Follow this and additional works at: https://digitalcommons.fiu.edu/etd

Part of the Advertising and Promotion Management Commons

\section{Recommended Citation}

Dublish, Sandipa, "Advertising effects on brand search and preference: assessing the mediational role of Aad and Ab" (1997). FIU Electronic Theses and Dissertations. 3093.

https://digitalcommons.fiu.edu/etd/3093 
Miami, Florida

\section{ADVERTISING EFFECTS ON BRAND SEARCH AND PREFERENCE: ASSESSING THE MEDIATIONAL ROLE OF Aad AND Ab}

A dissertation submitted in partial satisfaction of the

requirements for the degree of

DOCTOR OF PHILOSOPHY

IN

BUSINESS

by

Sandipa Dublish

1998 


\section{To: Joyce Elam}

College of Business Administration

This dissertation, written by Sandipa Dublish, and entitled 'Advertising Effects on Brand Search and Preference: Assessing the Mediational Role of $\mathbf{A a d}$ and $\mathbf{A b}$ ', having been approved in respect to style and intellectual content, is referred to you for judgement.

We have read this dissertation and recommend that it be approved.

Paul W. Miniard, Major Professor

Mike Barone

Eric Shaw

Kimberly Taylor

Date of Defense: August 13, 1997

The dissertation of Sandipa Dublish is approved.

Dean Joyce Elam

College of Business Administration

Dr. Richard Campbell

Dean of Graduate Studies

Florida Intermational University, 1998 
${ }^{\circledR}$ COPYRIGHT 1998 by Sandipa Dublish

All rights reserved 


\section{ACKNOWLEDGMENTS}

I would like to thank my fellow doctoral students; Minnie Dunbar, Lenn Gomes, Marissa Guillama, William Lucky, Sarah Maxwell, Justin Peart, Les Vermillion, and Laurie Zalka, for their friendship and support. A special thanks to Hilda Aguiar and Irene Young for creating a warm and pleasant office environment and providing the morning coffee.

I am grateful to Dr. John Nicholls for putting things in perspective and keeping me focused. Also, Dr. Barnett Greenberg for being a great chairperson, always sensitive to the needs of doctoral students. I would like to express my appreciation for all faculty members in the Department of Marketing; Dr. Goodrich, Dr. Hogner, Dr. Paul, Dr. Seaton, and Dr. Tsalikis, for their friendly and cooperative attitude.

My sincere respect goes to my advisor, Dr. Paul Miniard, for being tough and noncompromising. My heartfelt thanks to my committee members; Dr. Mike Barone, Dr. Eric Shaw, and Dr. Kim Taylor, for reading the various drafts of this dissertation and providing valuable comments.

Together, all of you made the $\mathrm{Ph} . \mathrm{D}$ experience so wonderful and memorable. Thank you Very Much! 


\title{
ABSTRACT OF THE DISSERTATION
}

\section{ADVERTISING EFFECTS ON BRAND SEARCH AND PREFERENCE: ASSESSING THE MEDIATIONAL ROLE OF Aad AND Ab}

\author{
by \\ Sandipa Dublish \\ Florida International University, 1998 \\ Professor Paul W. Miniard, Major Professor
}

Most advertising research has focussed at examining effects of advertising on attitudinal responses or brand preference and choice. However, in a natural environment, the time period between advertising exposure and purchase decision is filled with prepurchase search. Prepurchase external search refers to information search from sources other than memory, prior to making a purchase decision. Usually consumers access only a small subset of available information and base their choice decisions on it. Prepurchase search therefore acts as a filter and, the final 
choice depends critically on the small subset of potential inputs the consumer notes in the environment and integrates into the decision. Previous research has identified a variety of factors that affect consumers' prepurchase search behavior. However, there is little understanding of how specific advertisements designed by marketers impact consumers' prepurchase search. A marketer would like consumers to search information that reflects favorably on his/her brand. Hence, s/he would attempt to influence the brands and attributes on which consumers seek information prior to making a choice. The dissertation investigates the process by which a particular marketer's advertising influences consumers' search on available brands, i.e., the marketer's brand and other competing brands. The dissertation considers a situation where exposure to advertising occurs prior to seeking information from any other source. Hence, the impact of advertising on subsequent search behavior is the topic of interest. The dissertation develops a conceptual model of advertising effects on brand search and conducts two experiments to test the tenets of this model. Specifically, the dissertation demonstrates that attitudinal responses generated by advertising mediate advertising effects on search attitudes and behaviors. The dissertation goes on to examine how attitudinal responses generated by advertising and subsequent effects on search alter brand preference and choice. 


\section{TABLE OF CONTENTS}

CHAPTER

PAGE

ONE: INTRODUCTION . . . . . . . . . . . . . . . 1

TWO: PREPURCHASE INFORMATION SEARCH $\ldots \ldots \ldots \ldots$

Defining the Construct $\ldots \ldots \ldots \ldots \ldots \ldots$

Depth of Search . . . . . . . . . . . . . . . . . 6

Content of Search . . . . . . . . . . . . . . . . . . . 9

Sequence of Search . . . . . . . . . . . . . . . 10

Summary . . . . . . . . . . . . . . . . 12

THREE: ADVERTISING AND PREPURCHASE SEARCH $\ldots \ldots \ldots \ldots 14$

Advertising Influences on Attitudes . . . . . . . . . . . 14

Advertising Influence on Prepurchase Search . . . . . . . . . 17

Advertising, Search, and Brand Evaluation . . . . . . . . . 19

Summary . . . . . . . . . . . . . . . . . . 22

FOUR: CONCEPTUAL MODEL AND RESEARCH HYPOTHESES . . . 23

FIVE: RESEARCH METHODOLOGY . . . . . . . . . . . . . . . 29

Overview . . . . . . . . . . . . . . . . . . . . 29

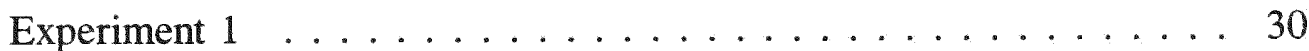

Research Design ................ . . . . 30

Computer Search Task . . . . . . . . . . . . . . 31

Stimulus Product . . . . . . . . . . . . . . . . 32

Independent Variables . . . . . . . . . . . . . 33

Ability to process . . . . . . . . . . . 33

Focal Brand Advertisement ........... . . 35

Subjects and Procedures . . . . . . . . . . . . . 35

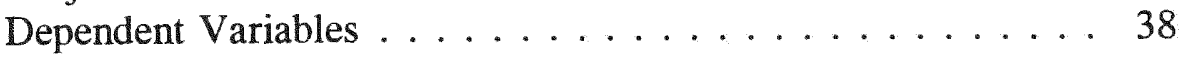

Subjective Knowledge . . . . . . . . . . . 38

Ability to Process . . . . . . . . . . . . 38

Attitude toward the Ad . . . . . . . . . . . 38

Attitude toward the Brand . . . . . . . . . . . . . . . 39

Attitude toward Search . . . . . . . . . . . . . 39

Task Involvement . . . . . . . . . . . . . . . . 39

Search Behavior . . . . . . . . . . . . . . . 40

Brand Preference and Choice ... . . . . . . . 41 


\section{TABLE OF CONTENTS}

CHAPTER

PAGE

FIVE: RESEARCH METHODOLOGY (contd)

Experiment $2 \ldots \ldots \ldots \ldots \ldots \ldots \ldots \ldots \ldots \ldots \ldots \ldots$

Research Design . . . . . . . . . . . . . . . 41

Independent Variables . . . . . . . . . . . . . . 41

Ability to Process . . . . . . . . . . . . . 4 41

Focal Brand Advertisement . . . . . . . . . . . . 41

Subjects and Procedures . . . . . . . . . . . . . . 42

Dependent Variables . . . . . . . . . . . . . . . . . 42

SIX: RESULTS: EXPERIMENT 1 . . . . . . . . . . . . . . . 44

Ability to Process Manipulation Check . . . . . . . . . . . . . 44

Task Involvement Induction . . . . . . . . . . . . . . . 45

Tests of Hypotheses . . . . . . . . . . . . . . . . . . 46

Effects on Attitude toward Searching Focal Brand (Asf) . . . 46

Effects on Attitude toward Searching Competing Brands

(Asc) . . . . . . . . . . . . . . . . . 48

Effects on Focal Brand Search . . . . . . . . . . . . 50

Effects on Competing Brand Search $(\mathrm{Sc}) \ldots \ldots \ldots 54$

Effects on Brand Preference and Choice .......... 56

SEVEN: RESULTS: EXPERIMENT $2 \ldots \ldots \ldots \ldots$. . . . . . . . 59

Ability to Process Manipulation Check . . . . . . . . . . . . 59

Task Involvement Induction . . . . . . . . . . . . . . . . . . . 59

Tests of Hypotheses . . . . . . . . . . . . . . . . . 60

Effects on Attitude toward Searching Focal Brand (Asf) . . . 60

Effects on Attitude toward Searching Competing Brands (Asc) . . . . . . . . . . . . . . . . . . 63

Effects on Search Behavior. . . . . . . . . . . 63

Mediational Analysis . . . . . . . . . . . . . 64 


\section{TABLE OF CONTENTS}

CHAPTER

PAGE

EIGHT: DISCUSSION . . . . . . . . . . . . . . . 65

Overview ......................... . . 65

Advertising Effects on Search Attitudes . . . . . . . . . . 65

Advertising and Search Behavior . . . . . . . . . . . 66

Attitudinal Mediators of Advertising Effects . . . . . . . . . 66

Experiment 2 Results . . . . . . . . . . . . . . . 67

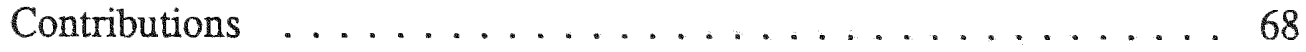

Limitations . . . . . . . . . . . . . . . . . . . . . . 69

Future Research . . . . . . . . . . . . . . . . . . 71

Marketing Implications . . . . . . . . . . . . . . . . 74

LIST OF REFERENCES . . . . . . . . . . . . . . . 76

APPENDICES ....................... 83 


\section{APPENDICES}

A: STIMULUS PRODUCT SELECTION SURVEY $\ldots \ldots \ldots . \ldots . \ldots 8$

B: RESULTS: STIMULUS PRODUCT SELECTION SURVEY . . . . . . 88

C: FICTITIOUS BRAND DESCRIPTIONS . . . . . . . . . . 90

D: INFORMATION TABLE PROVIDED TO SUBJECTS IN HIGH KNOWLEDGE GROUP . . . . . . . 9 92

E: FOCAL BRAND CONTROL AD: EXPERIMENT $1 \ldots \ldots$. . . . . . . 94

F: FOCAL BRAND STRONG CLAIMS AD: EXPERIMENT $1 \ldots \ldots 6$

G: COMPETING BRAND AD . . . . . . . . . . . . . 98

H: PURCHASE GOAL SCENARIO . . . . . . . . . . . . . 100

I: SURVEY INSTRUMENT: EXPERIMENT $1 \ldots \ldots$. . . . . . . . 102

J: FOCAL BRAND CONTROL AD: EXPERIMENT $2 \ldots \ldots \ldots$

K: FOCAL BRAND POSITIVE PERIPHERAL CUE AD:

EXPERIMENT $2 \ldots \ldots \ldots \ldots \ldots$ 


\section{SUMMARY OF TABLES}

1: SUMMARY OF MEASURES USED IN EXPERIMENT $1 \ldots \ldots$

2: SUMMARY OF MEASURES USED IN EXPERIMENT $2 \ldots \ldots$

3: CELL MEANS FOR MANIPULATION AND INDUCTION CHECKS:

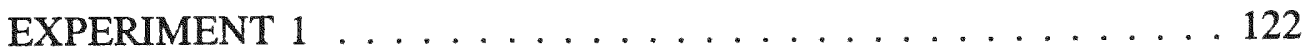

4: MANIPULATION AND INDUCTION CHECKS: EXPERIMENT 1

F-values for $2 \times 2$ ANOVAs . . . . . . . 123

5: ANALYSIS FOR H1: EXPERIMENT $1 \ldots \ldots \ldots \ldots$

6: ANALYSIS FOR H2: EXPERIMENT $\ldots \ldots \ldots \ldots \ldots \ldots$

7: ANALYSIS FOR H3a: EXPERIMENT $1 \ldots \ldots$. . . . . . . . 129

8: ANALYSIS FOR H3b: EXPERIMENT $1 \ldots \ldots \ldots \ldots$

9: ANALYSIS FOR H4a/b: EXPERIMENT $1 \ldots \ldots \ldots \ldots$

10: CELL MEANS FOR MANIPULATION AND INDUCTION CHECKS:

EXPERIMENT $2 \ldots \ldots \ldots \ldots$. . . . . . . . . . . 139

11: MANIPULATION AND INDUCTION CHECKS: EXPERIMENT $2 \ldots 140$

12: CELL MEANS FOR ATTITUDES AND BEHAVIOR:

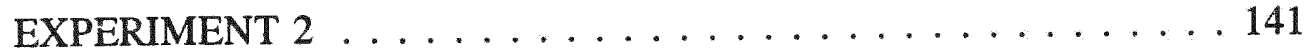

13: SEARCH ATTITUDES AND BEHAVIOR: EXPERIMENT $2 \ldots \ldots 143$

Figure 1: CONCEPTUAL MODEL $\ldots \ldots \ldots \ldots \ldots \ldots$ 


\section{CHAPTER ONE}

\section{INTRODUCTION}

Most advertising research has been directed towards understanding consumers' attitudinal responses to advertising, such as attitude toward the ad-Aad and attitude toward the brand-Ab (see MacInnis and Jaworski 1989 for a review). However, in the marketplace consumers have the opportunity to learn about products from a variety of sources, such as opinions of friends/family members, Consumer Reports etc. Often, the time period between advertising exposure and purchase decision may be filled with deliberations about which brand to buy and the search for information to help make this choice (Baker 1993).

Prepurchase information search refers to the gathering of information needed for making brand judgements and choice decisions (Bloch, Sherrell, and Ridgway 1986). A consistent finding across many studies is that consumers engage in limited information search (Katona and Mueller 1954; Newman and Staelin 1972). Usually, consumers access only a small subset of the available information and base their judgements and choices on the subset of information they have considered (Alba, Hutchinson, and Lynch 1991; Sheluga, Jaccard, and Jacoby 1979).

Given the importance of information search to product evaluation, marketers are interested in influencing consumers' search so as to benefit their own brand. Therefore, a marketer may want consumers to (1) include his/her brand in their search, (2) exclude or include certain other competing brands in their search, and 
(3) focus their search on attributes more favorable to his/her brand, i.e., attributes on which the brand is superior or comparable to competition. This dissertation is concerned with consumers' brand search behavior. This is in contrast to previous studies on prepurchase search which have primarily examined consumers' search behavior at the product category level, for example, purchase of an automobile, apparel, appliances etc. (see Beatty and Smith 1987 for a review).

Prepurchase search literature treats advertising as one of the many sources of information (i.e., a component of search) rather than an influencer of search behavior. However, advertising differs from other sources of information in that it is most directly controlled by the marketer and is very pervasive. Advertising messages account for a substantial proportion of all communication people receive from nonpersonal sources. In the United States, advertising occupies almost onefourth of the roughly 25 hours the average person spends weekly with television; nearly a fifth of the 20 hours spent with radio; fills three-fifths of the space in newspapers; and over half the pages in magazines (Bogart 1995, p.72).

Surveys have shown that advertising is sometimes welcomed by consumers and is perceived as informative and useful for making purchase decisions (Bogart 1989, p.49; Engel, Blackwell, and Miniard 1995, p.189). Advertising may contribute significantly to consumers' initial learning about products because (1) it is plentiful and repetitive (Wright and Barbour 1975) and (2) advertising information is available at virtually no cost to the consumer (Nelson 1974; Wernerfelt 1996). 
The dissertation considers a situation in which exposure to advertising occurs prior to seeking information from any other source. Hence, the impact of advertising on subsequent search behavior is the topic of interest. The dissertation investigates the process by which a particular marketer's advertising can influence consumers' search on available brands, i.e., the marketer's brand and other competing brands.

Consumers' information processing from advertising and consumers' information search behavior constitute two prominent research streams (see MacInnis and Jaworski 1989 and Srinivasan 1990 for reviews). However, presently there is little understanding of whether exposure to advertising affects consumers' information search behavior and, if so, in what ways? The association between advertising and information search behavior constitutes the focus of this dissertation. The dissertation develops a conceptual model of how exposure to a particular marketer's advertising impacts consumers' brand search.

The model puts forth 'attitude toward search' as the link between the adexposure context and the prepurchase search context. The construct of 'attitude toward search' is not new and has been incorporated in past studies. A strong positive relationship between attitude toward search and actual search behavior has been observed. Research has revealed that consumers with more positive attitude toward search spend more time and effort in searching information from a variety of sources (Beatty and Smith 1987). However, thus far the relationship between attitude to search and actual search, has been examined at the product category level 
and not at the brand level (Beatty and Smith 1987; Punj and Staelin 1983).

Another stream of research has demonstrated that advertising improves brand evaluation when it is seen prior to exposure to other factual or experiential information about the brand (Deighton 1984; Hoch and Ha 1986). Although it has been suggested that this effect is a result of advertising's influence on consumers' information search behavior, not much empirical evidence has been provided for this contention. This dissertation examines how attitudinal responses generated by advertising and subsequent effects on search alter brand preference and choice. The dissertation is organized as follows:

Chapter 2: Discusses relevant findings from the prepurchase information search literature.

Chapter 3: Discusses relevant findings from the advertising information processing literature and the advertisinginformation search relationship.

Chapter 4: $\quad$ Presents the conceptual model and consequent research hypotheses.

Chapter 5: Presents the research methodology.

Chapters 6 \& 7: Present the results from Experiments 1 and 2 respectively.

Chapter 8: Summarizes the dissertation and discusses the implications thereof. 


\section{CHAPTER TWO}

\section{PREPURCHASE INFORMATION SEARCH}

\section{Defining the Construct}

Information required for decision making can be acquired either from memory, i.e., internal search, or from other outside sources, i.e., external search (Bettman 1979). Past studies on information search have focused on understanding consumers' prepurchase external search effort, defined as "the degree of attention, perception, and effort devoted toward obtaining environmental data or information related to the specific purchase under consideration. The focus is directed toward active rather than passive search due to the ambiguity and difficulty of measuring passive search" (Beatty and Smith 1987, p.85). Srinivasan (1990) provides another definition of prepurchase external search as, "the conscious, goal-oriented behavioral response for acquisition of information from environmental stimuli (and not memory)," (p. 154). In line with previous research, this dissertation also studies consumers' active, prepurchase external search for information.

Three dimensions of prepurchase external search have been identified - depth, content, and sequence (Bettman 1978; Jacoby, Chestnut, and Fisher 1978). Depth of search refers to the total amount of information acquired, i.e., the total search effort exerted by consumers (e.g., number of brands searched, number of attributes searched, number of stores visited, total time spent on search). Content implies the specific pieces of information acquired (which brand? which attribute? from what 
source?). Sequence specifies the pattern of search, i.e., the order in which information is acquired (e.g., is it brand based versus attributes based; which brand or attribute is searched first? second?). Research findings concerning these three search dimensions are discussed in the following sections.

\section{Depth of Search}

Two theoretical perspectives summarize the major forces governing depth of prepurchase information search, which refers to consumers' total search effort. The first perspective comes from economics of information - EOI (Stigler 1961), which seeks to understand 'why' consumers search for information in terms of costs and benefits of search. According to EOI, one can determine the optimum amount of search effort by equating expected marginal benefits of search to the expected marginal costs of search. In other words, consumers will search for information until they reach the point at which the incremental benefits of search are less than the incremental costs of search. Costs of search include time, effort, and money spent in searching for information, frustration, and other psychological costs, such as the delay of the decision. Benefits of search include finding the most satisfactory option (lowest price, best quality), or feeling that one did a thorough job (Bettman 1979, p. 124). Lower search costs and higher search benefits increase search effort, whereas higher search costs and lower search benefits reduce search (Duncan and Olshavsky 1982).

There is considerable support for the link between costs-benefits and search 
effort. Lanzetta (1963) found that, as costs increased, less information was purchased. Bucklin (1966) found that lower shopping costs were related to greater external search from stores. Lutz and Reilly (1974) observed that in purchase situations where perceived risk was low, i.e., lower search benefits, consumers preferred to buy and try a product rather than seek information from other sources. Other researchers have noted that consumers search more for higher priced products, presumably because perceived risk, and consequently search benefits, are higher for expensive products (Bucklin 1966; Dommermuth and Cundiff 1967; Katona and Mueller 1954). Swan (1969) found that when subjects received payoffs (benefit) for making the optimal choice, search increased. Also, Claxton, Fry and Portis (1974) showed that presence of financial constraints for a consumer implied more search. If finances are tight, presumably cost savings (benefits of search) are more important. Another perspective for understanding consumers' information search behavior is the information processing perspective (Bettman and Park 1980; Johnson and Russo 1984). According to this perspective, search effort depends on consumers' motivation and ability to search for information. Motivation has been defined as the desire to expend effort on a task (Bettman 1979). Motivation to search could be influenced by several variables, such as an individual's need for cognition, product involvement, purchase involvement, or attitude toward shopping (Beatty and Smith 1987; Bloch, Sherrell, and Ridgway 1986).

Ability to search is defined as the perceived cognitive capability for searching 
and processing information, and involves cognitive processing ability, knowledge of sources of information, and knowledge of procedures for searching (Brucks 1985). Consumers' prior product knowledge is one factor that significantly determines their ability to search (Johnson and Russo 1984). Knowledge about a product category usually comprises awareness of product terminology, product attributes, attribute importance, product usage information, purchasing and decision making procedures (Engel, Blackwell, and Miniard 1995, p.338; Marks and Olson 1981).

More specifically, we can differentiate between (1) Brand knowledge knowledge of brand specific facts such as brand names, features possessed, performance, etc. and (2) Product category knowledge - knowledge of product terminology, relevant attributes, attribute covariance, etc. (Fiske, Lubbehusen, Miyazaki, and Urbany 1994; Punj and Staelin 1983). Most studies which used measures of product category knowledge have observed a positive relation between knowledge and search (e.g., Brucks 1985; Duncan and Olshavsky 1982), whereas studies which have measured brand knowledge have found a negative relationship between knowledge and search (e.g., Beatty and Smith 1987; Moore and Lehmann 1980).

Thus, consumers search less if they already possess relevant information on brands. Higher knowledge of the product in general, however, facilitates acquisition and comprehension of brand-attribute information (Miyake and Norman 1979). In a situation where consumers possess little brand knowledge, for example, when faced 
with new or unfamiliar brands, we would expect their search behavior to be primarily governed by their product category knowledge.

Usually the term 'product knowledge' is used to refer to product information that is stored in consumers' memory as a result of past experiences, information search, etc., and is retrieved when performing a particular task. However, even when such information is not stored in memory, ability to search can be enhanced by providing external information stimulus (Moorman 1990).

\section{Content of Search}

Content of information search, i.e., the specific items of information sought by consumers, is in large part determined by consumers' purchase goals for that particular situation (Bettman 1978). Goals are abstract attributes or benefits that consumers seek from the product, such as, an economical car versus a sporty car or an easy to use camera versus a versatile camera (Huffman 1996).

Prior product knowledge is yet another important determinant of search content. Specifically, consumers with higher levels of product knowledge seek product attribute information to make their own judgements about the product. In contrast, consumers possessing low product knowledge prefer to 'subcontract' the decision, i.e., seek judgements or recommendations from other personal/nonpersonal sources (Solomon 1986). Rosen and Olshavsky (1987) observed that subjects who made their own choice decisions, without relying on others' opinions, had significantly higher levels of product knowledge as compared to subjects who relied 
on others' judgements. Subjects who relied on others' recommendations acquired less product attribute information as compared to subjects who judged products by themselves. Brucks (1985) observed similar patterns. She found that the number of product attributes examined increased with an increase in consumers' prior product category knowledge. Subjects with higher levels of knowledge tended to rely on their own judgements whereas subjects with lower levels of knowledge tended to seek dealer recommendations.

Consumers with low levels of product knowledge do not seek information on specific product attributes because they are either unaware of which attributes to consider (Miyake and Norman 1979) or they lack the ability to comprehend the information obtained. Consumers with low levels of product knowledge are not able to infer related product benefits from attribute information (Maheswaran and Sternthal 1990). Maheswaran and Sternthal found that novices preferred advertisements that linked product attribute information with end benefits of the product over advertisements which provided attribute information only.

\section{Sequence of Search}

Sequence of search refers to the order in which the different brands and attributes are searched. Regarding attribute search, prepurchase search literature suggests that the order in which information is acquired for an attribute is highly correlated with its subjective importance (Holbrook and Maeir 1978; Sheluga, Jaccard, and Jacoby 1979). Hence, the more important an attribute, the greater the 
likelihood that it will be searched earlier in the prepurchase search task (Simonson, Huber, and Payne 1988).

A normative model of consumers' brand search behavior has been provided by Meyer (1982). According to this model, search on a brand is a function of its perceived utility. The higher the initial utility of a brand the greater the likelihood that it will be searched and searched earlier. The 'utility' of a particular brand is the level of preference the consumer associates with the brand at the onset of the search process. A reduced set comprising of brands with relatively higher utility values forms the focus for subsequent search. Thus, a brand will be searched only if it has a reasonable chance of being chosen. Such brands tend to be brands that have a higher initial preference. One indicator of brand utility is consumers' attitude toward the brand (Ab). Simonson, Huber, and Payne (1988) observed that information on brands with higher prior attractiveness (more favorable $\mathrm{Ab}$ ) was acquired earlier in the search process.

Meyer's (1982) model assumes that though consumers estimate the utility value of each alternative brand, the possibility that additional information may change the utility values (and therefore preference rankings) of available brands provides a motivation to search additional information. However, if one brand has a much higher utility value than other alternatives, further information will be less likely to affect utility rankings and choice. Hence, perceived benefits of additional information will be low, thereby reducing search effort (Hagerty and Aaker 1984). 
Therefore, a high prior utility associated with a specific brand could result in reduced search on competing brands.

\section{Summary}

This chapter outlined the major determinants of prepurchase search - costs versus benefits of search, consumers' motivation and ability to search, purchase goals, attribute importance, and brand utility. This dissertation is primarily concerned with consumers' brand search behavior, i.e., which brands are searched? in what order? how much search effort is devoted to each brand? An important determinant of brand search is the brand's expected utility at the commencement of the search task.

One indicator of brand utility is consumers' $\mathrm{Ab}$ (Simonson, Huber, and Payne 1988). Marketers rely considerably on advertising to help create a favorable attitude for their brand. A few studies have found that advertised brands are searched more than nonadvertised brands (Hoch and Ha 1986; Mothersbaugh 1996). One explanation for these findings could be that advertising encourages search on advertised brand(s) by creating favorable $\mathrm{Ab}$ and thereby enhancing perceived utility vis a vis competing brands.

Advertising is therefore expected to affect brand utility by creating a favorable or (unfavorable) $\mathrm{Ab}$. The main premise of this dissertation is that, when consumers are seeking information to make a purchase decision, initial exposure to advertising will influence their subsequent search for product information. Specifically, the 
dissertation investigates how a marketer can influence search on his/her brand and competing brands by using advertising to create a favorable attitude toward his/her brand. Chapter Three reviews research findings from the advertising information processing literature and develops the rationale for advertising's influence on prepurchase search. 


\section{CHAPTER THREE}

\section{ADVERTISING AND PREPURCHASE SEARCH}

\section{Advertising Influences on Attitudes}

Usually an important goal of advertising is to change consumers' attitudes in a direction more favorable to the advertised brand. Consequently, a primary focus of advertising based studies has been to understand how advertising affects consumers' attitude toward the advertised brand (see Belch, Belch, and Villareal 1987 and MacInnis and Jaworski 1989 for reviews). Research has shown that attitude toward the brand (Ab) is affected both by brand related beliefs (brand cognitions) and attitude toward the advertisement (Aad) itself (Gardner 1985; Lutz, MacKenzie, and Belch 1982; Mitchell and Olson 1981).

Aad not only affects $\mathrm{Ab}$, but also directly impacts 'brand interest'. Brand interest is defined as the "base level of approachability, inquisitiveness, openness, or curiosity an individual has about a brand; it is conceived as having a behavioral orientation much like exploring" (Machleit, Allen, and Madden 1993, p. 73). Aad was the primary antecedent of brand interest in the Machleit et al. study (because they were dealing with mature brands). Hence, even if an advertisement has minimal influence on consumers' brand attitudes, it could still lead them to 'think twice' or

stimulate an 'approach' response to the brand by creating brand interest (provided it generates a favorable Aad).

A particularly useful framework for understanding how consumers process 
information from advertising and the consequent attitudinal responses to it is provided by the elaboration likelihood model (ELM) put forth by Petty and Cacioppo (1986). According to the ELM, the influence exerted by various communication elements depends on the amount of issue-relevant thinking (elaboration) that occurs during processing. When elaboration is high, the central route to persuasion is followed, in which only those message elements relevant to forming a reasoned opinion (termed 'arguments') are influential. Conversely, the peripheral route to persuasion occurs under low levels of elaboration as elements that are irrelevant to developing a reasoned opinion (termed 'peripheral cues') become influential.

Elaboration, in turn, depends on consumers' motivation or ability during message processing (Petty and Cacioppo 1986). When situational or individual variables ensure high motivation and ability for issue relevant thinking, the elaboration likelihood is said to be high. As a consequence, the probability that the recipient follows central route processing is high. The peripheral route is traveled when motivation or ability is lacking (Engel, Blackwell, and Miniard 1995, pp.560$562)$.

Motivation is defined as the consumer's desire or readiness to process brand information in an advertisement. It is an internal readiness to process information, created by the personal relevance of the stimulus and facilitates greater information acquisition and elaboration (Moorman 1990). Ability refers to the consumer's skill 
or proficiency in interpreting brand information in an advertisement. The availability and accessibility of relevant knowledge structures provides the foundation for processing ability (MacInnis, Moorman, and Jaworski 1991). Hence, high ability implies that the prior knowledge necessary to interpret brand information is both present and accessed (Alba and Hutchinson 1987; Sujan 1985).

In ELM based studies, a typical manipulation for inducing higher motivation to process advertising information is to inform subjects that they are in a situation where they have to make a purchase decision (e.g., Petty, Cacioppo, and Schuman 1983). It would therefore be reasonable to assume that consumers who come across product advertising during the course of prepurchase search will be sufficiently motivated to process advertising information. The term 'sufficiently motivated' implies that consumers will make an effort to process and interpret advertising information. Hence, in this dissertation differences in subjects' processing of advertising information are expected to occur mainly on account of differences in their ability to process advertising information.

Research testing the ELM has been largely supportive of its validity (see Chaiken and Stangor 1987 for a review). In general, studies have confirmed the ELM prediction that the quality of message claims influences attitude judgements more when recipients are highly motivated or able to engage in greater elaboration (e.g., Cacioppo, Petty, Kao, and Rodriguez 1986; Petty, Cacioppo, and Schuman 1983). A strong claim is one which is "logically sound, defensible, and compelling" 
and a weak claim is one which is "open to skepticism and easy refutation" (Petty, Cacioppo, and Heesacker 1981, p.435). When motivation or ability is low, recipients attitudes are influenced by peripheral cues such as attractive pictures that are devoid of issue relevant information.

The sheer number of claims or amount of information presented in the advertisement may also be used as a peripheral cue. Petty and Cacioppo (1984) found that, irrespective of claim strength, advertisements providing six claims generated a more favorable attitude as compared to advertisements providing three claims amongst low involvement subjects. Therefore, brand attitudes may be more (less) favorable when the advertisement provides more (less) product information, regardless of the quality of message claims, when consumers view the advertisement under conditions of low motivation or ability.

\section{Advertising Influence on Prepurchase Search}

In a situation where consumers encounter advertising prior to seeking information from any other source, further search effort by consumers, following ad processing, should be determined by their perceived benefits of search. Search benefits after ad-exposure refer to consumers' perceptions that searching information beyond what is available at the advertising exposure stage will lead to a better decision (Urbany, Bearden, and Weilbaker 1988) - the improvement in value or price that the buyer believes can be obtained by searching (Stigler 1961). According to Meyer (1982), the higher the perceived utility of a brand, the greater should be the 
likelihood of it being searched. Also, the higher the perceived utility of the advertised brand, the lower should be the perceived benefits of conducting additional search. Brand utility post ad-exposure would be indicated by Ab (Simonson et al 1988).

Consider a situation where the marketer provides strong arguments i.e., information relevant to forming a reasoned judgement of the product in the advertisement. The stronger the arguments, the more positive will be the resultant Ab for consumers with higher ability (HA) to process the advertising information. Attitudes of consumers with lower ability (LA) will be less affected by argument strength. However, the presence of more (versus less) claims may itself lead to a more favorable $\mathrm{Ab}$ amongst this group. Hence, the presence of strong (more) arguments in an ad should create favorable $\mathrm{Ab}$ among both HA and LA consumers, resulting in a higher perceived utility of the advertised brand and increasing search on it.

In contrast, peripheral cues will have minimal impact on $\mathrm{Ab}$ when subjects viewing the ad have higher ability. Yet, such cues may increase the likelihood of searching focal brand by generating favorable Aad and thus enhancing interest in searching the focal brand. For consumers possessing lower ability to process, the effects of peripheral cues are expected to be stronger. Thus, positive peripheral cues will have a stronger impact on Aad and $\mathrm{Ab}$ for consumers with lower ability. Consequently, positive peripheral cues should raise the perceived utility of the focal 
brand and increase the chances of it being searched.

How would claims provided in the advertisement of one particular brand affect search on other competing brands? An advertisement presenting strong arguments in support of the brand should create a perception of superior brand performance and, hence, higher brand utility. As the utility of advertised brand increases relative to other available brands it should lower consumers' expectation of finding a better brand (than the advertised brand) in the market. If so, then this should lower perceived benefits of search and reduce search on competing brands (Urbany et al. 1988).

As peripheral cues have weak effects on Ab of HA consumers, use of such cues in advertising should have no effects on HA consumers' search on competing brands. However, positive peripheral cues should have stronger effects on $A b$ for consumers with lower ability to process product information. Thus, use of positive peripheral cues in advertising should raise the perceived utility of the focal brand, reduce perceived benefits of additional search, and therefore, reduce search on competing brands.

Advertising, Search, and Brand Evaluation

The ultimate objective of any marketing effort is to create a favorable disposition towards the advertised brand with a view to increasing its sales potential. A few studies in the marketing literature have examined how advertising influences interpretation of product information/trial in favor of the advertised brand (Deighton 
1984; Hoch and Ha 1986; Ha and Hoch 1989). Deighton's (1984) two stage model states that at stage 1 advertising creates tentative beliefs. These beliefs, in turn, bias the interpretation of objective product evidence (i.e., actual consumption experiences) at stage 2 , because consumers use heuristics that favor confirmation of ad-based beliefs.

Hoch and $\mathrm{Ha}$ (1986) demonstrated that exposure to advertising biased product judgements favorably in a situation where product trial was ambiguous (i.e., open to multiple interpretations) but not when it was unambiguous. Their findings also lend some support to the contention that advertising leads to more favorable brand evaluations by altering the manner in which consumers search for product information. In their study exposure to an ad for the focal brand resulted in a reallocation of attention to the focal brand, i.e., subjects spent greater time inspecting the focal brand when they saw its ad as compared to a 'no ad' condition. Further, inspection time emerged as a marginally significant covariate of advertising effects on brand evaluation in one out of the two experiments reported in the paper.

Whereas Hoch and $\mathrm{Ha}$ (1986) studied how the presence of advertising (as compared to absence of advertising) biased one aspect of information search behavior (i.e., inspection time), Mothersbaugh (1996) examined how changes in the content of advertising affected information search behavior. Mothersbaugh observed that adding positive nonsubstantive (i.e., peripheral) features to focal brand advertising increased the probability of it being searched. 
The integrated information response model (IIRM) put forth by Smith and Swinyard $(1983,1988)$ states that when consumers receive product information from advertising and trial, the items will be combined as:

$$
R=W_{\text {ad }} S_{a d}+W_{\text {trial }} S_{\text {trial }}
$$

where

$\mathrm{R}=$ evaluation of brand after exposure to advertising and trial

$\mathrm{W}=$ weight given to ad or trial information

$S=$ evaluative position advocated by ad or trial information

Hence, evaluation of a brand post information search would be an aggregation of two factors: (1) attitudes created by advertising and (2) evaluative implications of product information obtained during search. By creating more favorable Aad and $\mathrm{Ab}$, advertising can enhance brand evaluation (assuming product information obtained in search environment is not incompatible with ad induced attitudes). IIRM, however, makes no predictions (or assumptions) about how advertising may affect search and acquisition of potential product information.

Thus, the literature on advertising effects on information search and subsequent brand evaluations based on advertising and other product information is somewhat sketchy. This dissertation examines in greater detail the effects of ad generated attitudes on consumers' information search behavior and the impact of these attitudes plus information searched on brand preference and choice. 


\section{Summary}

This chapter integrated findings from the advertising information processing literature with findings from the prepurchase search literature, and provided an explanation of the process by which a particular marketer's advertising may influence consumers' search behavior. Advertising is expected to influence brand search search on the marketer's brand versus competing brands - by affecting Aad and $\mathrm{Ab}$, which together are expected to influence consumers' interest in knowing more about the brand as also its perceived utility. The dissertation contends that by affecting consumers' information search behavior, advertising alters the product evidence acquired by consumers in favor of the advertised brand and, consequently, affects brand preference and choice. 


\section{CHAPTER FOUR}

\section{CONCEPTUAL MODEL AND RESEARCH HYPOTHESES}

The conceptual model of advertising effects on search emerging from the discussion in Chapter Three is shown in Figure 1. The model depicts the process by which advertising for one particular brand is expected to affect prepurchase search on that brand and competing brands. Here it should be noted that the model deals with a situation where all brands available in the search environment are new or unfamiliar to the consumer. Hence, the consumer has no prior brand perceptions or preferences to guide his/her search except those created by advertising. Definitions of the terms used in the model are as follows:

1. Focal Brand Ad: focal brand refers to the particular brand whose advertisement will be manipulated and consequent effects on search studied. Focal brand advertising could take different forms to enhance Aad and Ab. In line with ELM, Aad and $\mathrm{Ab}$ could be enhanced by using either strong arguments or positive peripheral cues.

2. Consumer Ability: indicates consumers' skill or proficiency in interpreting brand information provided in the focal brand advertisement (MacInnis and Jaworski 1989).

3. Attitude Toward the Focal Brand Ad (Aad): consumers' evaluation of the focal brand's advertisement post ad exposure. 
4. Attitude Toward the Focal Brand (Ab): consumers' evaluation of the focal brand.

5. Brand Interest: consumers' inquisitiveness or curiosity to know more about the focal brand.

6. Perceived Search Benefits: consumers' expectations of finding a brand better than the focal brand through search.

7. Attitude Toward Searching Focal Brand (Asf): consumers' favorable or unfavorable disposition toward exerting time and effort to search information on the focal brand post ad exposure.

8. Attitude Toward Searching Competing Brands (Asc): consumers' favorable or unfavorable disposition toward exerting time and effort to search information on brands other than the focal brand post ad exposure.

9. Search on Focal Brand (Sf): search directed toward obtaining information on the focal brand. This would consist of the following measures - inclusion of the focal brand in the consideration set; search order of the focal brand (is it the first brand searched?); amount of information sought on the focal brand; and proportion of search effort devoted to the focal brand.

10. Search on Competing Brands (Sc): search directed towards obtaining information on brands, other than the focal brand, available in the search task. This would comprise of the following measures - number of other brands searched, amount of information sought on other brands, and 
proportion of search effort devoted to other competing brands.

11. Focal Brand Preference and Choice: refers to the relative preference and choice of focal brand, post information search.

According to the model, attitudinal responses to focal brand advertising (i.e., Aad and $A b$ ) affect attitude toward searching the focal brand (Asf) and, consequently, search on that brand. Attitudinal responses to advertising are dependent on the content of the focal brand advertisement, i.e., strength of arguments provided, type of peripheral cues used. Consumers' ability to comprehend the content of advertising will moderate their attitudinal response to a particular type of advertisement. For example, attitudes of consumers with higher ability to process product information will be less affected by positive peripheral cues, whereas attitudes of lower ability to process subjects will be significantly impacted by such cues.

Aad and Ab could affect focal brand search in two different ways. First, they may result in an interest to know more about the advertised brand (Machleit, Allen, and Madden 1993). This, in turn, should create a favorable attitude toward searching the focal brand and therefore encourage search on the focal brand. Second, they may enhance the brand's perceived utility at the commencement of search. The higher the perceived utility of the brand, the greater should be the likelihood of it being searched. 
Hence, any advertising element that creates a positive Aad or Ab should help increase search on the focal brand (Sf). Favorable Aad and $\mathrm{Ab}$ are expected to enhance the perceived utility of the brand plus create an interest in knowing more about the brand. Therefore:

$\mathrm{H1}$ : Following ad exposure, consumers' focal brand Aad and Ab will affect their Asf. The more favorable their Aad and Ab, the more favorable their Asf.

To affect search on other competing brands, the focal brand advertisement will have to impact consumers' perceived benefits of searching those brands. If advertising succeeds in creating a highly favorable $\mathrm{Ab}$ (i.e., enhance the perceived utility of the focal brand relative to competing brands), it should reduce consumers' expectation of finding a brand better than the focal brand through search (i.e., reduce perceived benefits of searching competing brands). Consequently, attitude toward searching competing brands (Asc) should be lowered. If so, less search should be conducted on competing brands (Sc).

H2(a): Following ad exposure, consumers' focal brand Ab will affect their perceived search benefits. The more favorable the focal brand $A b$, the lower their perceived search benefits.

H2(b): Following ad exposure, consumers' perceived search benefits will affect their Asc. The lower their perceived search benefits, the less favorable their Asc.

Given the positive relationship observed between attitude toward search and 
search behavior at the product category level (see Beatty and Smith 1987), and in line with other research which supports the attitude-behavior consistency (see Ajzen and Fishbein 1977; Fazio and Zanna 1978), it is predicted that attitude toward searching the focal (competing) brand(s) will govern the actual search behavior on focal (competing) brand(s):

H3(a): Sf depends on Asf. The former becomes more likely as the latter becomes more favorable

H3(b): Sc depends on Asc. The former becomes more likely as the latter becomes more favorable.

In line with past research which has indicated that exposure to advertising biases brand evaluations in favor of the advertised brand (Deighton 1984; Hoch and Ha 1986), it is predicted that:

$\mathrm{H} 4$ : Following ad-exposure, focal brand Aad and $\mathrm{Ab}$ will affect brand preference and choice. The more favorable the Aad and $\mathrm{Ab}$, the:

(a) higher the focal brand preference

(b) greater the focal brand choice probability

This completes the discussion of the conceptual model and the research hypotheses emerging from it. To summarize, the model posits that advertising effects on prepurchase search are mediated by the attitudinal responses to advertising, namely Aad and Ab. Two dimensions of search behavior are studied: (1) search on focal brand (Sf) and (2) search on brands other than the focal brand (Sc). The model then looks at the implications of ad generated attitudes and consequent search 
behaviors on focal brand preference and choice. The vertical line in the center of the model separates that part of the model which is borrowed from the advertising information processing literature (section to the left of vertical line) from the part which represents the contribution of this dissertation and indicates advertising's impact on attitude toward searching, search behavior, and brand preference and choice (section to the right of vertical line). 


\section{CHAPTER FIVE}

\section{RESEARCH METHODOLOGY}

\section{Overview}

Though the hypotheses put forth in Chapter Four could have been tested using correlational data, ${ }^{1}$ a more rigorous and definitive approach to causality entails manipulating ad content and then testing whether ad effects observed for a given construct are mediated by the presumed antecedents. Hence, an experimental design was used in the dissertation.

The conceptual model was tested empirically in two separate experiments. The experimental manipulations followed from the ELM (elaboration likelihood model) which states that elements of an ad, namely, arguments versus peripheral cues, are processed differently by subjects with high (low) ability and motivation. Specifically, brand attitude of subjects with higher ability and motivation to process is favorably affected by strong arguments but not positive peripheral cues. In contrast, both strong arguments and positive peripheral cues can favorably influence brand attitude of subjects with lower ability and motivation to process ad messages.

The first experiment was designed to study the effects of using strong arguments in advertising, and the second experiment was designed to study the

${ }^{1}$ Subjects could be shown any advertisement, followed by measures of attitudes and search behavior. Correlations between the different measures could be analyzed to interpret the strength of relationships. 
effects of using positive peripheral cues. Two factors were manipulated (1) content of the focal brand ad and (2) subjects' ability to process the information in the ads and search environment. It should be noted that the differences in ad processing between lower versus higher ability subjects were expected only in the condition where positive peripheral cues were used, i.e., Experiment 2. However, to maintain consistency in the reporting of results, the ability manipulation was used in both experiments.

The experiments were conducted in a computer lab. Subjects first read the purchase goal induction and were informed that their task was to choose a camera model for a particular (fictitious) person. The purchase goal induction was used to ensure a common purchase goal and create high levels of task involvement in all treatment conditions. Following this subjects answered questions pertaining to perceived and actual awareness of camera features and their ability to judge a good from a bad camera. They were then exposed to a few ads of fictitious camera models and given the opportunity to search information contained in the computer before making a choice.

\section{Experiment 1}

$\underline{\text { Research Design }}$

Experiment 1 used a 2 (ability: lower or higher) x 2 (ad content: control, strong arguments) factorial design. Sample sizes within each cell are presented in the table overleaf: 
Experiment 1: Sample Sizes

\begin{tabular}{||c|c|c|}
\hline \multirow{2}{*}{$\begin{array}{c}\text { Focal Brand Ad } \\
\text { Condition }\end{array}$} & \multicolumn{2}{|c|}{ Subject's Ability to Process } \\
\cline { 2 - 3 } & Lower & Higher \\
\hline Control & 20 & 20 \\
\hline Strong Arguments & 32 & 32 \\
\hline
\end{tabular}

\section{Computer Search Task}

Researchers' use of computer-controlled experiments to study information acquisition and search is increasing (e.g., Brucks 1985; Mothersbaugh 1996; Simonson, Huber, and Payne 1988). This study used a microcomputer program called Search Monitor (Brucks 1988). Search Monitor is a menu-driven user interface, with data collection and recording facilities.

Menu screens, which are created by the researcher for each experimental application, contain a message followed by a series of options. A subject's response or option choice to each menu determines the subsequent menu. Search Monitor keeps a record of the sequence of menus visited, the choices made at each menu, and the time expended at each menu. Subjects receive information on brands by filling in the blanks in questions such as:

"What type of does Brand have?"

Once a question is typed, the answer appears on the computer screen. If the question is asked on an attribute not incorporated into the research, the computer 
message informs the subject that there is no answer for that question.

The search environment simulated a typical in-store information environment where a consumer has access to information about available brands on a variety of attributes. The information provided is usually objective and phrased in technical terms (e.g., EV Compensation -2 to +2 ).

\section{Stimulus Product}

A pretest based on 35 undergraduate business students was used to identify a suitable stimulus product for this dissertation. Based on a review of products used in previous research studies, six products were chosen and students' views on these were sought. The products were: CD player, compact stereo, television, VCR, $35 \mathrm{~mm}$ camera, and camcorder. All six products are relevant to students and possess a variety of 'search' attributes, i.e., attributes which subjects could inspect prior to purchase (Nelson 1974). The presence of search attributes implied that subjects could make fairly well-informed decisions without product trial. For each product, students were asked questions to assess the following: product involvement; subjective knowledge; brand parity perception; likelihood of search prior to purchase. The survey instrument used for this purpose is presented in Appendix A.

Results from this pretest are shown in Appendix B. Findings indicated that on two factors, brand parity perception and likelihood of searching prior to purchase, there was little difference across the six products. However, students exhibited the lowest knowledge and usage scores for $35 \mathrm{~mm}$ camera and camcorder. The $35 \mathrm{~mm}$ 
camera was chosen as the stimulus product because (a) given the price range, a $35 \mathrm{~mm}$ camera purchase would be more realistic for students than a camcorder purchase and (b) business students indicated low knowledge and experience with this product, thereby rendering them as having 'low ability' to process product information. This was desirable as it made it easier to create a group of 'high ability' subjects using experimental manipulations.

As a first step toward developing fictitious brand descriptions, a list of various camera features was compiled using three sources: (1) Consumer Reports, (2) Popular Photography (a leading photography magazine), and (3) visits to retail outlets. An analysis of the features of available camera models revealed that some automatic features such as autoflash, autofocus, etc., are standard and available in all cameras. Differences are usually found on complex features such as exposure compensation and manual override. Description of fictitious brands were developed along the same lines.

Descriptions of the fictitious brands were arranged in a dominance hierarchy. The dominant brand ' $F$ ' was better than all other brands on at least one feature and worse on none. The focal brand 'A' was the 'third best' choice, as it was inferior to the dominating brand ' $F$ ' and one other competing brand ' $B$ ', but dominated all other brands (see Appendix C).

Independent Variables

Ability to process. For the purpose of this study the objective was to provide 
product relevant information to a group of subjects so that they would be more proficient in comprehending and interpreting brand information presented in the ads/search task. Thus, that group of subjects would have relatively higher levels of product information available and accessible to them when processing ad messages and conducting prepurchase search, thereby enhancing their ability to process product information. The higher ability (HA) subjects were therefore given information to enhance their understanding of the following (Brucks 1986):

1. product terminology: e.g., what do the terms 'exposure compensation' or ' manual override' refer to?

2. general attribute evaluations: e.g., manual override is desired over automatic features for complex photography tasks.

3. attribute expectations: refers to expectations of what constitutes a typical configuration of attributes and what performance levels can be typically expected from brands within that product category - e.g., a typical automatic camera offers a smallest field of $15 "$.

It was also important that this information be highly accessible to subjects when participating in the experiment (MacInnis, Moorman, and Jaworski 1991). This was accomplished by providing the subjects assigned to the HA condition an information table. The table provided a brief description of the important features in a camera and also indicated how a typical camera would perform on these features. Subjects could consult this information table at all times when viewing the 
ads and searching for information. The information table is presented in Appendix D.

Focal Brand Advertisement. Two separate ads were designed for the focal brand - control and strong arguments. The ads contained a headline followed by a picture of the camera itself, and then a description of brand features. The control ad was devoid of any information on specific product features. The strong arguments ad mentioned a number of specific product features, for example, "framing accuracy $=95 \% "$. The ads were pretested to ensure that the strong arguments ad generated more favorable attitudes as compared to the control ad. The focal brand ads are presented in Appendices $\mathrm{E}$ and $\mathrm{F}$.

Subjects and Procedures

Experiment 1 was conducted with 104 business undergraduates in Summer 1997. The experiment was conducted in a computer lab, and students received extra credit for participating in the research. As a first step, subjects read a scenario which provided the purchase goal induction. The scenario described an individual and his need to buy a camera. The scenario described 'Robert' as an individual who needed a camera for performing relatively complex photography tasks. The complex task was designed to facilitate differences in search between LA and HA subjects (Brucks 1985).

To increase involvement, subjects were asked to assume that Robert was a good friend of theirs. Subjects were also informed that they would have a chance 
of winning a cash reward of $\$ 100$ at the completion of the study. The chances of winning the reward were linked to the final choice they made. The more appropriate the chosen camera for Robert, the higher would be the subject's chance of winning the cash reward. The purchase goal scenario is presented in Appendix H.

All subjects were given the same scenario to read. The main objective of the scenario was to provide all subjects with an identical purchase goal. Goals are an important determinant of consumers' search behavior (Bettman 1979). Providing the same goal to all subjects ensured to a large extent that variations in search across subjects were not on account of differences in perceived purchase goals.

After the purchase goal induction, subjects were asked to answer a few questions designed to measure their subjective knowledge of automatic $35 \mathrm{~mm}$ cameras. Following this subjects were asked five other questions to assess their awareness of camera features and their ability to distinguish a good versus bad camera on particular features. The only difference between HA and LA subjects was that HA subjects were provided the information table (explained in the ability to process manipulation section).

Next, subjects were asked to examine the advertisement of the focal brand and one competing brand. Subjects in the control group saw a focal brand advertisement with minimal product information. In the other experimental group, advertisement for the focal brand was modified, i.e., strong arguments (product claims) were added to it. However, the competing brand advertisement remained the 
same. After viewing each ad, subjects responded to questions on Aad and $A b$.

The competing brand ad was included to detract subjects from paying undue attention to the focal brand, simply because it was the only brand advertised in the choice set. The competing brand ad contained a headline, picture of a camera, and a text which was descriptive but did not mention specific product features. This was done so that the competing brand ad would not interfere with the arguments provided in the focal brand ad (see Appendix G).

Following this, subjects were informed that six other brands were also available in the choice set and they had the option of searching additional information before making a choice between the eight available brands. At this point responses on perceived search benefits, attitude toward searching the focal brand, the advertised competing brand, and the rest of the nonadvertised competing brands were taken. Subjects were instructed on how to search for information on the computer. A list of attributes on which information about brands could be accessed was provided to the subjects on a separate sheet of paper. Subjects were also provided a note pad to write down information during the search task. The note pad served as an external memory device, thus reducing the need to go back and ask the same question again. This also mirrors a decision process which is not exclusively stimulus-based (refers to information acquired through search) nor memory-based (refers to information provided in the ad context), but has elements of both (Brucks 1985).

Once subjects had completed the search task and made a choice, they were 
asked to rate all eight brands in terms of choice preference. Finally, measures on subjects' task involvement, their satisfaction with the information available to them, and their confidence with the choice made, were collected. Subjects were also asked to indicate the purpose of the study. Most thought it was a study on information search. None of the subjects mentioned that the purpose was to understand how advertising influenced information search. The survey instrument is presented in Appendix I.

\section{Dependent Variables}

Subjective Knowledge. Subjects rated their knowledge of automatic cameras in general, and relative to the rest of the population, on two 7-point numerical scales. The scales were anchored: know very little/know a lot, and one of the least knowledgeable people/one of the most knowledgeable people. The Cronbach alpha coefficient of reliability for this two scale measure of subjective knowledge was .87 (also reported in Table 1).

Ability to Process. Subjects had to answer five questions specifically designed to assess their awareness of automatic camera features, and distinguish a good from a bad camera. A score of 1 was given for every correct answer. Hence the maximum score on ability to process index could be 5 and the minimum score was 0 . The reliability coefficient for this five scale measure was .86 .

Attitude toward the Ad. Subjects were asked to indicate their overall feelings toward the ad immediately after ad exposure on three 9-point numerical scales, 
anchored with endpoints: not likable/very likable; unfavorable/very favorable; and boring/very interesting. The Cronbach alpha coefficient of reliability for the three scale attitude toward the ad measure was .94 .

Attitude toward the Brand. Subjects reported their overall evaluation of the advertised brand on three 9-point numerical scales anchored with endpoints: bad/good; negative/positive; and dislike it very much/like it very much. The Cronbach alpha coefficient of reliability for this measure was .94.

Attitude toward Search. A single item 9-point numerical scale (with endpoints not at all interested/very interested) was used to measure attitude toward searching the focal brand. Similar single item scales were used for measuring attitude toward searching the (a) advertised competing brand and (b) all nonadvertised competing brands. Two measures of perceived search benefit were also taken, namely - the likelihood that additional search would help identify a brand superior to the (a) focal brand and (b) the advertised competing brand. Subjects responded on a 9-point scale with endpoints: very low likelihood/very high likelihood.

Task Involvement. Subjects were asked three separate questions (9-point scales) to assess their involvement with the experimental task. Subjects were asked how carefully they assessed the features of camera models in the experiment relative to how carefully they would assess features of (1) household products such as paper towels which typically indicate low involvement purchases, and (2) consumer 
electronics products such as stereos - which represent high involvement products (Mothersbaugh 1996). A third question asked subjects how important it was for them to choose the best camera model. The Cronbach alpha for the task involvement measure formed by aggregating these three scales was relatively low at .45. It was realized that the three items were measuring fairly disparate aspects of task involvement. Consequently, each was analyzed separately.

Search Behavior. Different measures of search behavior were obtained from the computer search task. Specifically, the following measures were analyzed: inclusion of focal brand in the consideration set; total number of questions asked on the focal brand; proportion of search effort devoted to focal brand; search priority of focal brand (i.e., how early in the search process was information acquired on the focal brand); number of competing brands searched; and number of questions asked for brands other than the focal brand.

Measures of total amount of search, such as total number of brands searched, total number of search questions asked, total time spent on search, etc., were not included in the analysis. The study focused on understanding how changes in advertising of focal brand affected search on the focal brand in relation to competing brands, hence, measures of total amount search were not relevant to the analysis. No predictions were made regarding total search effort as it was possible that increased search on focal brand would compensate for decreased search on competing brands and vice versa. 
Brand Preference and Choice. At the completion of the search task (i.e, when the subjects indicated they had enough information to make a decision), subjects were asked to choose the one brand they considered 'best' and were also asked to provide a preference rating for all eight brands.

\section{Experiment 2}

Research Design

Experiment 2 was a 2 (ability: low or high) x 2 (ad content: control or positive peripheral cues) factorial design. Subjects were assigned randomly to one of the four treatment conditions as shown below:

Experiment 2: Sample Sizes

\begin{tabular}{||c|c|c|}
\hline \multirow{2}{*}{$\begin{array}{c}\text { Focal Brand Ad } \\
\text { Condition }\end{array}$} & \multicolumn{2}{|c|}{ Subject's Ability to Process } \\
\cline { 2 - 3 } & Lower & Higher \\
\hline Control & 33 & 32 \\
\hline Positive Peripheral Cues & 33 & 32 \\
\hline
\end{tabular}

Independent Variables

Ability to Process. Subjects' ability to process was manipulated in the manner described in Experiment 1.

Focal Brand Advertisement. Two separate ads were designed for the focal brand - control and positive peripheral cues. The control ad contained a headline followed by two descriptive claims (but no mention of specific brand features) and 
a small picture of the camera at the bottom of the page. The positive peripheral cues ad had all the features of the control ad with two differences: (1) an attractive picture of two women playfully photographing themselves was included and (2) a more attractive font was used for writing the text.

Advertisements had to be designed such that the positive peripheral cues ad would generate a more favorable $\mathrm{Aad} / \mathrm{Ab}$ as compared to the control ad, but not affect beliefs about product performance. A pretest with 38 business undergraduates confirmed that the control and positive peripheral cues ads were performing as intended. The ads used in Experiment 2 are presented in Appendix $\mathrm{K}$ and L.

Subjects and Procedures

Experiment 2 was conducted with 130 business undergraduates in Summer 1997. The experimental procedure was similar to that of Experiment 1. Descriptions of brands used in the choice set remained the same.

Dependent Variables

The scales used in Experiment 2 were same as those used in Experiment 1. The reliability coefficients observed in Experiment 2 are presented in Table 2. As observed in Experiment 1, all measures except the task involvement scale had fairly high reliability coefficients. Hence, once again the three scales used for assessing task involvement were analyzed separately. Three new measures were added in Experiment 2 to assess subjects' brand beliefs after viewing the ad. Two measures pertained to subjects' beliefs about the advertised claims (in focal brand ad) - the 
camera's technological sophistication and user friendliness - and were measured using 9-point numeric scales. The third measure assessed subjects' inferences regarding the quality of pictures taken by the advertised camera. 


\section{CHAPTER SIX}

\section{RESULTS: EXPERIMENT 1}

\section{Ability to Process Manipulation Check}

Table 3 presents the cell means for the manipulation and induction check measures. The results of a 2-way ANOVA incorporating the two independent variables (ability to process and ad content) for each of these measures are shown in Table 4.

The ability to process manipulation was designed to vary the amount of product relevant information available to subjects while processing the ad and conducting prepurchase search. A successful manipulation required that subjects assigned to the lower ability (LA) group score low on the subjective knowledge measures and also on objective measures designed to assess their awareness and understanding of camera features, as compared to subjects assigned to the higher ability (HA) group. ${ }^{2}$ A 2-way ANOVA on the subjective knowledge and objective ability to process scales revealed that HA subjects scored significantly $(p<.001)$ higher on these measures (subjective: $\overline{\mathrm{x}}=4.35$; objective: $\overline{\mathrm{x}}=4.33$ ) as compared to LA subjects (subjective: $\overline{\mathrm{x}}=3.31$; objective: $\overline{\mathrm{x}}=1.42$ ). These results provide evidence for the success of the ability to process manipulation.

${ }^{2}$ The objective ability to process measure tested that subjects in the HA group had comprehended the product information provided to them, and could use it to make judgements about camera quality. Subjective knowledge measure tested subjects' confidence in their ability to make such judgements. 
Unexpectedly, the interaction between ability and ad content was significant $(\mathrm{p}<.05)$ for the objective ability to process measure. Examination of means revealed that LA subjects assigned to the control ad condition reported higher levels of ability to process $(\overline{\mathrm{x}}=1.90)$ as compared to LA subjects assigned to the strong arguments ad condition $(\overline{\mathrm{x}}=1.13)$. There is no apparent explanation for this difference, except that subjects in the two groups were not comparable on product knowledge at the beginning of the experimental task. However, the overall score was still very low, less than two out of a maximum possible of five, and much lower as compared to HA subjects. This marginal difference is therefore not expected to compromise the ability to process manipulation. No other significant differences were observed.

\section{Task Involvement Induction}

One assumption in this study was that subjects would be in a high involvement state, as they were placed in a situation requiring a purchase decision. Plus, subjects had a $\$ 100$ cash incentive to perform well on the task. Three measures were used to assess subjects' involvement with the study. Results from ttest's indicated that for two of the three measures, subjects' average scores were significantly higher than the scale midpoint of 5.0 (care vs paper towels: $\bar{x}=7.29$, $\mathrm{p}<.001$; care vs electronic products: $\overline{\mathrm{x}}=5.14, \mathrm{p}>.10$; importance of choosing the best model: $\overline{\mathrm{x}}=6.54, \mathrm{p}<.001)$.

2-way ANOVAs failed to reveal any significant $(p>.10)$ main or interactive 
effects for two of the involvement measures, thus indicating that under all conditions subjects had high (and comparable) levels of task involvement (see Tables 3 and 4). On the measure of attention given to the experimental task vis a vis effort put into buying electronic products, a marginally significant $(p<.10)$ effect of ad content was observed. LA and HA subjects who saw the control ad reported higher levels of attention as compared to those who saw the strong arguments ad. It is possible that, providing some of the relevant information in the ad reduced subjects need/effort to search for the same on their own. Hence, subjects in the strong arguments condition had to put less effort in the search task as compared to subjects in the control ad condition. However, given that this difference is marginal, plus no differences were found between experimental conditions on the other two measures, this does not compromise the task involvement induction.

\section{Tests of Hypotheses}

Effects on Attitude toward Searching Focal Brand (Asf). H1 predicted that following ad exposure, focal brand Aad and Ab will affect consumers' Asf. The more favorable the Aad and $\mathrm{Ab}$, the more favorable the Asf. Tables $5 \mathrm{~A}, \mathrm{~B}, \mathrm{C}$ present the relevant analysis for Aad, $\mathrm{Ab}$, and Asf measures. Two different ads were used for the focal brand. The control ad provided minimal information, whereas the strong arguments ad provided product feature information which reflected favorably on the focal brand. Based on the ELM it was expected that adding strong arguments to the focal brand ad would enhance Aad and Ab for both LA and HA subjects. A 2-way 
ANOVA on the Aad and $\mathrm{Ab}$ measures revealed a significant $(\mathrm{p}<.001)$ main effect of ad content (Table 5B). Both HA and LA subjects reacted more favorably to the strong arguments ad (HA: Aad $\bar{x}=6.29, \mathrm{Ab} \overline{\mathrm{x}}=6.95 ; \mathrm{LA}: \mathrm{Aad} \overline{\mathrm{x}}=6.02, \mathrm{Ab}$ $\overline{\mathrm{x}}=6.51)$ as compared to the control ad (HA: Aad $\overline{\mathrm{x}}=3.72, \mathrm{Ab} \overline{\mathrm{x}}=4.46$; LA: Aad $\bar{x}=3.93, A b \bar{x}=4.93)($ Table 5A).

A 2-way ANOVA on the single item scale used for measuring Asf revealed a significant $(\mathrm{p}<.001)$ main effect of ad content. HA and LA subjects expressed a more favorable Asf in the strong arguments condition (HA: $\bar{x}=5.74 ;$ LA: $\bar{x}=$ 6.19 ) as compared to the control ad condition (HA: $\overline{\mathrm{x}}=4.75$; LA: $\overline{\mathrm{x}}=3.70$ ). Thus, enhancing Aad and Ab by adding strong arguments did lead toward a more favorable disposition to search the focal brand.

According to the conceptual model, focal brand Aad and Ab were expected to mediate advertising effects on Asf. Analysis of covariance was used to examine the mediating role of $\mathrm{Aad}$ and $\mathrm{Ab}$ on $\mathrm{Asf}$. If $\mathrm{Aad}$ and $\mathrm{Ab}$ do indeed mediate advertising effects on Asf, we would expect that including these as covariates should reduce the main effect of ad content on Asf.

Though a 2-way ANCOVA was conducted, the results are presented only for the main effect of ad content (AC), as significant effects were observed on this dimension only. The first column in Table 5C shows the F-ratio and $\omega^{2}$ values for the main effect of ad content for Asf, as obtained in a 2-way ANOVA with no covariates. The $\omega^{2}$ statistic (Hayes 1963) reflects the proportion of variance in the 
dependent variable that can be accounted for by a particular treatment effect. The second column presents the residual F-ratios and the percentage change in the $\omega^{2}$ statistic $\left(\% \Delta \omega^{2}\right)$ as a result of using Aad and $A b$ as covariates (i.e., potential mediators) for $\mathrm{AC}$ (main effect of ad content). The percentage change in the $\omega^{2}$ statistic $\left(\% \Delta \omega^{2}\right)$ with a particular covariate indicates the magnitude of mediation attributable to that covariate (Hastak and Olson 1989).

The results show that Aad and $\mathrm{Ab}$ mediated $90 \%$ of the ad content effect on Asf. This coupled with the finding that the F-ratio for the ad content main effect became nonsignificant after the inclusion of $\mathrm{Aad} / \mathrm{Ab}$ covariates indicates that $\mathrm{Aad}$ and $\mathrm{Ab}$ are important mediators of focal brand ad effects on Asf. These results support H1.

Effects on Attitude toward Searching Competing Brands (Asc). H2a/b predicted that, following ad exposure, consumers' focal brand Ab will affect their Asc. It was expected that adding strong arguments to the focal brand ad would enhance $A b$, reduce perceived search benefits $(\mathrm{H} 2 \mathrm{a})$, and consequently lower Asc $(\mathrm{H} 2 b)$. This effect was expected for both HA and LA subjects. The relevant analysis for testing $\mathrm{H} 2$ is presented in Tables $6 \mathrm{~A}, \mathrm{~B}, \mathrm{C}$.

One measure of perceived search benefits looked at subjects' perceived likelihood of finding a brand better than the focal brand through search. Another measure looked at subjects' perceived likelihood of finding a brand better than the competing brand that was advertised along with the focal brand. 
2-way ANOVAs on the measures of perceived search benefits revealed a significant $(p<.01)$ main effect of ad content $($ Table 6B). As expected, perceived search benefits of finding a brand better than the focal brand were significantly lower when focal brand ad used strong arguments (LA: $\overline{\mathrm{x}}=6.72$; HA: $\overline{\mathrm{x}}=6.16$ ) as compared to when the control ad was used (LA: $\overline{\mathrm{x}}=7.95 ; \mathrm{HA}: \overline{\mathrm{x}}=7.25$ ) (Table 6A). In contrast, perceived search benefits of finding an option better than the advertised competing brand were lower when subjects saw the control focal brand ad (LA: $\overline{\mathrm{x}}=6.50 ; \mathrm{HA}: \overline{\mathrm{x}}=7.20$ ) and higher when subjects saw the strong arguments focal brand ad (LA: $\bar{x}=7.81 ;$ HA: $\bar{x}=7.84$ ). This seems appropriate when we examine the Aad and $\mathrm{Ab}$ scores for the advertised competing brand. The advertised competing brand received significantly $(\mathrm{p}<.001)$ lower scores from subjects who viewed the focal brand strong arguments ad (Aad: $\overline{\mathrm{x}}=4.83 ; \mathrm{Ab}: \overline{\mathrm{x}}=4.65$ ) as compared to subjects who viewed the focal brand control ad (Aad: $\overline{\mathrm{x}}=6.20 ; \mathrm{Ab}$ : $\overline{\mathrm{x}}=6.33)$.

A 2-way ANCOVA was used to examine the mediating effects of ad attitudinal responses. This analysis showed that $96 \%$ of the ad content main effect on perceived search benefits (likelihood of finding a better option that the focal brand) was mediated by $\mathrm{Aad} / \mathrm{Ab}$ (Table 6C). This finding supports $\mathrm{H} 2 \mathrm{a}$.

Regarding Asc, two measures were used. The first measure looked at subjects' attitude toward searching the advertised competing brand $\left(\mathrm{Asc}^{1}\right)$ and the second looked at subjects' attitude toward searching all nonadvertised competing 
brands $\left(A s c^{2}\right)$. The second measure, $A s c^{2}$, failed to provide any significant effects. The first measure, $A \mathrm{As}^{1}$, revealed a marginally significant $(\mathrm{p}<.10)$ effect of ad content. Specifically, Asc ${ }^{1}$ was lower when subjects viewed the strong arguments ad (LA: $\overline{\mathrm{x}}=5.69$; HA: $\overline{\mathrm{x}}=6.39$ ) and higher when subjects viewed the control ad (LA: $\overline{\mathrm{x}}=6.85 ; \mathrm{HA}: \overline{\mathrm{x}}=6.95$ ). Hence, enhancing focal brand Aad and $\mathrm{Ab}$ reduced the desire to search information on the advertised competing brand.

A 2-way ANCOVA was performed to assess the extent to which perceived search benefits mediated focal brand ad effects on Asc ${ }^{1}$. The ANCOVA revealed that perceived search benefits mediated $34 \%$ of the ad content effects on Asc'. Inclusion of perceived search benefits as a mediator rendered the main effect of ad content on $\mathrm{Asc}^{1}$ nonsignificant. Thus, perceived search benefits significantly mediated ad effects on $\mathrm{Asc}^{1}$.

Overall the results indicate that the focal brand ad failed to impact $\mathrm{Asc}^{2}$ (attitude toward searching the nonadvertised competing brands), but significantly impacted $\mathrm{Asc}^{1}$ (attitude toward searching the advertised competing brand). Thus, $\mathrm{H} 2 \mathrm{~b}$ is partially supported.

Effects on Focal Brand Search (Sf). H3a proposed that focal brand search (Sf) would be guided by Asf. The more favorable the Asf, the greater would be Sf. As discussed in the section pertaining to $\mathrm{H} 1$, Asf was significantly higher for subjects viewing the focal brand strong arguments ad as compared to subjects viewing the control ad. Given this, we would expect Sf to be higher (lower) for subjects who 
viewed the focal brand strong arguments (control) ad.

Several measures were used to track Sf. The first measure looked at the proportion of subjects who included the focal brand in their consideration set (i.e., searched information on the focal brand versus those who searched no information on focal brand). The second measure examined the search priority attached to the focal brand, i.e., whether it was the first brand searched or not. The third measure was a count of the number of search questions targeted at the focal brand. The fourth measure was a relative measure, i.e., the percentage of total search effort devoted to the focal brand.

The proportion of subjects who searched the focal brand at all (i.e., included it in their consideration set) under the different treatment conditions is presented in Table 7A. As can be observed, a fair proportion of LA subjects did not include the focal brand in their consideration set after viewing the control ad, whereas most subjects viewing the strong arguments ad did. In contrast, HA subjects' decision to search information on the focal brand did not appear to be affected by focal brand ad content. For the purposes of statistical evaluation, the data was analyzed using categorical modeling (CATMOD procedure in SAS: SAS Institute 1990). To examine whether ad content affected subjects' likelihood of searching the focal brand, a logit model describing search likelihood as a function of: (1) ad content (2) subject ability and (3) the interaction of the two was tested. Thus, search likelihood $=a d$ content + ability + ad content $x$ ability. A marginally significant main effect 
of ad content was found $\left(\chi^{2}=2.80, \mathrm{p}<.10\right)$, indicating that adding strong arguments to the focal brand ad increased the likelihood of the focal brand being searched.

Though HA subjects' search appeared to be less sensitive to changes in the ad content, the interaction effect was not significant $(p>.20)$. However, when the results for LA and HA subjects were analyzed separately, a significant difference was observed in the case of LA subjects $\left(\chi^{2}=5.53, \mathrm{p}<.05\right)$ but not HA subjects $\left(\chi^{2}=\right.$ $0.04, \mathrm{p}>.10)$

Changes in the focal brand ad content also impacted whether the focal brand was the first brand searched or not, as shown in Table 7B. The logit model revealed a significant interaction between ad content and ability to process for this measure $\left(\chi^{2}=4.16, p<.05\right)$. As can be seen from Table 7B, more (less) of the LA (HA) subjects searched the focal brand first when they saw the ad with strong arguments. Although the search pattern for LA subjects is consistent with $\mathrm{H} 3 \mathrm{a}$, such is not the case for HA subjects.

Why did a lower percentage of HA subjects search the focal brand first in the strong arguments ad condition even though it generated more favorable $\mathrm{Aad} / \mathrm{Ab}$ and Asf than the control ad? One possible explanation is that information provided in the strong arguments ad allowed HA subjects to evaluate focal brand performance, thus reducing the need to search it immediately. LA subjects could not assess focal brand performance from the information provided in the strong arguments ad, and 
therefore, searched it first as it was the brand with the highest appeal.

As there is no provision for incorporating a covariate in the CATMOD procedure, the mediation analysis needed to assess mediating effects of Asf on Sf was conducted using traditional ANCOVA procedures. However, prior to this, a traditional 2-way ANOVA was run and its results compared with the logit model. The ANOVA results were in line with the logit results, namely they too revealed a marginally significant main effect of ad content $(p<.10)$ on the percentage of subjects searching focal brand. Thus, it was considered appropriate to run 2-way ANCOVAs. The ANCOVAs revealed that Asf mediated $84 \%$ of advertising effects on the first measure of Sf (inclusion of focal brand in consideration set), and incorporating Asf as a covariate rendered the main effect of ad content nonsignificant (Table 7C).

Asf mediated $31 \%$ of the ad content/ability interaction effects on the second measure of Sf (focal brand searched first). However, the interaction effect remained marginally significant $(\mathrm{p}<.10)$ implying that Asf is a significant but not sole mediator of ad effects on sequence of search.

A 2-way ANOVA on the total number of search questions asked for the focal brand did not reveal any significant effects (Tables 7D/E). Similarly, significant effects were not observed for percentage of search effort devoted to the focal brand. However, the main effect of ad content was close to being considered marginally significant $(p=.11)$. The search patterns suggest that LA and HA subjects devoted 
a higher percentage of search effort to the focal brand in the strong arguments ad condition (LA: $\overline{\mathrm{x}}=23.14 \%$; HA: $\overline{\mathrm{x}}=21.26 \%$ ) as compared to the control ad condition (LA: $\overline{\mathrm{x}}=14.40 \%$; HA: $\overline{\mathrm{x}}=17.32 \%$ ) (Table 7D). When Asf was used as a covariate it mediated $33 \%$ of the ad content effect on percentage search effort devoted to the focal brand (Table 7E).

The results provide partial support for $\mathrm{H} 3 \mathrm{a}$ as enhancing Asf did affect three out of the four measures of focal brand search behavior. Also, Asf emerged as a significant but not sole mediator of advertising effects on focal brand search behavior. It should be noted that the four measures of search behavior may vary in terms of their sensitivity to ad manipulations. For example, while a more favorable Asf suggests greater odds of searching the focal brand, its impact on the amount of focal brand search is less direct.

Effects on Competing Brand Search (Sc). H3b predicted that Sc would be affected by Asc. The more favorable the Asc greater would be Sc. As regards search on the nonadvertised competing brands, three measures were taken. The first measure was a count of the number of brands searched. The second measure was a count of the number of search questions asked on nonadvertised brands, and the third measure looked at the percentage of search effort devoted to nonadvertised brands (Tables $8 D / E$ ). Significant effects were observed for the first measure only (number of nonadvertised brands searched). A significant $(p<.05)$ main effect of subject ability to process was observed, whereby HA subjects searched fewer brands $(\bar{x}=4.22)$ 
as compared to LA subjects $(\overline{\mathrm{x}}=5.08)$. However, the main effect of ad content was nonsignificant. Thus, changes in focal brand ad content had no effect on Sc for the nonadvertised competing brands.

Search behavior measures examined for the advertised competing brand were: (a) inclusion in the consideration set, (b) search priority, i.e., whether it was the first brand searched, (c) number of search questions asked, and (d) percentage search effort devoted. Results for the first measure of Sc are presented in Table 8A. Logit model using the CATMOD procedure revealed a marginally significant $(\mathrm{p}=.11)$ effect of ad content on this measure. Hence, fewer subjects included the advertised competing brand in their consideration set when the focal brand ad presented strong arguments. 2-way ANCOVA using Asc (advertised competing brand) as a covariate indicated that it mediated $45 \%$ of the focal brand effects on this measure of Sc (Table 8B).

The second measure of search (Table $8 \mathrm{C}$ ) revealed that the percentage of subjects searching the advertised competing brand first did not differ significantly under the two treatment conditions. The third measure - number of search questions asked - revealed a significant $(\mathrm{p}<.05)$ main effect of subject ability to process (Table 8E). HA subjects asked fewer questions on the advertised competing brand ( $\overline{\mathrm{x}}=$ $2.04)$ as compared to LA subjects $(\overline{\mathrm{x}}=3.14)$. The advertised competing brand was the worst brand in the set. These results imply that HA subjects were able to assess 
this by asking fewer questions as compared to LA subjects. The fourth measure, percentage search effort devoted to the advertised competing brand, produced no significant results (Table $8 \mathrm{E})$.

When discussing focal brand ad effects on attitude toward searching competing brands it was noted that changes in focal brand advertising only influenced Asc $^{1}$ (attitude toward searching the advertised competing brand), but failed to impact $\operatorname{Asc}^{2}$ (attitude toward searching nonadvertised competing brands). These results explain why no significant differences were observed in search on nonadvertised competing brands between the different experimental conditions. Yet, $\mathrm{H} 3 \mathrm{~b}$ receives little support, as changes in focal brand ad content affected only one out of the four measures of Sc for the advertised competing brand.

Effects on Brand Preference and Choice. $\mathrm{H} 4 \mathrm{a} / \mathrm{b}$ hypothesized that favorable attitudes generated by the focal brand ad would enhance subjects' preference for and likelihood of choosing the focal brand. At the completion of the search task, subjects were asked to choose one brand and were also asked to provide a preference rating for all the eight brands available in the choice set. A rating of ' 1 ' was the best and a rating of ' 8 ' was the worst. Recall that the correct rating of the focal brand was ' 3 ' and the correct rating for the advertised competing brand was ' 8 '.

For the purpose of analysis, subjects' preference ratings for the focal brand were grouped into three categories: (1) more favorable than actual, (2) same as actual, and (3) less favorable than actual. For the advertised competing brand only 
two categories were used: (1) more favorable than actual and (2) same as actual. The ratings obtained by the two brands are presented in Tables 9A/B.

Logit models derived using the CATMOD procedure revealed a significant main effect of ad content on focal brand preference rating $\left(\chi^{2}=10.64, p<.01\right)$ and on advertised competing brand preference rating $\left(\chi^{2}=5.76, p<.05\right)$. Specifically, the focal brand received a higher preference rating when subjects saw the strong arguments ad, whereas the converse was true for the advertised competing brand. A similar pattern was reflected in subjects' choice behavior as shown in Table 9C/D.

A significant main effect of ad content was found $\left(\chi^{2}=5.58, \mathrm{p}<.05\right)$ in the logit model for focal brand choice. Thus, enhancing the focal brand Aad/Ab significantly impacted subjects' likelihood of choosing the focal brand, even in a situation where they had access to competing brand information. Very few subjects actually chose the advertised competing brand (it was the worst brand) and the pattern did not vary significantly between treatment conditions.

To assess whether differences in brand preference ratings were mediated by $\mathrm{Aad} / \mathrm{Ab}$ or by Sf, two mediational analyses were performed. The first ANCOVA incorporated $\mathrm{Aad}$ and $\mathrm{Ab}$ as covariates, whereas the second ANCOVA incorporated search on focal brand (whether it was included in the consideration set) as a covariate (Table 9E).

Table 9E shows that Aad and Ab mediated about $52 \%$ of the ad content effect on focal brand preference rating. The fact that a main effect of ad content remained 
significant even after statistical removal of the mediating effects of $\mathrm{Aad} / \mathrm{Ab}$ indicates that these two attitudinal measures might not be the sole mediators of advertising effects on brand preference. ANCOVA using search on focal brand as a covariate revealed that it minimally reduced (16\%) the effect of ad content on brand evaluation and thus was not a strong mediator of advertising effects on brand preference.

Mediational analysis conducted on focal brand choice data showed that $\mathrm{Aad} / \mathrm{Ab}$ mediated $58 \%$ of the ad content effects on focal brand choice. However, search on focal brand did not emerge as a significant mediator.

The results support H4a/b. In line with past research (Deighton 1984; Hoch and $\mathrm{Ha}$ 1986), this study too demonstrated that advertising can bias consumer evaluation of the advertised brand. Hence, when advertising created more (less) favorable ad and brand attitudes by using strong claims (control), it improved (lowered) subjects' focal brand preferences post-information search. 


\section{CHAPTER SEVEN}

\section{RESULTS: EXPERIMENT 2}

\section{Ability to Process Manipulation Check}

Table 10 presents the cell means for the manipulation and induction check measures. The results of a 2 (ability to process) $\times 2$ (ad content) ANOVA on each of these measures are shown in Table 11. A 2-way ANOVA on the subjective knowledge and objective ability to process scales revealed that HA subjects scored significantly higher on these measures (subjective: $\bar{x}=4.45$; objective: $\bar{x}=4.03$ ) as compared to LA subjects (subjective: $\bar{x}=3.27$; objective: $\bar{x}=1.08$ ). These results support the success of the ability manipulation.

\section{Task Involvement Induction}

T-tests of subjects' scores on the three task involvement measures were used to confirm that subjects' average scores on these were significantly higher than the scale midpoint of 5.0 (care vs paper towels: $\overline{\mathrm{x}}=7.09, \mathrm{p}<.001$; care vs electronic products: $\overline{\mathrm{x}}=5.40, \mathrm{p}<.01$; importance of choosing the best model: $\overline{\mathrm{x}}=6.65$, $\mathrm{p}<.001$ ). 2-way ANOVAs on these measures only revealed a significant main effect of knowledge for two measures, namely, care vs paper towels and care vs electronic products. It was found that HA subjects reported higher levels of involvement (care vs paper towels: $\overline{\mathrm{x}}=7.44$; care vs electronic products: $\overline{\mathrm{x}}=5.79$ ) as compared to LA subjects (care vs paper towels: $\overline{\mathrm{x}}=6.75$; care vs electronic products: $\overline{\mathrm{x}}=$ $5.03)$. 
Hence, task involvement levels were not comparable for LA and HA subjects. However, LA subjects' reported involvement level was well above the midpoint on two of the three measures. Thus, the task involvement induction was successful but partly compromised, as HA subjects had relatively higher scores than LA subjects. This 'compromised' induction, however, does not pose a concern in terms of masking treatment effects. In fact, if anything, it would work toward strengthening the hypothesized effects.

According to the ELM, central route processing increases with subject's ability and motivation to process advertising information. Hence, higher motivation should heighten the likelihood of central route processing by HA subjects. Consequently, HA subjects' reaction to the positive peripheral cues in advertising should be less favorable, as compared to a situation where motivation levels were comparatively lower. We should, therefore, have observed bigger differences in HA and LA subjects' reaction to the focal brand ad.

\section{Tests of Hypotheses}

Effects on Attitude toward Searching Focal Brand (Asf). Of the two different ads used for the focal brand, the control ad was very plain - it contained a small picture of the camera and the text was printed in a tiny unattractive font. The positive peripheral cue ad included an attractive picture and attractive font. Based on ELM research it was expected that adding such positive peripheral cues would enhance focal brand Aad for both LA and HA subjects. Peripheral cues were expected to 
favorably impact $\mathrm{Ab}$ for $\mathrm{LA}$ subjects, but not HA subjects. $\mathrm{H} 1$ predicted that enhancing either focal brand Aad or Ab would result in more favorable Asf.

A 2-way ANOVA (see Tables 12 and 13) on the Aad measure revealed a significant $(\mathrm{p}<.001)$ main effect of ad content (control: $\overline{\mathrm{x}}=3.55$; peripheral: $\overline{\mathrm{x}}=$ 4.92). However, the reaction to the positive peripheral cue ad was not highly favorable. The mean Aad rating of 4.99 (LA)/ 4.84 (HA) on a 9-point scale would put it closer to the midpoint than at the higher end. In addition, though the peripheral cue ad generated significantly higher Aad than the control ad, the actual magnitude of the difference was 1.37 points (control: $\overline{\mathrm{x}}=3.55$; peripheral: $\overline{\mathrm{x}}=$ 4.92). This is much smaller when contrasted with the difference observed in Experiment 1 which was 2.32 points (control: $\overline{\mathrm{x}}=3.83$; strong arguments: $\overline{\mathrm{x}}=$ 6.15). Thus, the Aad created by the peripheral cue manipulation was only moderately more favorable than the Aad created by the control ad.

The effect on $A b$ was marginal $(p<.10)$ (control: $\bar{x}=4.48$; peripheral: $\bar{x}$ $=5.07$ ). Interaction effects were not significant, indicating that, for both LA and HA subjects, the positive peripheral cue ad generated marginally favorable $\mathrm{Ab}$ than the control ad. An examination of means, however, revealed that the peripheral ad did not generate a more favorable response from LA subjects (control: $\overline{\mathrm{x}}=4.91$; peripheral: $\overline{\mathrm{x}}=5.04$ ), but did generate a more favorable $\mathrm{Ab}$ amongst HA subjects (control: $\overline{\mathrm{x}}=4.05$; peripheral: $\overline{\mathrm{x}}=5.10$ ). This was confirmed by examining the simple main effects, whereby a significant main effect of ad content $(F(1,62)=$ 
$17.54, \mathrm{p}<.05)$ was observed for HA subjects, but not for LA subjects $(\mathrm{F}(1,65)=$ $0.09, \mathrm{p}>.10)$

To assess whether the manipulated ad stimuli did serve as peripheral cues, 2way ANOVAs were performed on the three belief measures (see Tables 10 and 11). The results showed that ad content did not have a significant $(\mathrm{p}>.10)$ impact on the three belief measures of picture quality (control: $\bar{x}=4.83$; peripheral: $\bar{x}=4.65$ ), technological sophistication (control: $\overline{\mathrm{x}}=4.51$; peripheral: $\overline{\mathrm{x}}=4.74$ ), or user friendliness (control: $\overline{\mathrm{x}}=6.14$; peripheral: $\overline{\mathrm{x}}=6.58$ ). These null effects on belief measures indicate that the peripheral cue manipulation did not alter subjects' expectations about the product's performance. Yet, the mean scores indicated that peripheral ad created more favorable brand beliefs among the HA group, however, simple main effects analysis too did not reveal any significant differences.

The results discussed thus far indicate that the manipulation of 'peripheral cues' in the focal brand ad was successful in creating moderately favorable Aad (for both LA and HA subjects) and moderately favorable Ab (only for HA subjects). Differences in Aad and $\mathrm{Ab}$ constitute the starting point of the conceptual model and the research hypotheses. Patterns in subsequent search attitudes and behaviors are expected to follow from the differences in Aad and $\mathrm{Ab}$ generated by specific ads.

As the positive peripheral cues ad did not produce markedly higher Aad and Ab for LA subjects, we would expect to observe minimal differences in search attitudes and behaviors for this segment between the two treatment conditions. 
However, for HA subjects, one would expect to observe a greater (lower) interest in searching the focal (competing brands). Yet, no significant effects were observed when a 2-way ANOVA was conducted on the single item scale used for measuring Asf, thus not supporting H1. Though the mean scores for HA subjects seem to indicate a more favorable Asf in the peripheral ad condition (control: $\overline{\mathrm{x}}=3.94$; peripheral: $\overline{\mathrm{x}}=4.78$ ), these were not found to be significantly different in simple main effects analysis.

Effects on Attitude toward Searching Competing Brands (Asc). A 2-way ANOVA did not show any significant effects on the three perceived search benefit measures. Hence, $\mathrm{H} 2 \mathrm{a}$ was not supported. On the scale of attitude toward searching nonadvertised competing brands, a significant $(\mathrm{p}<.05)$ interaction between ability and ad content was found. The pattern of results suggested that LA subjects expressed greater interest in searching nonadvertised competing brands in the peripheral ad condition $(\overline{\mathrm{x}}=7.45)$ as compared to the control ad condition $(\overline{\mathrm{x}}=$ 6.76). In contrast, HA subjects expressed a lower interest in searching nonadvertised competing brands when exposed to the peripheral ad $(\overline{\mathrm{x}}=7.13)$ than when exposed to the control ad $(\bar{x}=7.78)$. However, simple main effect results for these measures were nonsignificant for both LA and HA subjects. Thus, H2b was not supported.

Effects on Search Behavior. No significant differences were observed between LA or HA subjects who viewed the control versus positive peripheral cue ad on any of 
the search measures. This was to be expected as changes in focal brand ad content failed to impact measures of Asf and Asc. These null findings indicate that the meager effects induced by the ad picture manipulation on Aad and Ab were not evident in the search data.

Mediational Analysis. No mediational analysis was performed for Experiment 2, as the results indicated that subjects search behavior did not differ across the various experimental conditions. 


\section{CHAPTER EIGHT}

\section{DISCUSSION}

\section{Overview}

The study was comprised of two experiments. Experiment 1 was designed to study the impact 'of ad arguments on subjects' search attitudes and behaviors. Experiment 2 was designed to study the impact of ad peripheral cues on search attitudes and behaviors. Results from Experiment 1 are discussed first.

\section{Advertising Effects on Search Attitudes}

Experiment 1 demonstrated that focal brand ad content impacts subjects' attitude toward searching the focal brand, perceived search benefits of examining other brands, and attitude toward searching an advertised competing brand. Though changes in focal brand ad content impacted attitude toward searching the advertised competing brand, it did not affect attitude toward searching the nonadvertised competing brands.

The advertisement for the competing brand was descriptive and did not mention any specific product feature specifications. Yet, when the focal brand ad presented strong arguments, subjects' $\mathrm{Aad}, \mathrm{Ab}$, and Asc for the advertised competing brand became less favorable. It appears that as long as subjects had some information on the competing brand, their attitudes toward it were affected (inversely) by changes in their focal brand Aad/Ab. Hence, when faced with information on two brands (even if it is sketchy and ambiguous), as information on 
one brand became more appealing, it lowered evaluation of the other brand. However, when no information was available (nonadvertised brands), subjects had no basis for making any such comparison.

Advertising and Search Behavior

Changes in focal brand advertising affected the likelihood of the brand being searched at all, being searched first, and percentage search effort devoted to it (marginal effect). Focal brand ad content had some effect on the likelihood of an advertised competing brand being searched, but did not affect search devoted to nonadvertised competing brands. This was not surprising considering that the focal brand advertising failed to impact attitudes toward searching nonadvertised competing brands.

\section{Attitudinal Mediators of Advertising Effects}

The ANCOVA results supported the contention that advertising effects on search attitudes are mediated by attitudinal responses to advertising, namely - Aad and $\mathrm{Ab}$. Strong mediation effects were observed for Asf and perceived search benefits (finding a better option than focal brand through search). Aad and $\mathrm{Ab}$ appear to be important mediators of advertising effects on search attitudes.

Perceived search benefits, in turn, mediated ad effects on Asc (advertised competing brand). Asf and Asc then mediated advertising effects on Sf and Sc (advertised competing brand) respectively. However, the mediation was not as strong as that observed for the Aad/Ab and Asf link. 
Aad and $\mathrm{Ab}$ were also important mediators of advertising effects on brand preference. In fact, these variables mediated brand preference better than the measure of search behavior, namely, inclusion of focal brand in the consideration set. As portrayed in the conceptual model, perceived search benefits mediated ad effects on Asc, and Asf and Asc mediated some measures of actual search behavior (Sf and Sc respectively). Hence, overall the model received support from the results in Experiment 1.

\section{Experiment 2 Results}

Experiment 2 provided null results on almost all measures of search attitudes and behaviors. This could be attributed to the fact that the ad peripheral cue manipulation was not strong enough. Recall that, on a 9-point scale, Aad generated by the peripheral ad was only 1.37 points higher than that generated by the control ad. Here it should be noted that the ads had been successfully pretested. Then why did the manipulation not work in the experiment?

One possibility is that the experimental environment differed from the pretest environment in certain ways. Though the same purchase goal induction was used in the pretest study, the pretests were conducted in a classroom setting whereas the actual experiment took place in a computer lab. Also, the $\$ 100$ reward was not mentioned in the pretests. Hence, the level of involvement in the pretest environment may not have been as high as it was in the experimental situation. Peripheral ad elements which successfully affected $\mathrm{Aad} / \mathrm{Ab}$ in the pretest setting 
could have become less effective as involvement levels rose and subjects attempted to do more central route processing.

\section{Contributions}

The dissertation provides a theoretical framework for examining effects of advertising on consumers' prepurchase search behavior. This study increases our understanding of the persuasive effects of advertising by demonstrating that exposure to advertising not only affects Aad and $\mathrm{Ab}$, but also affects search attitudes and behaviors, and the resultant brand choice. The study makes two major contributions. Firstly, it developed a conceptual model of advertising effects on consumers' brand search behavior. The model is comprehensive and explicitly combines insights from the advertising information processing literature and the prepurchase search literature into a cohesive whole. Secondly, the model was tested empirically and most of its propositions were supported.

The dissertation focuses on a research gap which has received little attention in the literature, namely the influence of marketer controlled information sources on consumers' self-guided prepurchase search. Results indicate that marketers can definitely induce greater search on their brand by using more attractive advertising, and in some instances, can reduce search on competing brands. Some past studies have indicated that marketer originated messages have limited direct value in consumer decisions, and usually personal sources and physical search dominate the search process (see Wright and Lynch 1995). As this dissertation reveals, the direct 
influence of marketer originated messages may be greater than is apparent because such messages can affect how consumers conduct search.

The distinguishing feature of the conceptual model is the emphasis given to advertising in creating consumers' prior brand perceptions and the careful delineation of the implications of these priors for search process. By creating favorable attitudes, advertising can influence consumers' prior brand perceptions and thus the order of search. Being high in the order of search may well determine the ultimate choice because the consumer will obtain additional information on only the brands in contention to be the winner.

Overall the findings add to a growing body of evidence that prior knowledge of specific brands can affect type of information processing carried out to make a decision (Punj and Staelin 1983; Simonson, Huber, and Payne 1988).

\section{$\underline{\text { Limitations }}$}

The present study examined advertising effects on search attitudes and search behaviors in an experimental setting using forced advertising exposure, student subjects, one product class, and just one argument strength and peripheral cue manipulation. Generalizability would be enhanced by future research examining different products, a broader set of advertising stimuli, a non-student sample, and more natural advertising-exposure conditions.

Persuasion experiments are vulnerable to demand contamination whenever the study's hypothesis predicts compliance with a persuasive communication, because the 
communication reveals the direction of the hypothesized compliance. This study is no exception. A number of precautions were taken not to give away the hypothesis. The task description was to choose the 'best' brand and a strong incentive ( $\$ 100$ reward) was attached to it. The focal brand ad was presented along with the ad for another brand. In the search environment subjects had the freedom to choose information on any brand in whatever order they preferred. Comments of respondents, when asked to write the purpose of study, indicated that goal of experiment was fairly obscured. Most thought it was a study on how consumers collect information to make a decision. Besides, it should be remembered that the focal brand ad was present in all conditions. Hence, any potential demand effects cannot explain the differential responses obtained under different conditions.

The uniqueness of the ability to process manipulation also raises questions about the generalizability of the results. To the extent that ability was created artificially in a contrived setting, further investigation into the effects of such an approach is needed. The manipulation did not create a group of subjects who were 'experts' in any sense of the term. The HA subjects in this study did not possess a detailed understanding of the product category. Nor did they have any extensive usage experience with the product. These subjects were merely provided specific information about selective features of the product (features on which brands in the choice set were defined).

In this study HA and LA subjects did not exhibit any differences in terms of 
their search behavior. Nonetheless, because HA subjects were better aware of the different product features and how to interpret information on the same, one might have expected them to conduct more search than LA subjects. However, the nature of search environment probably made it easy even for LA subjects to search information. Recall that all subjects were provided a list of the various attributes and brands on which information could be obtained from the computer, and subjects had access to this list during the entire search task. Two other factors in the search environment may have facilitated ease of processing for LA subjects. Firstly, the information dimensions were comparable for all brands, i.e., all brands were described using same terminology/scale on an identical set of attributes. Secondly,

for most dimensions, a higher value also indicated superior performance. LA subjects could have used a simple heuristic of 'more is better' and made the right decision without necessarily understanding the actual benefit of an attribute.

Another limitation relates to the construct of 'brand interest'. Although the construct was depicted in the model and its role in the conceptual model explained, it was not measured and analyzed in this dissertation. The brand interest scale developed by Machleit et al. (1993) incorporates the constructs of brand interest and attitude toward searching, hence it was not used. A separate scale to measure just brand interest could have been developed.

\section{Future Research}

Future research is needed to examine the impact of other factors which may 
affect search costs, such as time constraint, availability of relevant information, etc. Prepurchase search literature suggests that depth of search (total search effort) decreases as search costs increase. One would expect advertising effects on search behavior to intensify as search costs increase, because consumers may rely more on advertising information to make purchase decisions.

Post-hoc analysis of Experiment 1 data does seem to suggest that advertising effects may become stronger as depth of search decreases. The table below shows that a higher percentage of subjects gave better preference ratings and chose the focal brand when they did not search all the models and when the focal brand ad used strong arguments:

\begin{tabular}{|c|c|c|c|}
\hline & $\begin{array}{l}\text { Depth of Search } \\
\text { (Searched all } \\
\text { competing } \\
\text { models) }\end{array}$ & Control Ad & $\begin{array}{l}\text { Strong } \\
\text { Arguments Ad }\end{array}$ \\
\hline \multirow{2}{*}{$\begin{array}{l}\text { Focal brand } \\
\text { rated more } \\
\text { favorable than } \\
\text { actual }\end{array}$} & Yes & $16.7 \%$ & $20.5 \%$ \\
\hline & No & $28.6 \%$ & $70.8 \%$ \\
\hline \multirow{2}{*}{$\begin{array}{l}\text { Focal brand } \\
\text { chosen }\end{array}$} & Yes & $0.0 \%$ & $2.6 \%$ \\
\hline & No & $1.0 \%$ & $50.0 \%$ \\
\hline
\end{tabular}

In this study, brands in the choice set were arranged in a dominance hierarchy (i.e., the choice set was unambiguous). Past research has demonstrated that effects of advertising on brand evaluation are stronger when the choice set is ambiguous 
rather than unambiguous (Ha and Hoch 1989). The same may apply for search behavior also. Perhaps if the brands are not arranged in a dominance hierarchy and consumers have to trade off attributes, they may rely more on advertising to guide search and choice. To examine this possibility another post-hoc analysis was conducted on Experiment 1 data. The table below shows how preference and choice of focal brand was affected by the presence (or absence) of the dominant brand in the search set.

\begin{tabular}{||l|l|l|l|}
\hline & $\begin{array}{l}\text { Inclusion of } \\
\text { dominant brand } \\
\text { in search }\end{array}$ & Control Ad & $\begin{array}{l}\text { Strong } \\
\text { Arguments Ad }\end{array}$ \\
\hline $\begin{array}{l}\text { Focal brand } \\
\text { rated more } \\
\text { favorable than } \\
\text { actual }\end{array}$ & Included & $2.7 \%$ & $26.5 \%$ \\
\cline { 2 - 4 } & Not included & $22.7 \%$ & $85.7 \%$ \\
\hline $\begin{array}{l}\text { Focal brand } \\
\text { chosen }\end{array}$ & Included & $1.0 \%$ & $6.0 \%$ \\
\cline { 2 - 5 } & Not included & $0.0 \%$ & $71.4 \%$ \\
\hline
\end{tabular}

As can be noted from the above table, preference for and choice of the focal brand were much higher when the dominant brand was not included in the subjects' consideration set and when subjects saw the strong arguments ad. Future research on the impact of ad content on search under ambiguous versus unambiguous choice sets may reveal interesting insights.

The advertising product claims used in this study referred to 'search' 
attributes and completely overlapped the information available in the search environment. Subjects could therefore confirm/disconfirm the claims made in advertising and also compare the advertised brand with competing brands on the advertised attributes. However, marketers can also use 'experience' or 'credence' attributes in their advertising. Unlike search attributes, consumers cannot evaluate a product on experience/credence attributes in a prepurchase search situation and will have to rely entirely on the perceptions created by advertising. Whether the use of such attributes strengthens advertising effects on search and post-search evaluations is an interesting research topic.

The ad manipulations used in this study were designed to increase or decrease subjects' Aad and $\mathrm{Ab}$ for the focal brand and were essentially noncomparative in nature. It was assumed that changes in focal brand Aad and Ab would produce similar (but directionally opposite) affects on Asc and Sc. However, as the results indicate, the ad manipulations failed to produce any effects on Asc and Sc for nonadvertised competing brands. Marketers often use comparative ads to influence consumer perceptions of their brand relative to its competing brands. Usually the objective is to enhance focal brand $\mathrm{Aad} / \mathrm{Ab}$ and lower competing brand(s) $\mathrm{Aad} / \mathrm{Ab}$. Another area for future research would be to explore if comparative ads have a stronger effect on Asc and Sc as compared to noncomparative ads.

\section{Marketing Implications}

The present study holds some implications regarding advertising effects on 
consumer decisions. Ads are usually designed to build certain mental associations with and beliefs about the brand advertised, which may lead to ultimate buying action. Critics of advertising consider it to be a persuasive mechanism, which may lead to consumer confusion and questionable evaluations. Proponents of advertising view advertising as a means of information dissemination that stimulates competition.

In this study advertising was just one source of information, and subjects had full freedom to obtain objective information on all brands in the choice set. Yet, the findings show that exposure to advertising and the resultant attitudes did impact subjects' evaluation and choice of the focal brand. Ads which created more favorable attitudes enhanced post-search brand evaluation and choice probability. These findings support the view that, advertising can bias product evaluations, by establishing conditions under which consumers view the product more favorably than they would otherwise.

Post-hoc analysis indicated that advertising effects on preference and choice intensified as amount of search effort reduced. These results are important in view of the well-known fact that consumers usually engage in limited prepurchase search. Managerially, the model provides a theoretical basis for why advertising may be useful, even for product categories in which the consumer is expected to consult more objective information sources before making the purchase decision. Also, it will be a good practice to include measures of attitude toward search when pretesting alternative advertising executions 


\section{LIST OF REFERENCES}

Ajzen, Izek and M. Fishbein (1977), "Attitude-Behavior Relations: A Theoretical Analysis and Review of Empirical Research," Psychological Bulletin, 84(5), 888918.

Alba, Joseph W., J. Wesley Hutchinson (1987), "Dimensions of Consumer Expertise," Journal of Consumer Research, 13 (March), 411-454.

-, -, and John G. Lynch Jr. (1991), "Memory and Decision Making," in Thomas S. Robertson and Harold H. Kassarjan (eds.), Handbook of Consumer Behavior, Chapter 1.

Baker, William (1993),"The Relevance Accessibility Model of Advertising Effectiveness," in Andrew Mitchell ed. Advertising. Exposure, Memory, and Choice, 49-85.

Beatty, Sharon E. and Scott M. Smith (1987),"External Search Effort: An Investigation Across Several Product Categories," Journal of Consumer Research, 14 (June), 83-95.

Belch, George E., Michael A. Belch, and Angelica Villareal (1987), "Effects of Advertising Communications: Review of Research," in Research in Marketing, Vol 9, 59-117.

Bettman, James R. (1979) An Information Processing Theory of Consumer Choice: Addison Wesley Pub. Co.

- (1978), "Consumer Information Acquisition and Search Strategies," in The Effect of Information on Consumers and Market Behavior, ed. Andrew A. Mitchell: AMA, $35-48$

Bettman, James R. and C. Whan Park (1980), "Effects of Prior Knowledge and Experience and Phase of the Choice Process on Consumer Decision Processes: A Protocol Analysis," Journal of Consumer Research, 7 (December), 234-248.

Bloch, Peter H., Daniel L. Sherrell, and Nancy M. Ridgway (1986), "Consumer Search: An Extended Framework, " Journal of Consumer Research, 13 (June), 119126. 
Brucks, Merrie (1988), "Search Monitor: An Approach For Computer-Controlled Experiments Involving Consumer Information Search," Journal of Consumer Research, 15 (June), 117-21.

- (1986),"A Typology of Consumer Knowledge," in Advances in Consumer Research, Vol 13, ed. Richard J. Lutz, Association of Consumer Research: Provo, UT, 58-63.

- (1985),"The Effects of Product Class Knowledge on Information Search Behavior," Journal of Consumer Research, 12 (June), 1-16.

Bogart, Leo (1995), Commercial Culture: The Media System and the Public Interest, New York: Oxford University Press.

- (1989), Press and Public, New Jersey: Lawrence Erlbaum Associates, 2nd ed.

Bucklin, Louis P. (1966), "Testing Propensities to Shop," Journal of Marketing, 30 (January), 22-27.

Cacioppo, John T., Richard E. Petty, Chuan Feng Kao, and Regina Rodriguez (1986), "Central and Peripheral Routes to Persuasion: An Individual Difference Perspective," Journal of Personality and Social Psychology, 51 (5), 1032-1043.

Chaiken, Shelley and Charles Stangor (1987), "Attitudes and Attitude Change," Annual Review of Psychology, 38, 575-630.

Claxton, John D., Joseph N. Fry, and Bernard Portis (1974), "A Taxonomy of Prepurchase Information Gathering Patterns," Journal of Consumer Research, 1 (December), 35-42.

Deighton, John (1984), "The Interaction of Advertising and evidence," Journal of Consumer Research, 11 (December), 763-70.

Dommermuth, William P. and Edward W. Cundiff (1967), "Shopping Goods, Shopping Centers, and Selling Strategies, " Journal of Marketing, 31 (January), 32 36.

Duncan, Calvin P. and Richard W. Olshavsky (1982), "External Search: The Role of Consumer Beliefs, "Journal of Marketing Research, 19 (February), 32-43.

Engel, James, F., Roger D. Blackwell, and Paul W. Miniard (1995), Consumer 
Behavior, 5th ed., The Dryden Press.

Fazio, Russel H., and Mark P. Zanna (1978), "On The Predictive Validity of Attitudes: The Role of Direct Experiences and Confidence," Journal of Personality, 46(2), 228-243.

Fiske, Carol A., Lisa A. Luebbehusen, Anthony D. Miyazaki, and Joel E. Urbany (1994), "The Relationship Between Knowledge and Search: It Depends," in Advances in Consumer Research, Vol 21, eds. Chris T. Allen and Deborah Roedder John, Provo: UT, Association for Consumer Research, 43-50.

Gardner, Meryl Paula (1985), "Does Attitude Toward the Ad Affect Brand Attitude Under a Brand Evaluation Set?" Journal of Marketing Research, 22 (May), 192-198.

Jacoby, Jacob, Robert W. Chestnut and William A. Fisher (1978), "A Behavioral Process Approach to Information Acquisition in Nondurable Purchasing, "Journal of Marketing Research, 15 (November), 532-544.

Johnson, Eric and Edward J. Russo (1984), "Product Familiarity and Learning New Information," Journal of Consumer Research, 11 (June), 542-550.

Ha, Young-Won and Stephen J. Hoch (1989), "Ambiguity Processing Strategy, and Advertising-Evidence Interactions, "Journal of Consumer Research, 16 (December), 354-60.

Hagerty, Michael R. and David A. Aaker (1984), "A Normative Model of Consumer Information Processing," Marketing Science, 3 (3), 227-246.

Hansen, Fleming (1972), "Psychological Theories of Consumer Choice," Journal of Consumer Research, 3 (December), 117-142.

Hastak, Manoj and Jerry C. Olson (1989), "Assessing the Role of Brand-Related Cognitive Responses as Mediators of Communication Effects on Cognitive Structure," Journal of Consumer Research, 15 (March), 444-456.

Hayes, William L. (1963), Statistics for Psychologists, New York: Holt, Rinehard \& Winston.

Hoch, Stephen J. and Young-Won Ha (1986), "Consumer Learning: Advertising and Ambiguity of Product Experience," Journal of Consumer Research, 13 (September), 221-232. 
Holbrook, Morris B. and Karl A. Maier (1978), "A Study of the Interface Between Attitude Structure and Information Acquisition Using a Questionnaire Based Information-Display Sheet," in Advances in Consumer Research, Vol 5, ed. Keith Hunt, Ann Arbor, MI: Association for Consumer Research, 93-98.

Huffman, Cynthia (1996), "Goal Change, Information Acquisition, and Transfer," Journal of Consumer Psychology, 5 (1), 1-25.

Katona, George and E. Mueller (1954), "A Study of Purchase Decisions," in Consumer Behavior: The Dynamics of Consumer Reaction, Vol. 1, ed. Lincoln H. Clark, New York: New York University Press.

Lanzetta, John T. (1963), "Information Acquisition in Decision Making," in O.J.Harvey, ed. Motivation and Social Interaction-Cognitive Determinant, New York: Ronald Press, 239-265.

Lutz, Richard J. and Patrick J. Reilly (1974), "An Exploration of the Effects of Perceived Social and Performance Risk on Consumer Information Acquisition," in Advances in Consumer Research, Vol. 1, eds. Scott Ward and Peter Wright, Chicago: Association for Consumer Research.

Lutz, Richard J., Scott B. MacKenzie, and George Belch (1982), "Attitude Toward the Ad as a Mediator of Advertising Effectiveness: Determinants and Consequences," in Advances in Consumer Research, Vol. 10, Richard Bagozzi and Alice Tybout, eds. San Francisco, CA: Association for Consumer Research, 532-539.

Machleit, Karen A., Chris T. Allen, and Thomas J. Madden (1993), "The Mature Brand and Brand Interest: An Alternative Consequence of Ad-Evoked Affect," Journal of Marketing, 57 (October), 72-82.

MacInnis, Deborah J., Christine Moorman, and Bernard J. Jaworski (1991), "Enhancing and Measuring Consumers Motivation, Opportunity, and Ability to Process Brand Information From Ads," Journal of Marketing, 55 (October), 32 53.

MacInnis, Deborah J. and Bernard Jaworski (1989), "Information Processing From Advertisements: Toward an Integrative Framework," Journal of Marketing, 53 (October), 1-23.

Maheswaran, Durairaj and Brian Sternthal (1990),"The Effect of Knowledge, Motivation, and Type of Message on Ad Processing and Product Judgements," 
Journal of Consumer Research, 17 (June), 66-73.

Marks, Larry J. and Jerry C. Olson (1981), "Toward a Cognitive Structure Conceptualization of Product Familiarity," in Advances in Consumer Research, Vol 8, ed. Kent B. Monroe, Association for Consumer Research, 145-150.

Meyer, Robert J. (1982), "A Descriptive Model of Consumer Information Search Behavior," Marketing Science, 7 (Winter), 93-121.

Mitchell, Andrew A. and Jerry C. Olson (1981), "Are Product Attribute Beliefs the Only Mediator of Advertising Effects on Brand Attitudes?," Journal of Marketing Research, 18 (August), 318-331.

Miyake, Naomi and Donald Norman (1979), "To Ask a Question, One Must Know Enough to Know What is Not Known," Journal of Verbal Learning and Verbal Behavior, 18 (June), 357-364.

Moore, William L. and Donald R. Lehmann (1980), "Individual Differences in Search Behavior for a NonDurable," Journal of Consumer Research, 7 (December), 296-307.

Moorman, Christine (1990),"The Effects of Stimulus and Consumer Characteristics on the Utilization of Nutrition Information," Journal of Consumer Research, 17 (December), 362-374.

Mothersbaugh, David L. (1996), Advertising as Search Heuristic: Implications for Brand Consideration and Choice, unpublished dissertation, University of Pittsburgh.

Nelson, Phillip (1974), "Advertising and Information, " Journal of Political Economy, $81,729-754$.

Newman, Joseph W. (1977), "Consumer External Search: Amount and Determinants, " in Arch G. Woodside, Jagdish N. Sheth, and Peter D. Bennett (eds.), Consumer and Industrial Buying Behavior, New York: North-Holland, Ch.6.

- and Richard Staelin (1972), "Prepurchase Information Seeking for New Cars and Major Household Appliances," Journal of Marketing Research, 9 (August), 249-257.

Petty, Richard E. and John T. Cacioppo (1986), "The Elaboration Likelihood Model of Persuasion," in Advances in Experimental Social Psychology, Vol. 19, ed. L. Berkowitz, New York: Academic Press, 123-205. 
- and - (1984),"The Effects of Involvement on Responses to Argument Quantity and Quality: Central and Peripheral Routes to Persuasion," Journal of Personality and Social Psychology, 46 (1), 69-81.

,,-- and Schumann (1983), "Central and Peripheral Routes to Advertising Effectiveness: The Moderating Role of Involvement, " Journal of Consumer Research, 10 (September), 135-146.

Petty, Richard E., John T. Cacioppo, and Martin Heesacker (1981), "Effects of Rhetorical Questions on Persuasion: A Cognitive Response Analysis," Journal of Personality and Social Psychology, 40, 432-440.

Punj, Girish N. and Richard Staelin (1983), "A Model of Consumer Information Search Behavior for New Automobiles, "Journal of Consumer Research, 9 (March), 366-380.

Rosen, Dennis L. and Richard W. Olshavsky (1987), "A Protocol Analysis of Brand Choice Strategies Involving Recommendations, "Journal of Consumer Research, 14 (December), 440-444.

SAS Institute (1990), SAS/STAT Users Guide, Version 6, Cary, NC: SAS Institute, Inc.

Sheluga, David A., James Jaccard, and Jacob Jacoby (1979), "Preference, Search, and Choice: An Integrative Approach," Journal of Consumer Research, 6 (September), 166-176.

Simonson, Itamar, Joel Huber, and John Payne (1988), "The Relationship Between Prior Brand Knowledge and Information Acquisition Order, "Journal of Consumer Research, 14 (March), 566-578.

Smith, Robert E. and William R. Swinyard (1983), "Attitude-Behavior Consistency: The Impact of Product Trial versus Advertising, "Journal of Marketing Research, 20 (August), 257-267.

- and - (1982), "Information Response Models: An Integrated Approach," Journal of Marketing, 46 (Winter), 81-93.

Solomon, Michael R. (1986), "The Missing Link: Surrogate Consumers in the Marketing Chain," Journal of Marketing, 50 (October), 208-218. 
Sujan, Mita (1985), "Consumer Knowledge: Effects on Evaluation Processes Mediating Consumer Judgements," Journal of Consumer Research, 12 (June), 31-46.

Srinivasan, Narasimhan (1990), "Pre-Purchase External Search for Information," in Review of Marketing, ed. Valarie Zeithaml, Chicago: American Marketing Association, 153-189.

Stigler, George J. (1961),"The Economics of Information," Journal of Political Economy, 69 (June),'213-225.

Swan, J.E. (1969), "Experimental Analysis of Predecision Information Seeking," Journal of Marketing Research, 6, 192-197.

Urbany, Joel E., William O. Bearden, and Dan C. Weilbaker (1988),"The Effects of Plausible and Exaggerated Reference Prices on Consumer Perceptions and Price Search," Journal of Consumer Research, 15 (June), 95-110.

Wernerfelt, Birger (1996),"Efficient Marketing Communication: Helping the Customer Learn," Journal of Marketing Research, 33 (May), 239-246.

Wright, Alice A. and John G. Lynch, Jr. (1995), "Communication Effects of Advertising Versus Direct Experience When Both Search And Experience Attributes Are Present," Journal of Consumer Research, 22 (March), 108-18.

Wright, Peter L. and Frederick Barbour (1975), "The Relevance of Decision Process Models in Structuring Persuasive Messages," Communications Research, 2 (July), 246-259. 
APPENDIX A

STIMULUS PRODUCT SELECTION SURVEY 


\section{Thank You For Your Contribution}

This research project pertains to students' familiarity and interest levels with certain types of products. This research is being done as part of my doctoral dissertation, and I will greatly appreciate if you could spend some time answering the questions in this survey. The questionnaire will take only a few minutes, and all of your responses will be kept confidential. Please remember, that there are no right or wrong answers to any question, I am simply interested in obtaining your honest opinion.

In this research I would like to understand your familiarity and interest with the following products - CD Players, Compact Stereos, Televisions, VCR's, 35mm SLR Cameras and, Camcorders. Once again thank you for your cooperation. 


\section{5mm SLR CAMERAS}

This section focuses on your opinions on $35 \mathrm{~mm}$ SLR cameras. The following questions are relatively simple and straightforward, however, if anything is unclear to you, please raise your hand. Answer each question by circling the appropriate number.

1. I like to engage in conversations about $35 \mathrm{~mm}$ SLR Cameras.

Strongly Agree

$\begin{array}{lllllll}1 & 2 & 3 & 4 & 5 & 6 & 7\end{array}$

2. Because of my lifestyle, I feel a $35 \mathrm{~mm}$ SLR Camera is an important product for me.

Strongly Agree

$\begin{array}{lllllll}1 & 2 & 3 & 4 & 5 & 6 & 7\end{array}$

Strongly Disagree

Strongly Disagree 7

3. If I was buying a new $35 \mathrm{~mm}$ SLR Camera, I would be very concerned about the economic consequences of making a poor or incorrect choice.

Strongly Agree

$\begin{array}{lllllll}1 & 2 & 3 & 4 & 5 & 6 & 7\end{array}$

4. In your opinion how much do you think you know about the features and uses of $35 \mathrm{~mm}$ SLR Cameras in general?

Know a LOT

$\begin{array}{lllllll}1 & 2 & 3 & 4 & 5 & 6 & 7\end{array}$

Strongly Disagree 7

5. In your opinion how much do you think you know about the features and uses of $35 \mathrm{~mm}$ SLR Cameras as compared to an average student?

Know a LOT

$$
\begin{array}{llllllll}
1 & 2 & 3 & 4 & 5 & 6 & 7
\end{array}
$$

Know very LITTLE 7

6. In your opinion how much do you think you know about the features and uses of $35 \mathrm{~mm}$ SLR Cameras as compared to experts?

Know a LOT

$\begin{array}{llllllll}1 & 2 & 3 & 4 & 5 & 6 & 7\end{array}$


7. Have you ever searched for information about $35 \mathrm{~mm}$ SLR Cameras?

$$
\begin{array}{lll}
\text { Yes } 1 & \text { No } 2
\end{array}
$$

8. Have you ever used a $35 \mathrm{~mm}$ SLR Camera?

$$
\begin{array}{lll}
\text { Yes } 1 & \text { No } 2
\end{array}
$$

9. Do you currently' own a $35 \mathrm{~mm}$ SLR Camera?

$$
\text { Yes } 1 \text { No } 2
$$

10. Please indicate your agreement or disagreement with the following statements.

a. In general I am quite capable when it comes to distinguishing a good $35 \mathrm{~mm}$ SLR Camera from a bad $35 \mathrm{~mm}$ SLR Camera.

Strongly Agree

$\begin{array}{lllllll}1 & 2 & 3 & 4 & 5 & 6 & 7\end{array}$

b. I can't think of many differences between major brands of $35 \mathrm{~mm}$ SLR Cameras.

Strongly Agree

$\begin{array}{lllllll}1 & 2 & 3 & 4 & 5 & 6 & 7\end{array}$

Strongly Disagree 7

c. The only difference between major brands of $35 \mathrm{~mm}$ SLR Cameras is the price.

Strongly Agree

$\begin{array}{lllllll}1 & 2 & 3 & 4 & 5 & 6 & 7\end{array}$

Strongly Disagree 7

d. All major brands of $35 \mathrm{~mm}$ SLR Cameras are basically alike.

Strongly Agree

$$
1
$$

34

5
Strongly Disagree 7

e. If I was buying a new $35 \mathrm{~mm}$ SLR Camera, I would need to look at al the available options in order to decide which is the best one. 
Strongly Agree

$\begin{array}{llllllll} & 1 & 2 & 3 & 4 & 5 & 6 & 7\end{array}$

f. By rushing into purchase of a new $35 \mathrm{~mm}$ SLR camera, one is bound to miss a good deal.

$\begin{array}{rrrrrrrr}\text { Strongly Agree } & & 2 & 3 & 4 & 5 & 6 & 7\end{array}$

g. I would spend a lot of time and effort searching for information on different brands/models before buying a new 35mm SLR Camera.

Strongly Agree

$\begin{array}{lllllll}1 & 2 & 3 & 4 & 5 & 6 & 7\end{array}$

Strongly Disagree

7 
APPENDIX B

RESULTS: STIMULUS PRODUCT SELECTION SURVEY 
NOTE: Used a 7 point scale. Low scores indicate High involvement, High knowledge, High brand parity perception and Higher need to search.

Sample size: 35 undergraduates in business. Summer 1996

\begin{tabular}{|l|l|l|l|l|l|l|}
\hline & CD pl & Stereo & TV & VCR & $35 \mathrm{~mm}$ & Camcor \\
\hline INVOLVEMENT & 3.56 & 3.61 & 2.70 & 3.04 & 4.22 & 4.12 \\
\hline KNOWLEDGE & 3.98 & 4.08 & 3.29 & 3.56 & 5.08 & 5.28 \\
\hline PARITY & 4.28 & 4.83 & 4.85 & 4.99 & 4.98 & 4.74 \\
\hline SEARCH & 2.48 & 2.39 & 2.27 & 2.35 & 2.52 & 2.07 \\
\hline ever search & $43 \%$ & $43 \%$ & $71 \%$ & $69 \%$ & $49 \%$ & $31 \%$ \\
\hline ever use & $100 \%$ & $86 \%$ & $100 \%$ & $100 \%$ & $89 \%$ & $63 \%$ \\
\hline own & $86 \%$ & $71 \%$ & $100 \%$ & $97 \%$ & $69 \%$ & $31 \%$ \\
\hline
\end{tabular}


APPENDIX C

FICTITIOUS BRAND DESCRIPTIONS 


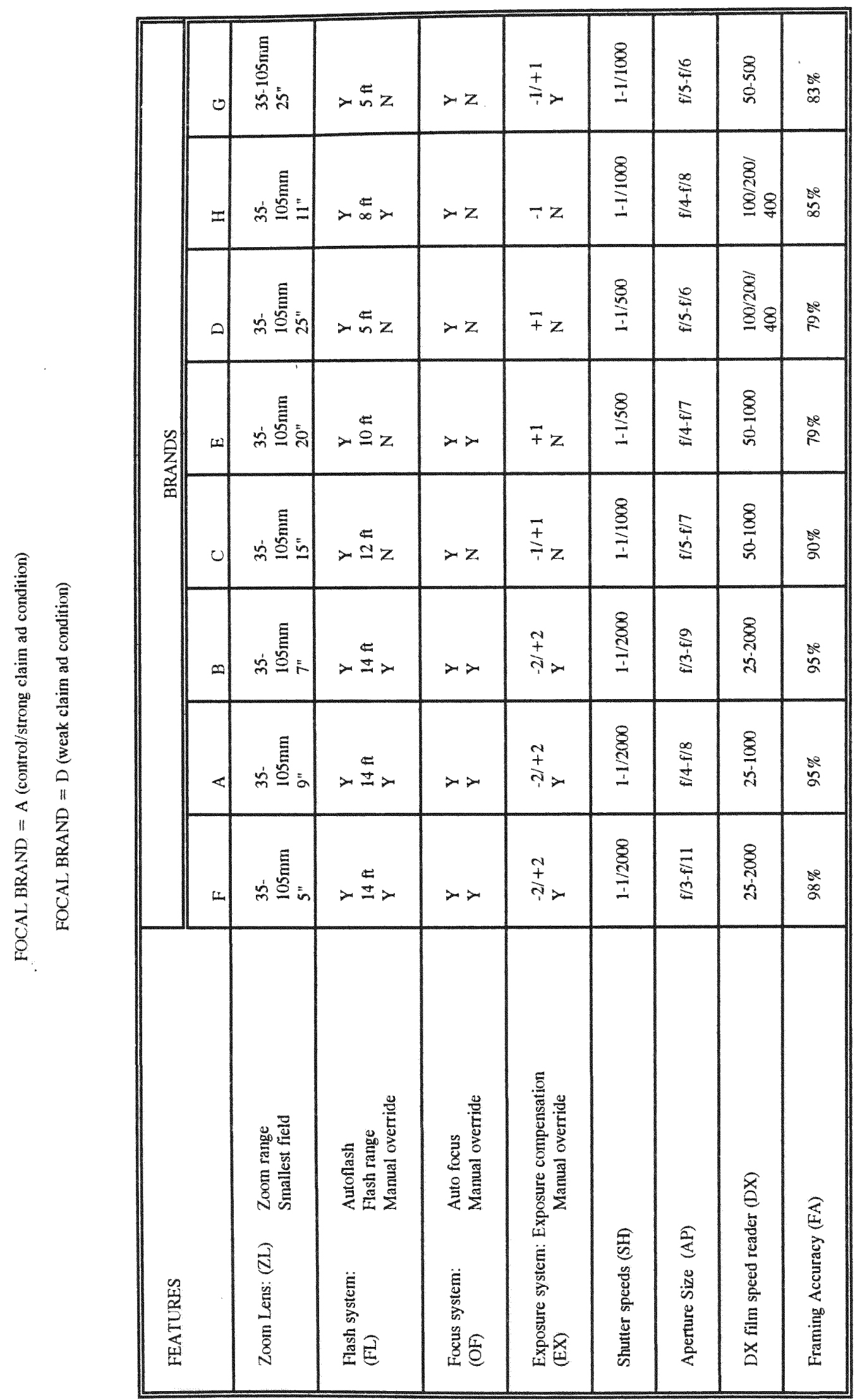




\section{APPENDIX D}

INFORMATION TABLE PROVIDED TO SUBJECTS IN HIGH KNOWLEDGE GROUP 


\begin{tabular}{|c|c|c|}
\hline FEATURE & DESCRIPTION & $\begin{array}{l}\text { TYPICAL } \\
\text { OFFER }\end{array}$ \\
\hline Aperture size & $\begin{array}{l}\text { Opening of the lens through which light enters the camera. } \\
\text { Indicated by a coded numerical series called f numbers. Wider } \\
\text { range of apertures is better. }\end{array}$ & $f / 4$ to $f / 8$ \\
\hline $\begin{array}{l}\text { DX Fulm } \\
\text { speed reader }\end{array}$ & $\begin{array}{l}\text { Film speed refers to the film's sensitivity to light, and is } \\
\text { represented by an ISO number. Commonly used film speeds are } \\
\text { ISO } 100,200,400 \text {. Wider range of film speed reader is better. }\end{array}$ & $\begin{array}{l}\text { ISO } 100 \\
200,400\end{array}$ \\
\hline $\begin{array}{l}\text { Exposure } \\
\text { compensation }\end{array}$ & $\begin{array}{l}\text { Used for making slight adjustments to the autoexposure settings. } \\
\text { Plus compensation is used when you desire more exposure than } \\
\text { that set by autoexposure; minus compensation is used when you } \\
\text { desire less exposure. Wider range of compensation is better. }\end{array}$ & -1 to +1 \\
\hline Flash range & $\begin{array}{l}\text { The distance up to which the flash illuminates the subject. } \\
\text { Longer range is better. }\end{array}$ & $8 f t$ \\
\hline $\begin{array}{l}\text { Framing } \\
\text { accuracy }\end{array}$ & $\begin{array}{l}\text { Percentage of the image area in a photo that shows in the } \\
\text { viewfinder. High framing accuracy is better. }\end{array}$ & $85 \%$ \\
\hline $\begin{array}{l}\text { Manual } \\
\text { override }\end{array}$ & $\begin{array}{l}\text { Automatic features constrain your creative flexibility. Manual } \\
\text { override feature allows you to override the automatic settings, } \\
\text { and decide which exposure, flash, and focus settings you want. }\end{array}$ & $\begin{array}{l}\text { does not } \\
\text { include } \\
\text { manual } \\
\text { override }\end{array}$ \\
\hline Shutter speed & $\begin{array}{l}\text { How long the shutter remains open. Is indicated in fractions of } \\
\text { a second. Wider range of speeds is better. }\end{array}$ & $1-1 / 1000$ \\
\hline $\begin{array}{l}\text { Smallest } \\
\text { field }\end{array}$ & $\begin{array}{l}\text { Width of the smallest object that fills the frame at near focus. } \\
\text { Small values are better than high values }\end{array}$ & $15^{\prime \prime}$ \\
\hline $\begin{array}{l}\text { Zoom lens } \\
\text { range }\end{array}$ & $\begin{array}{l}\text { The lens's ability to magnify distant objects. Long range lenses } \\
\text { allow greater magnification. }\end{array}$ & $35-85 \mathrm{~mm}$ \\
\hline
\end{tabular}


APPENDIX E

FOCAL BRAND CONTROL AD:

EXPERIMENT 1 


\section{Many Visions .... One Camera! \\ the model " $A$ "}

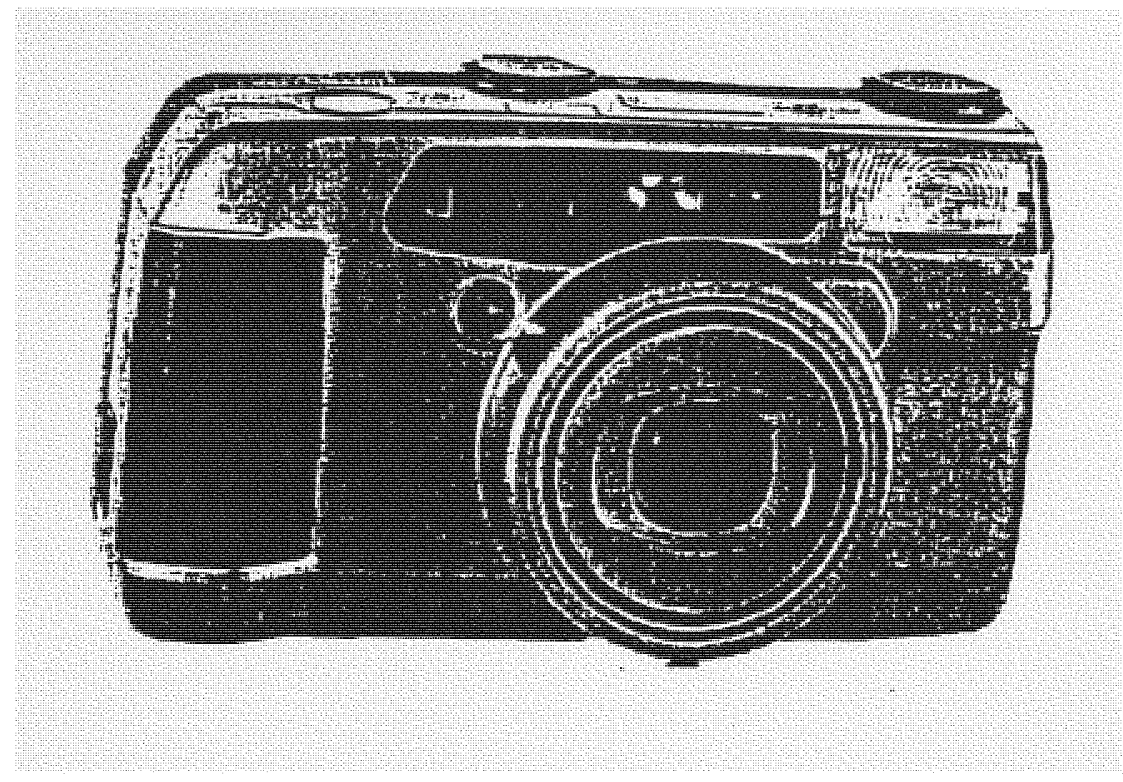

No matter how you see things, the NEW model "A" lets you capture ACL your visions.

For fast information FAX your request to 1-800-559-4215 model "A" Corporation 


\section{APPENDIX F \\ FOCAL BRAND STRONG CLAIMS AD: \\ EXPERIMENT 1}




\section{Many Visions ..... One Camera! \\ The model "A"}

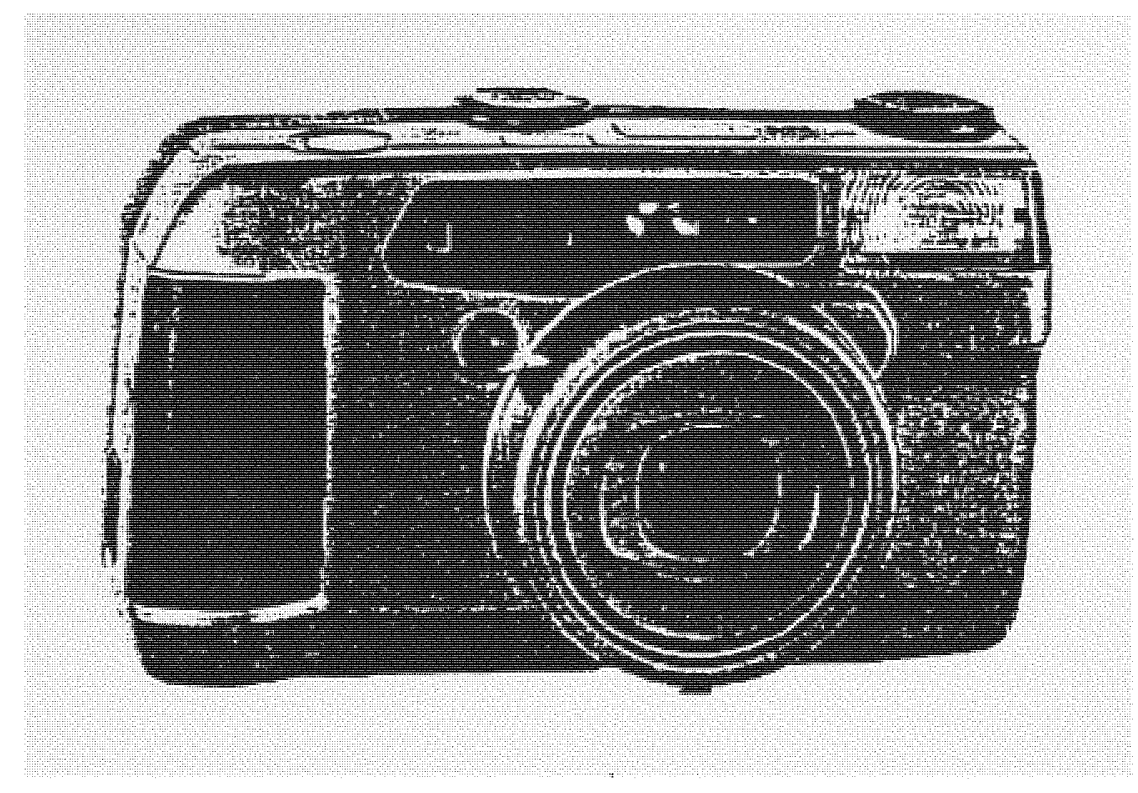

No matter how you see things, the NEW model "A" lets you capture ACL your visions.

- Built-in powerful 35-105 mm Zoom Lens

- All automatic functions: autoflash, autofocus, autoexposure, CAN be manually overriden

- Autoflash range $=14 \mathrm{ft}$

- Exposure compensation $=-2$ to +2

- $\quad$ Shutter speed $=1-112000$

- DX film speed reader $=25-1000$

- $\quad$ raming accuracy $=95 \%$

For fast information FAX your request to 1-800-559-4215 model "A" Corporation 
APPENDIX G

COMPETING BRAND AD 


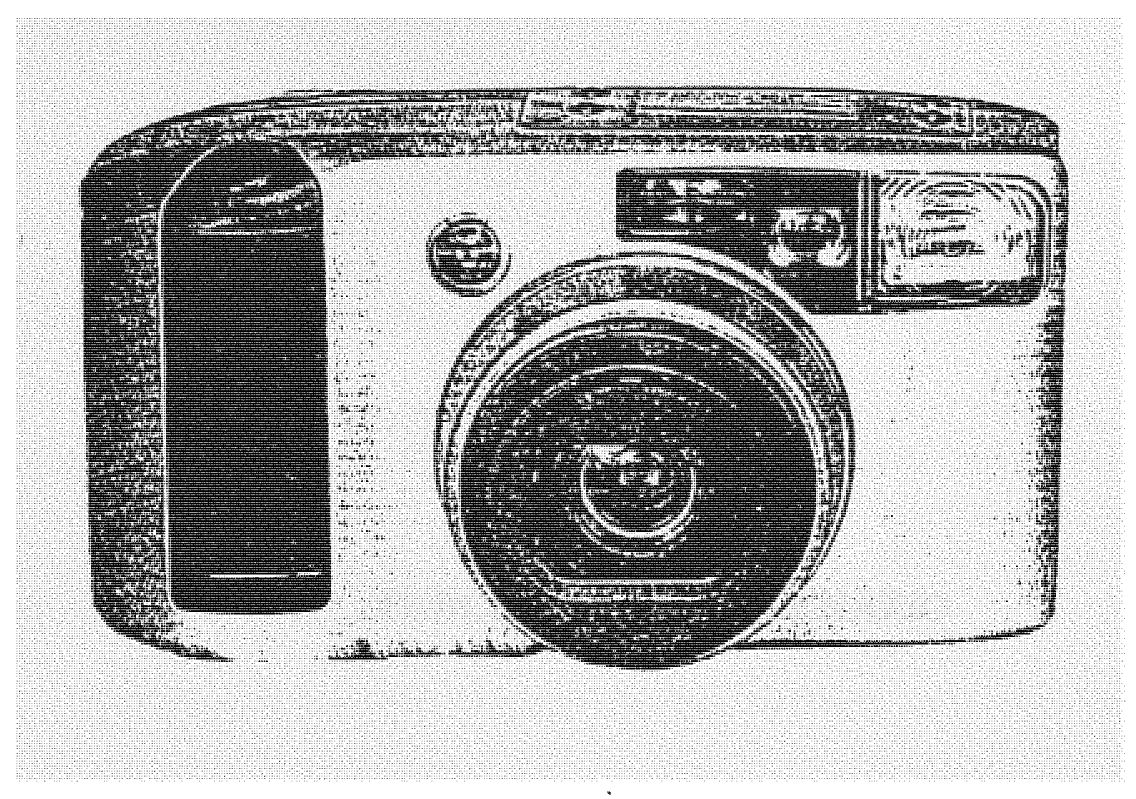

- You won't believe the amazing clarity, sharp definiton, and rich contrast of the pictures taken on a model " $D$ " camera!

The NEW model "D" meets the needs of both snapshooters and serious photographers. model " $D$ " is versatile with $A L L$ the features a photographer needs.

Try the model "D"... a camera so fitted to your hand and vision, it might even make you fall in love with photography all over again.

Call now for free information, or visit our world web site at http://www.modelD.com 
APPENDIX H

PURCHASE GOAL SCENARIO 


\section{PLEASE READ CAREFULLY}

For the purpose of this survey assume that a student named 'Robert' is a good friend of yours. Robert has recently taken up photography as a hobby. He is serious about this hobby and has even taken a few classes in photography at FIU. Robert lost his old camera and therefore, needs to buy a new camera for himself.

Robert uses his camera to take a variety of pictures - portraits of people; closeup shots of flowers and other small objects; and landscapes. Robert takes pride in the pictures he shoots and often takes several different shots of the same subject/object before he is satisfied with the picture. He therefore wants a camera which gives him flexibility in composing shots.

Having lost his old camera, Robert needs a new one now. Robert is considering buying an automatic camera with all the latest features, and is willing to spend a maximum of $\$ 400$. Being a good friend you are trying to help Robert find a camera that will best meet his needs.

You have a chance of winning a $\$ 100$ reward for participating in this study. Your chance of winning the reward, however, is linked to the camera you choose. The more appropriate the chosen camera is for Robert, the higher will be your chance of winning the reward. 
APPENDIX I

SURVEY INSTRUMENT: EXPERIMENT 1 


\section{THANK YOU FOR YOUR COOPERATION}

I thank you for agreeing to participate in this research project. I am a Ph.D student in the Department of Marketing \& Business Environment, and this study is being conducted as part of my doctoral dissertation. Your contribution to this study is VERY IMPORTANT. So please give your serious attention to this study.

Please pay careful attention to all the instructions and information that you are provided in this study. This is very important because if you miss out any information you will not be able to complete the study as required.

You will notice that there are some colored folders in front of you. Please open these folders only when instructed to do so. If at any time you need a clarification, simply raise your hand and you will be assisted.

Please follow the sequence of the study, and proceed page by page. Once you have read a page and moved forward, please do not go back to refer to it, unless otherwise instructed.

Before we go any further, please read and sign the next sheet of paper titled:

INFORMED CONSENT SHEET

THANK YOU FOR HELPING ME WITH THIS PROJECT 


\section{INFORMED CONSENT SHEET}

Please read the following page and sign at the bottom to indicate that your participation in this study is voluntary.

I freely and voluntarily consent to be a participant in the research project listed above to be conducted at Florida International University during the 1996-1997 school year with Ms. Sandipa Dublish as the principal investigator. I have been told that this study will last approximately $30-40$ minutes.

I understand that the purpose of this study is to examine consumers knowledge of cameras. I understand that the research procedures will be as follows: I will be asked to fill up a paper and pencil survey, followed by a short task on the computer.

I understand that the risks involved in this project are limited to those inherent in any study of this nature (time commitment, moderate fatigue). I further understand that my only known benefit for participating in this study, will be extra credit and a chance to win a $\$ 100$ lottery. All data collected on the approximately 200 participants will be kept strictly confidential and I will be identified only by a control number.

I understand that I may withdraw my consent and discontinue participation in this research project at any time with no negative consequences. I have been given the right to ask questions concerning the procedures, and any questions have been answered to my satisfaction.

I understand that if I desire further information about this research, I should contact Ms. Sandipa Dublish at 305-348-2571. I have been offered a copy of this informed consent form.

I have read and I understand the above.

Participant's Signature

Date

I have explained and defined in detail the research procedure in which the participant has agreed to participate and have offered her/him a copy of this informed consent form.

Principal Investigator's Signature

$\underline{5 / 10 / 97}$

Date 
Please answer a few questions given below. To answer a question, simply circle the appropriate number/option.

1. How much do you think you know about the features and uses of automatic cameras?

$\begin{array}{cccccccc}\text { Know very LITTLE } & & & & & & & \text { Know a LOT }\end{array}$

2. How would you rate your knowledge about automatic cameras relative to the rest of the population?

\begin{tabular}{|c|c|}
\hline $\begin{array}{l}\text { One of the LEAST } \\
\text { knowledgeable people }\end{array}$ & \\
\hline 2 & 3 \\
\hline
\end{tabular}

3. What is the purpose of having a manual override feature in an automatic camera? If you do not know the answer circle \# 8 .

Don't Know 8

4. You have to make a choice between four cameras which are similar on all fearures (including price) except their aperture range. The aperture range information on these cameras is presented below. Which camera would you choose based on this information?

Don't know 8

\begin{tabular}{|c|c|c|c|}
\hline Camera 1: & $\mathrm{f} / 3$ to $\mathrm{f} / 11$ & Camera 2: & $\mathrm{f} / 4$ to $\mathrm{f} / 8$ \\
\hline Camera 3: & $\mathrm{f} / 5$ to $\mathrm{f} / 6$ & Camera 4: & $\mathrm{f} / 4$ to $\mathrm{f} / 7$ \\
\hline
\end{tabular}


5. You have to make a choice between four cameras which are similar on all features (including price) except their smallest field. The smallest field information on these cameras is presented below. Which camera would you choose based on this information?

\section{Don't know 8}

$\begin{array}{lcll}\text { Camera 1: } & 5^{\prime \prime} & \text { Camera 2: } & 10^{\prime \prime} \\ \text { Camera 3: } & 1^{\prime \prime} & \text { Camera 4: } & 25^{\prime \prime}\end{array}$

6. Which one of the two cameras described below is a better camera? Why?

Camera 1: $\quad$ has a DX film speed reader $=$ ISO $100,200,400$

Camera 2: $\quad$ has a DX film speed reader $=1 S O 50-1000$

Don't know 8

7. Which of the following gives you the BEST exposure compensation? Why?

\section{Don't know 8}

1. Exposure compensation $=+1$

3. Exposure compensation $=-1$ to +1
2. Exposure compensation $=-1$

4. Exposure compensation $=-2$ to +2 


\section{REMINDER}

Your task in this study is to find a camera that best match ROBERT'S needs. Robert has recently taken up photography as a hobby. He is serious about this hobby and has even taken a few classes in photography at FIU. Robert lost his old camera and therefore, needs to buy a new camera for himself.

Robert uses his camera to take a variety of pictures - portraits of people; closeup shots of flowers and other small objects; and landscapes. Robert takes pride in the pictures he shoots and often takes several different shots of the same subject/object before he is satisfied with the picture. He therefore, wants a camera which gives him flexibility in composing shots.

Having lost his old camera, Robert needs a new one now. Robert is considering buying an automatic camera with all the latest features, and is willing to spend a maximum of $\$ 400$. Being a good friend you are trying to help Robert find a camera that will best meet his needs.

In your search for a camera for Robert you are flipping through a photography magazine and come across an advertisement for a new camera - model " $\mathrm{A}$ " which is priced around $\$ 350$, and is manufactured by a reputed company.

Assuming that you are choosing a camera for 'Robert', answer a few simple questions after reading this advertisement.

IMPORTANT: Please read the advertisement carefully. Once you start answering the survey questions DO NOT go back and look at the advertisement. Please answer the questions in the order in which they are asked, and once you have moved forward, do not go back to a previous question.

Please remember that there are no right or wrong answers to any question. I am simply interested in obtaining your honest opinion. Please read all questions carefully before answering them. Try to answer ALL questions to the best of your ability. If any question is not clear to you, raise your hand.

Now you can turn this page and look at the advertisement for model " $A$ " camera 
Now that you have seen the advertisement for model "A" camera, I would like to ask you a few questions based on it.

I. How would you describe your feelings toward the model "A" advertisement? Please circle one number for each pair of adjectives.

$\begin{array}{lllllllllll}\text { Not likable } & 1 & 2 & 3 & 4 & 5 & 6 & 7 & 8 & 9 & \text { Very likable } \\ \text { Unfavorable } & 1 & 2 & 3 & 4 & 5 & 6 & 7 & 8 & 9 & \text { Very favorable } \\ \text { Boring } & 1 & 2 & 3 & 4 & 5 & 6 & 7 & 8 & 9 & \text { Very interesting }\end{array}$

II. How would you describe your feelings toward model "A" camera. Please circle one number for each pair of adjectives.

$\begin{array}{lllllllllll}\text { Bad } & 1 & 2 & 3 & 4 & 5 & 6 & 7 & 8 & 9 & \text { Good } \\ \text { Negative } & 1 & 2 & 3 & 4 & 5 & 6 & 7 & 8 & 9 & \text { Positive } \\ \begin{array}{l}\text { Dislike it very } \\ \text { much }\end{array} & 1 & 2 & 3 & 4 & 5 & 6 & 7 & 8 & 9 & \text { Like it very much }\end{array}$

III. In your opinion how appropriate would it be to buy the model "A" camera for Robert?

$\begin{array}{llllllllllll}\text { Not at all } & 1 & 2 & 3 & 4 & 5 & 6 & 7 & 8 & 9 & \text { Very Appropriate }\end{array}$ Appropriate

Thank you for answering the questions on model " $\mathrm{A}$ " advertisement. As you are reading the photography magazine, you soon come across yet another advertisement. This time the camera is model "D". Model "D" is also priced at around $\$ 350$ and is manufactured by a reputed company. Please read the model " $D$ " advertisement carefully and answer a few questions about it. 
Now that you have seen the advertisement for model "D" camera, I would like to ask you a few questions based on it.

I. How would you describe your feelings toward the model "D" advertisement? Please circle one number for each pair of adjectives.

$\begin{array}{lllllllllll}\text { Not likable } & 1 & 2 & 3 & 4 & 5 & 6 & 7 & 8 & 9 & \text { Very likable } \\ \text { Unfavorable } & 1 & 2 & 3 & 4 & 5 & 6 & 7 & 8 & 9 & \text { Very favorable } \\ \text { Boring } & 1 & 2 & 3 & 4 & 5 & 6 & 7 & 8 & 9 & \text { Very interesting }\end{array}$

II. How would you describe your feelings toward model "D" camera. Please circle one number for each pair of adjectives.

$\begin{array}{lllllllllll}\text { Bad } & 1 & 2 & 3 & 4 & 5 & 6 & 7 & 8 & 9 & \text { Good } \\ \text { Negative } & 1 & 2 & 3 & 4 & 5 & 6 & 7 & 8 & 9 & \text { Positive } \\ \begin{array}{l}\text { Dislike it very } \\ \text { much }\end{array} & 1 & 2 & 3 & 4 & 5 & 6 & 7 & 8 & 9 & \text { Like it very much }\end{array}$

III. In your opinion how appropriate would it be to buy the model " $D$ " camera for Robert?

$\begin{array}{lllllllllll}\text { Not at all } & 1 & 2 & 3 & 4 & 5 & 6 & 7 & 8 & 9 & \text { Very Appropriate }\end{array}$ Appropriate 
Now assume that you go to a store to choose a camera for ROBERT. In the store you find eight cameras. Two of these are models "A" and "D", whose advertisements, you saw a while back. Plus, there are six other models. All models are similarly priced at around $\$ 350$ and are from reputed companies.

So now you have a choice between eight models, which are:
1. model "A"
5. model "E"
2. model "B"
6. model " $F "$
3. model " $\mathrm{C}^{n}$
7. model " $\mathrm{G}$ "
4. model " $\mathrm{D}$ "
8. model "H"

The store has information on the features of these models, which you can obtain before making a choice.

I. How interested are you in obtaining information about model "A"?

$\begin{array}{llllllllllll}\text { Not at all Interested } & 1 & 2 & 3 & 4 & 5 & 6 & 7 & 8 & 9 & \text { Very Interested }\end{array}$

II. How interested are you in obtaining information about model "D"?

$\begin{array}{llllllllllll}\text { Not at all Interested } & 1 & 2 & 3 & 4 & 5 & 6 & 7 & 8 & 9 & \text { Very Interested }\end{array}$

III. How interested are you in obtaining information about the other six models?

$\begin{array}{llllllllllll}\text { Not at all Interested } & 1 & 2 & 3 & 4 & 5 & 6 & 7 & 8 & 9 & \text { Very Interested }\end{array}$ 
IV. In your opinion what is the likelihood that additional information will help you find a camera which is better than model "A"?

$\begin{array}{llllllllllll}\text { Very low likelihood } & 1 & 2 & 3 & 4 & 5 & 6 & 7 & 8 & 9 & \text { Very high likelihood }\end{array}$

V. In your opinion what is the likelihood that additional information will help you find a camera which is better than model " $D$ "?

$\begin{array}{lllllllllll}\text { Very low likelihood } & 1 & 2 & 3 & 4 & 5 & 6 & 7 & 8 & 9 & \text { Very high likelihood }\end{array}$

You can use the computer to obtain information about these camera models. The computer will provide you information about the different features of these models.

To obtain information on any model, you will have to fill in a question format with two blanks, as shown below:

1. What type of does model have?

Suppose you wanted information on the weight of model "D". When the computer flashes the question:

1. What type of does model have?

You will first hit the number ' 1 ' key and then the ENTER key.

Then you will type - W - (abbreviation for weight) in the first blank and hit the ENTER key. The cursor will move to the second blank, where you will type - D - and hit the ENTER key again. The answer to your question will then appear on the screen.

Let us do a practice run. Please remove the white sheet from the computer screen, and ask the computer to give you information on the weight $(\mathbf{W})$ of model $\mathbf{D}$. 
Do keep in mind that your task is to choose a camera for ROBERT. Your chance of winning the $\$ 100$ reward is linked to the camera you choose. To refresh your memory, a written description of ROBERT is provided in the YELLOW folder in front of you.

If you feel the need to write down any piece of information, a pen and notepad has been provided for that purpose. If you have any questions at this stage, please raise your hand and you will be assisted.

Please use the list given below when typing the features in the blanks. Type the abbreviated terms only and not the full form. For example, if you want information about zoom lens, you simply have to type $-\mathbb{Z L}$.

\section{YOU HAVE TO MAKE A CHOICE FROM THE FOLLOWING CAMERA MODELS}

$\begin{array}{lll}\text { 1. model A } & \text { 4. model D }\end{array}$

2. model $\mathbf{B} \quad$ 5. model $\mathbf{E} \quad$ 8. model $\mathbf{H}$

3. model $\mathbf{C} \quad$ 6. model $\mathbf{F}$

YOU CAN GET INFORMATION ON THE FOLLOWING FEATURES

FEATURE

1. Aperture size

2. DX film speed reader

3. Exposure system

4. Framing accuracy

5. Flash system

6. Focus system

7. Shutter speed

8. Zoom lens

\section{ABBREVIATION}

$\mathbf{A P}$

DX

EX

FA

FL

OF

SH

ZL 


\section{CONCLUSION OF STUDY FORM}

I. You have used information provided by the computer to evaluate the eight camera models. Could you please rank the eight models in order of preference, i.e., which model you think is the best choice for ROBERT? second best? third best? and so forth...

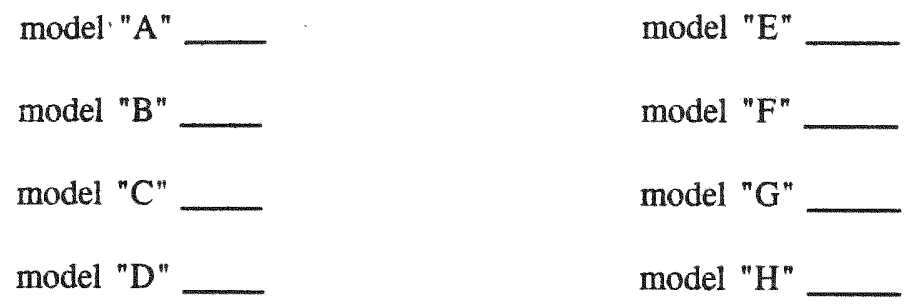

II. Please answer the following questions. I would like to remind you once again that your responses will be kept completely confidential. There are no right or wrong answers to any questions. I simply want your honest opinion.

a. How carefully did you assess the features of camera models you searched during this session, relative to how carefully you would assess features of household products such as paper towels.

Much less

carefully
About the

same
Much more carefully

$\begin{array}{lllllllll}1 & 2 & 3 & 4 & 5 & 6 & 7 & 8 & 9\end{array}$


b. How carefully did you assess the features of camera models you searched during this session, relative to how carefully you would assess fearures of consumer electronic products such as stereos.

Much less

About the

Much more

carefully same carefully

$\begin{array}{lllllllll}1 & 2 & 3 & 4 & 5 & 6 & 7 & 8 & 9\end{array}$

c. How satisfied are you with the quality of information provided by the computer?

Extremely

dissatisfied

$\begin{array}{lllllllll}1 & 2 & 3 & 4 & 5 & 6 & 7 & 8 & 9\end{array}$

Extremely

satisfied

9

d. How confident are you that you chose the camera model that was 'best' for Robert?

Not at all confident
Extremely

confident
1
2
3
45
6
$\begin{array}{ll}7 & 8\end{array}$
9

e. When doing this study, how important was it for you to make the right brand choice for Robert?

Not at all

important

Extremely important
1
2
3
4
56
$7 \quad 8$
9

IV. What in your opinion was the purpose behind the study you just completed 
V. Please provide the following classification information. This information is being taken for the purpose of analysis. Personal information is being collected, so that you can be contacted in the event you win the $\$ 100$ lottery.

Age: years

Gender:

Male

$1 \quad$ Female 2

Major area of study:

Name :

SS\# :

Phone:

Please close all folders and stack them together. Raise your hand to indicate that you have completed the study.

THANK YOU VERY MUCH ! 
APPENDIX J

FOCAL BRAND CONTROL AD

EXPERIMENT 2 
- cutting edge features for a sophisticated user

- user friendly operations for hassle free photography

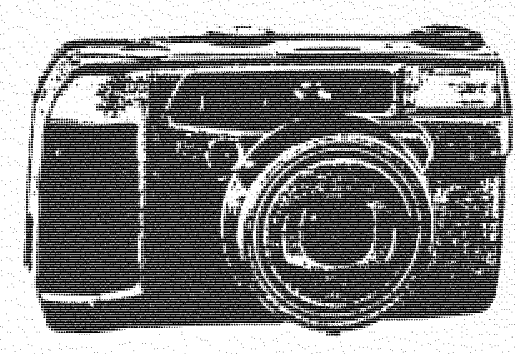

For fast information FAX your request to 1-800-559-4215 model "A" Corporation 
APPENDIX K

FOCAL BRAND POSITIVE PERIPHERAL CUE AD

EXPERIMENT 2 


\section{Introducing the ALC IN ONE model " $A$ " A camera for all occasions!}

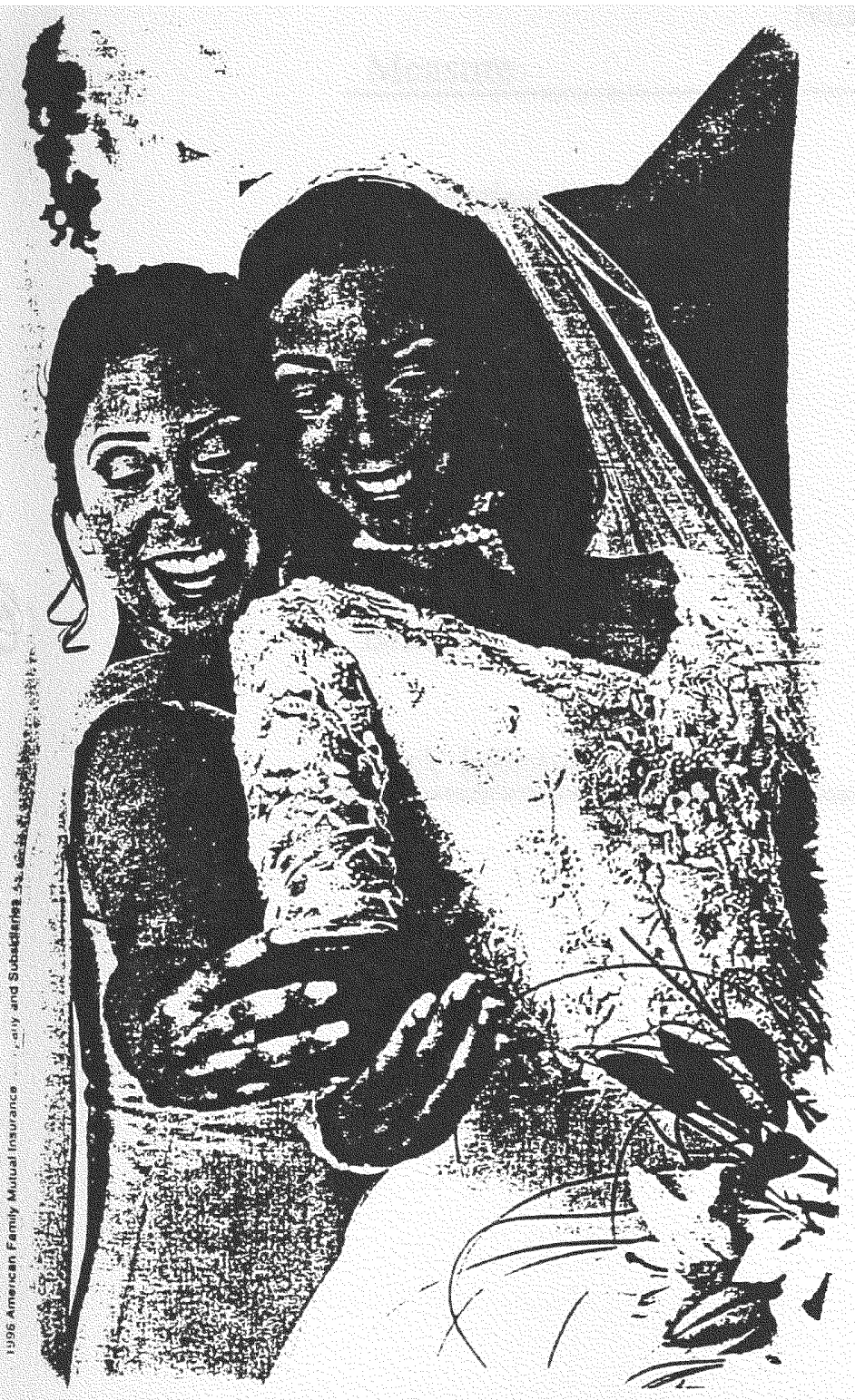

- cutting edge features for a sophisticated HSe:

- user friendly operations for hassle free photography

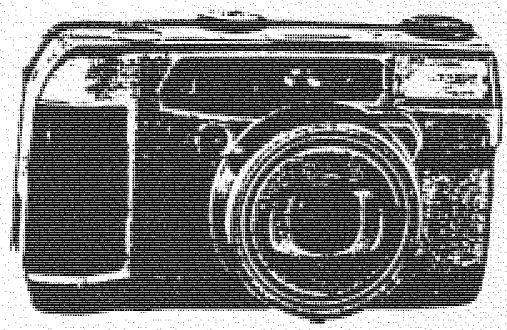

For fast information FAX your request to $1-800-559-4215$ model " $A$ " Corporation 
TABLE 1: SUMMARY OF MEASURES USED IN EXPERIMENT 1

\begin{tabular}{lcc}
\hline Measure & $\begin{array}{c}\text { Number of Scale } \\
\text { Items }\end{array}$ & $\begin{array}{c}\text { Reliability } \\
\text { Coefficient }\end{array}$ \\
\hline $\begin{array}{l}\text { Subjective knowledge } \\
\text { Ability to process }\end{array}$ & 2 & .87 \\
Attitude toward Ad & 3 & .86 \\
Attitude toward & 3 & .94 \\
Brand & 3 & .94 \\
Task Involvement & & .45 \\
\hline \hline
\end{tabular}


TABLE 2: SUMMARY OF MEASURES USED IN EXPERIMENT 2

\begin{tabular}{lcc}
\hline Measure & $\begin{array}{c}\text { Number of Scale } \\
\text { Items }\end{array}$ & $\begin{array}{c}\text { Reliability } \\
\text { Coefficient }\end{array}$ \\
\hline $\begin{array}{l}\text { Subjective knowledge } \\
\text { Ability to process }\end{array}$ & 2 & .80 \\
$\begin{array}{l}\text { Attitude toward Ad } \\
\text { Attitude toward }\end{array}$ & 3 & .87 \\
Brand & 3 & .92 \\
Task Involvement & 3 & .95 \\
\hline \hline
\end{tabular}




\section{TABLE 3: CELL MEANS FOR MANIPULATION AND INDUCTION CHECKS: EXPERIMENT 1}

\begin{tabular}{|c|c|c|c|c|}
\hline \multirow[b]{2}{*}{ Measures } & \multicolumn{2}{|c|}{ Lower Ability Group } & \multicolumn{2}{|c|}{ Higher Ability Group } \\
\hline & Control & $\begin{array}{l}\text { Strong } \\
\text { Claim }\end{array}$ & Control & Strong Claim \\
\hline
\end{tabular}

ABILITY TO PROCESS MANIPULATION

Subjective

3.63

3.11

4.25

4.41

knowledge ${ }^{a}$

Ability to process $^{\mathrm{b}}$

1.90

1.13

4.10

4.47

\section{TASK INVOLVEMENT INDUCTION}

Care vs paper

towels ${ }^{\mathrm{c}}$

7.55

7.22

7.40

7.13

Care vs

5.30

4.78

5.65

5.09

electronic

products $^{\mathrm{c}}$

Importance of

6.45

6.69

6.75

6.31

choosing the best model ${ }^{\mathrm{c}}$

a. Scale ranges from 1-7

b. Index ranges from 0-5

c. Scale ranges from 1-9 
TABLE 4: MANIPULATION AND INDUCTION CHECKS:

EXPERIMENT 1 (F-values for $2 \times 2$ ANOVAs)

\begin{tabular}{|c|c|c|c|}
\hline \multirow{2}{*}{ Measure } & \multicolumn{2}{|c|}{ Main Effects } & \multirow{2}{*}{$\begin{array}{l}\begin{array}{l}\text { Interaction } \\
\text { Effect }\end{array} \\
\text { AL } \times \text { AC }\end{array}$} \\
\hline & $\begin{array}{c}\text { Ability level } \\
(\mathrm{AL})\end{array}$ & $\begin{array}{l}\text { Ad Content } \\
\text { (AC) }\end{array}$ & \\
\hline \multicolumn{4}{|c|}{ ABILITY TO PROCESS MANIPULATION } \\
\hline $\begin{array}{l}\text { Subjective } \\
\text { knowledge }\end{array}$ & $21.86^{\mathrm{a}}$ & 0.62 & 2.17 \\
\hline $\begin{array}{l}\text { Ability to } \\
\text { process }\end{array}$ & $119.76^{\mathrm{a}}$ & 0.56 & $4.40^{c}$ \\
\hline \multicolumn{4}{|c|}{ TASK INVOLVEMENT INDUCTION } \\
\hline $\begin{array}{l}\text { Care vs paper } \\
\text { towels }\end{array}$ & 0.12 & 0.76 & 0.01 \\
\hline $\begin{array}{l}\text { Care vs } \\
\text { electronic } \\
\text { products }\end{array}$ & 1.26 & $3.22^{\mathrm{d}}$ & 0.00 \\
\hline $\begin{array}{l}\text { Importance of } \\
\text { choosing the } \\
\text { best model }\end{array}$ & 0.06 & 0.05 & 0.52 \\
\hline
\end{tabular}




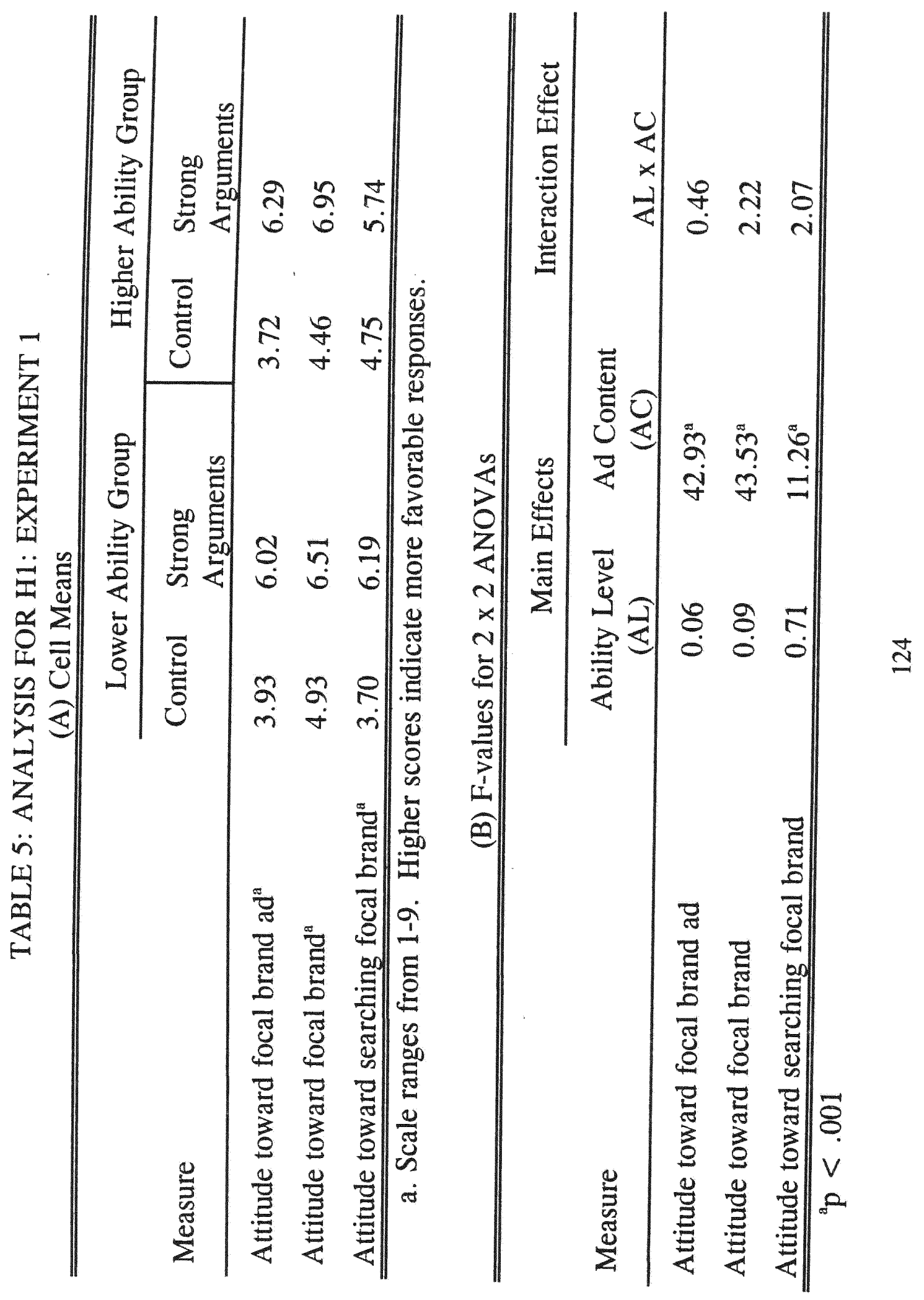




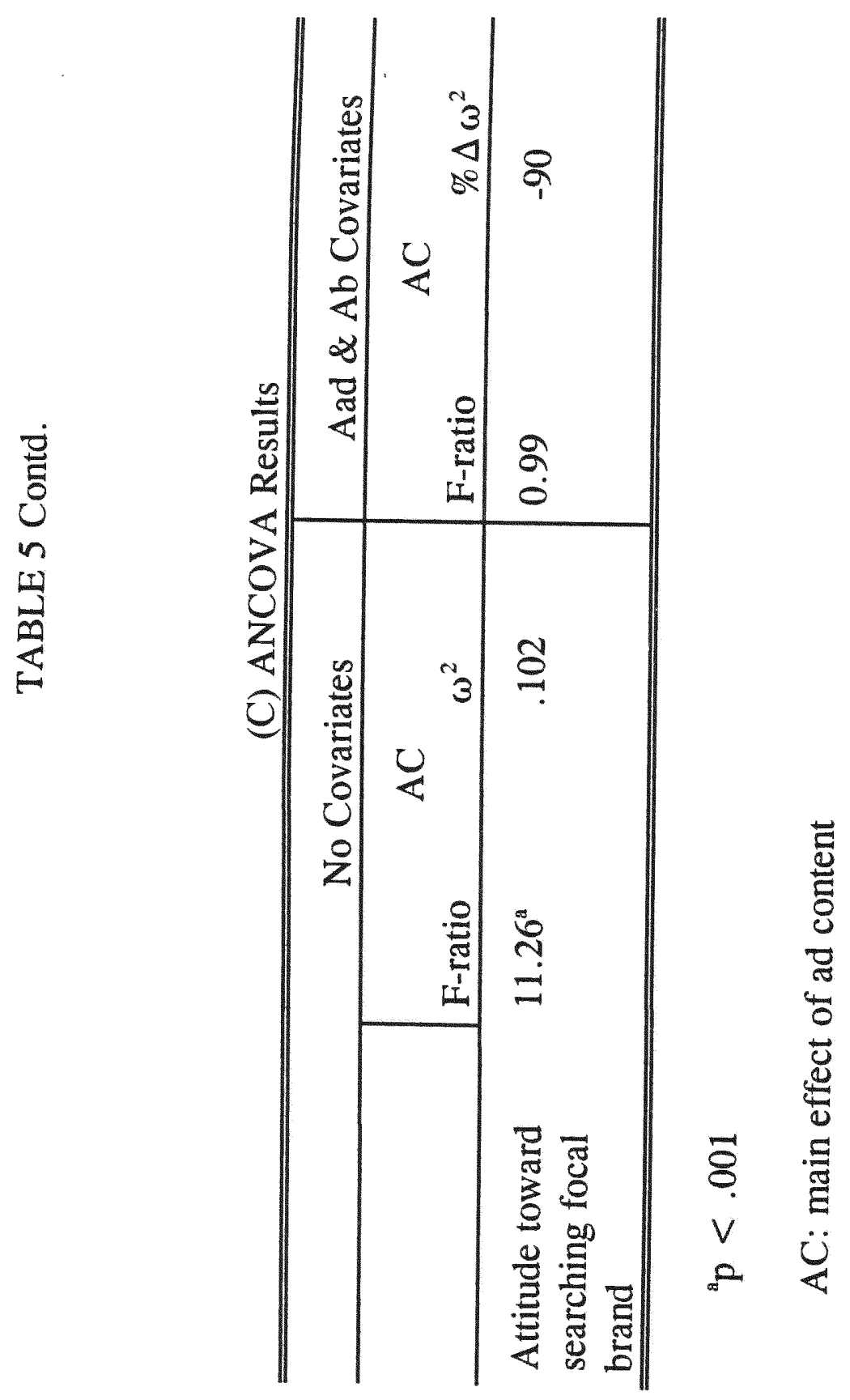

$\Xi$ 


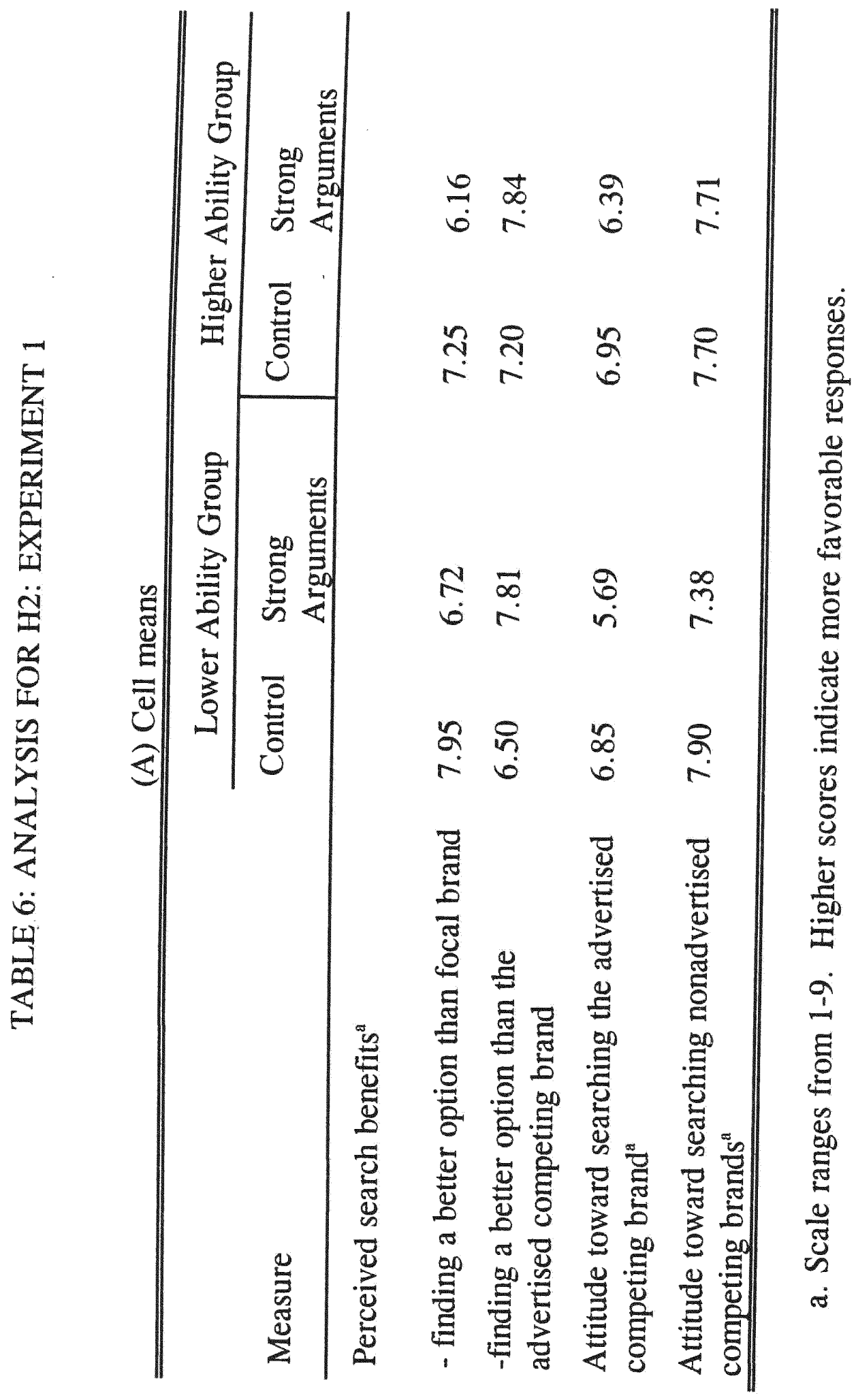

$\nsubseteq$ 


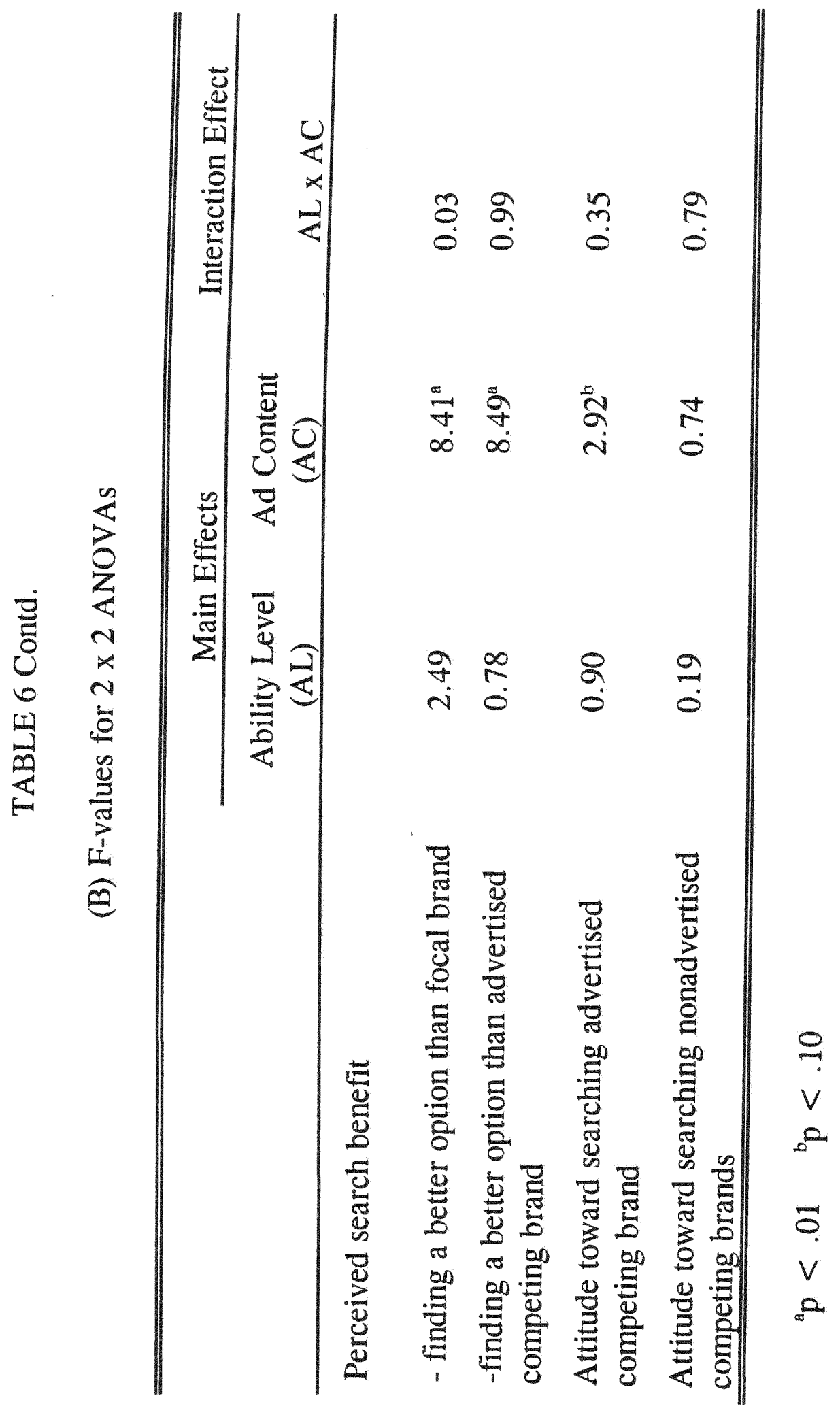




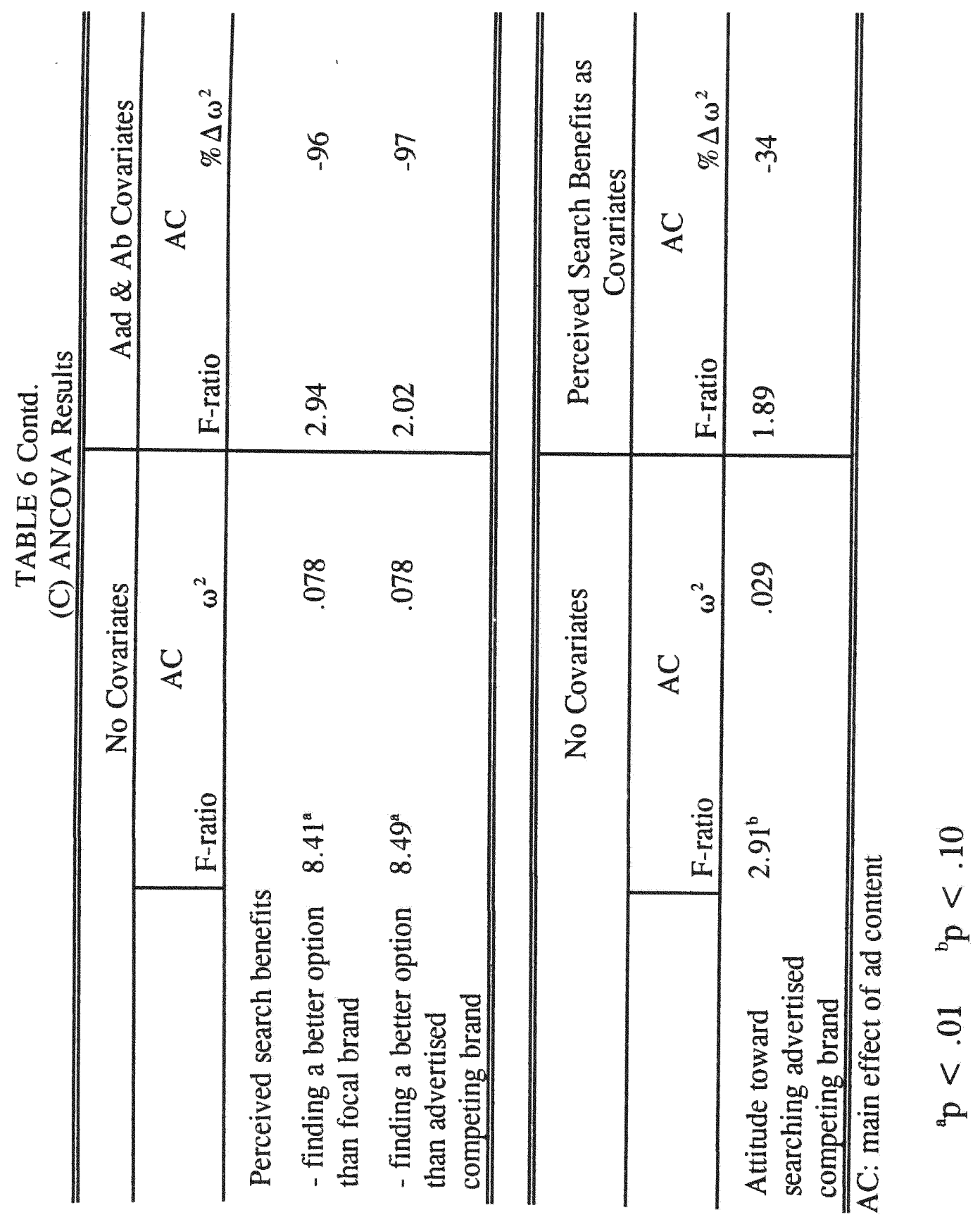

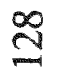


TABLE 7: ANALYSIS FOR H3a: EXPERIMENT 1

\begin{tabular}{l} 
(A) Percentage of Subjects Searching Focal Brand \\
\hline \begin{tabular}{|l|l|l|}
\hline Ability Level & $\begin{array}{l}\text { Control } \\
\text { Ad }\end{array}$ & $\begin{array}{l}\text { Strong } \\
\text { Arguments }\end{array}$ \\
\hline Lower & $68.4 \%$ & $93.5 \%$ \\
\hline Higher & $78.9 \%$ & $81.3 \%$ \\
\hline
\end{tabular}
\end{tabular}

(B) Percentage of Subjects Searching Focal Brand First

\begin{tabular}{||l|l|l|}
\hline Ability Level & $\begin{array}{l}\text { Control } \\
\text { Ad }\end{array}$ & $\begin{array}{l}\text { Strong } \\
\text { Arguments }\end{array}$ \\
\hline Lower & $42.1 \%$ & $67.7 \%$ \\
\hline Higher & $63.2 \%$ & $46.9 \%$ \\
\hline
\end{tabular}




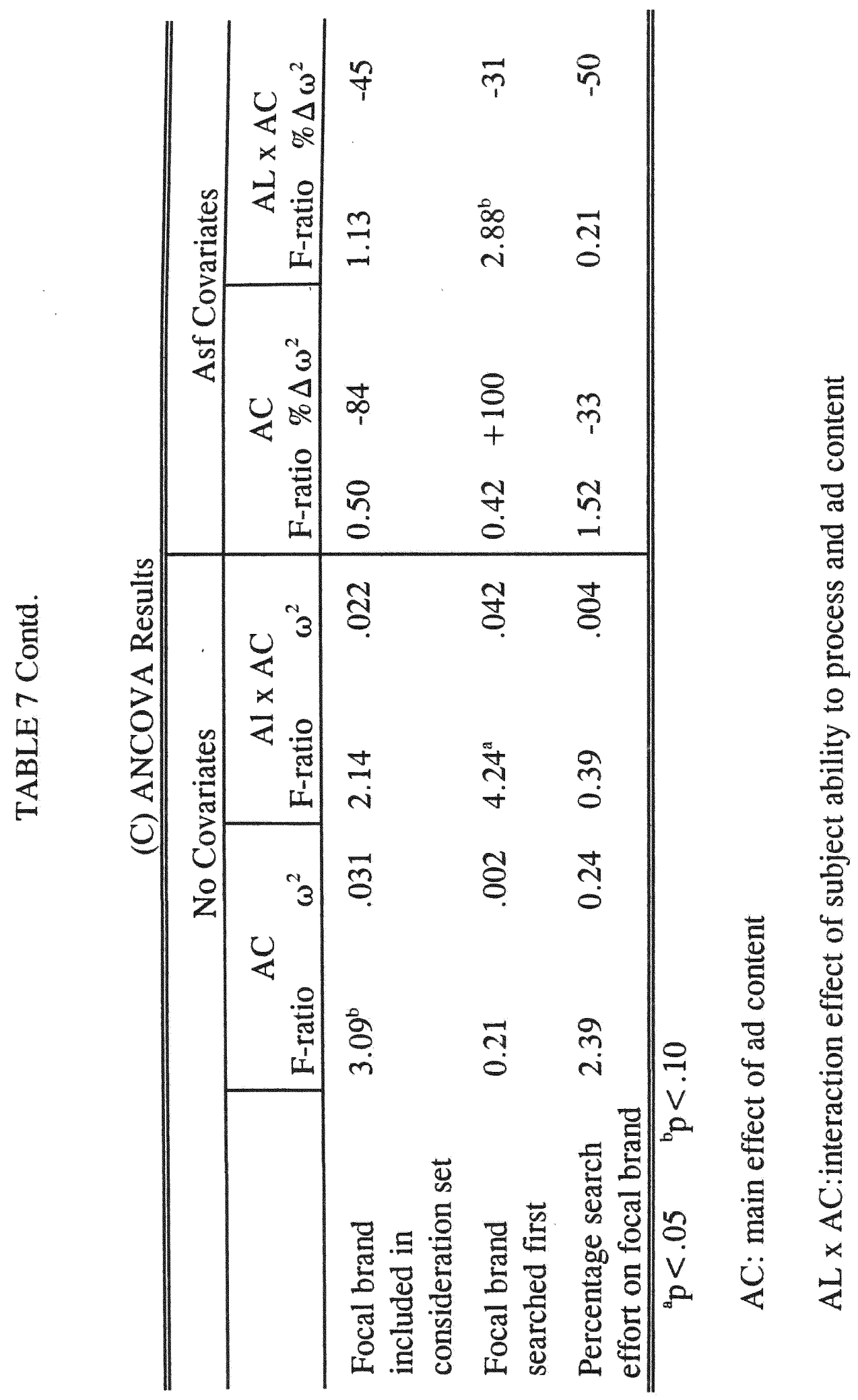




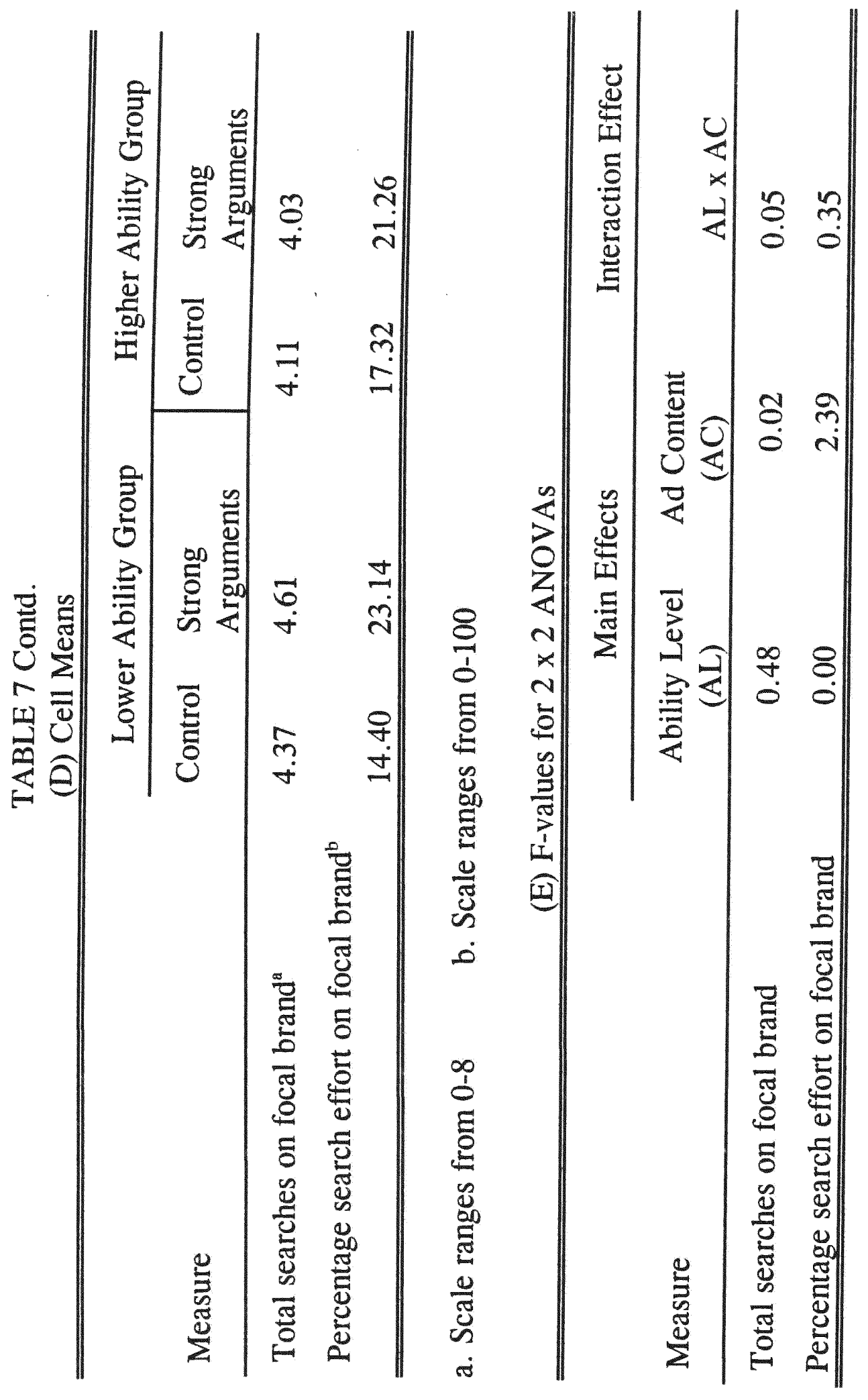




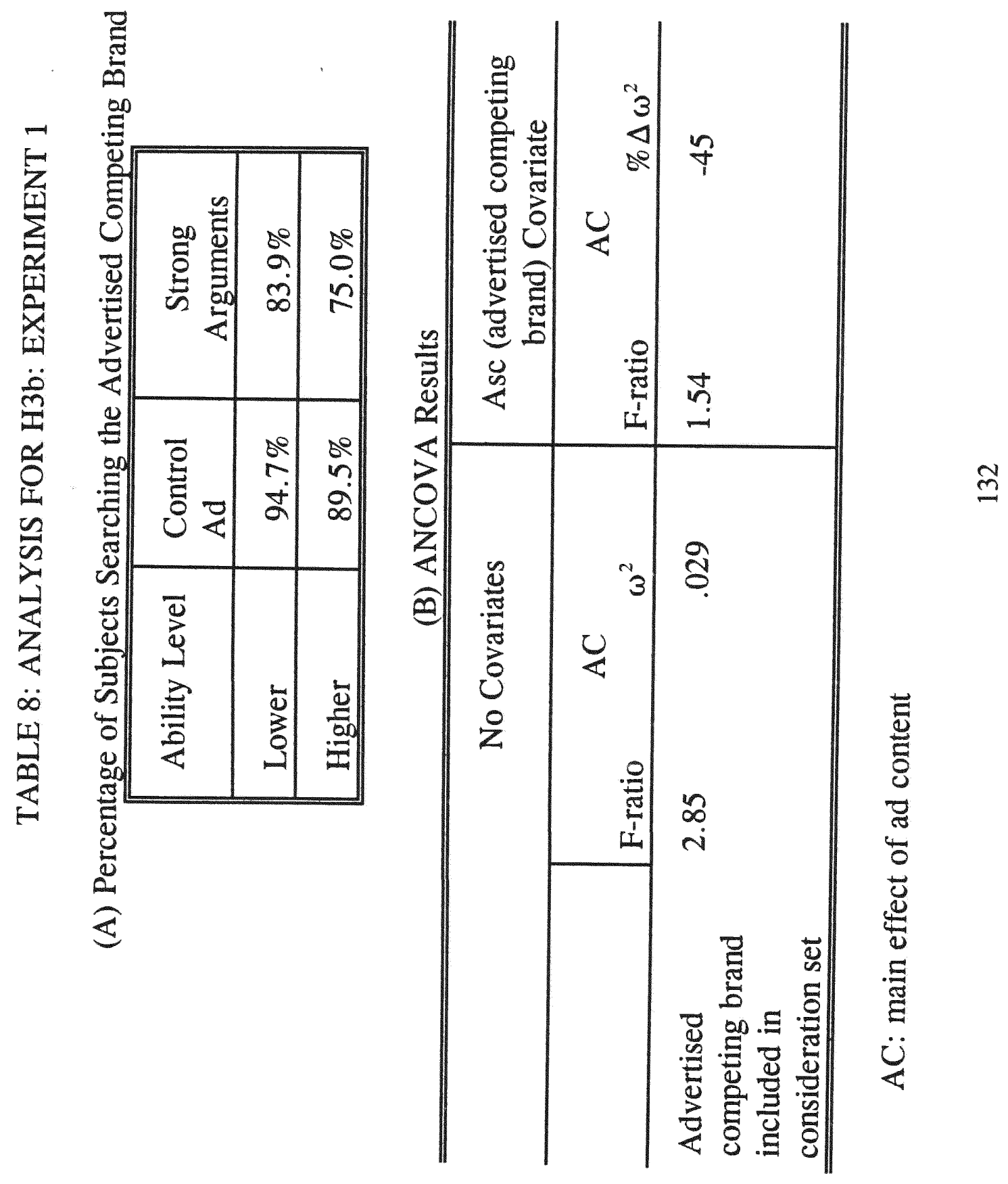




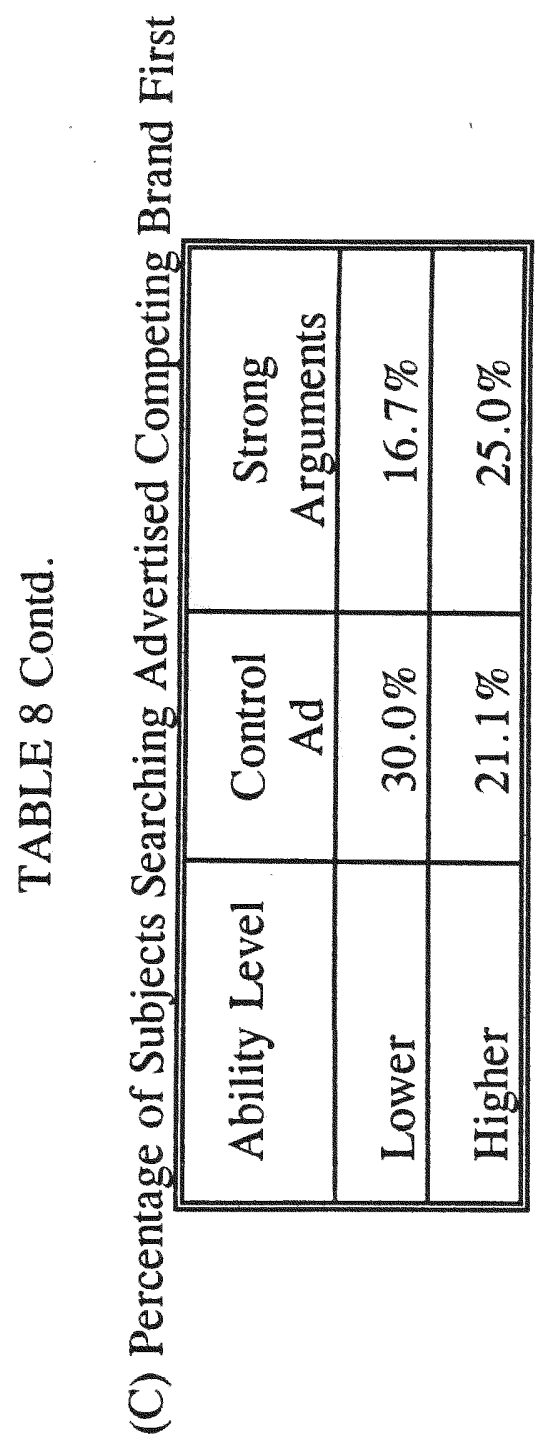

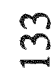




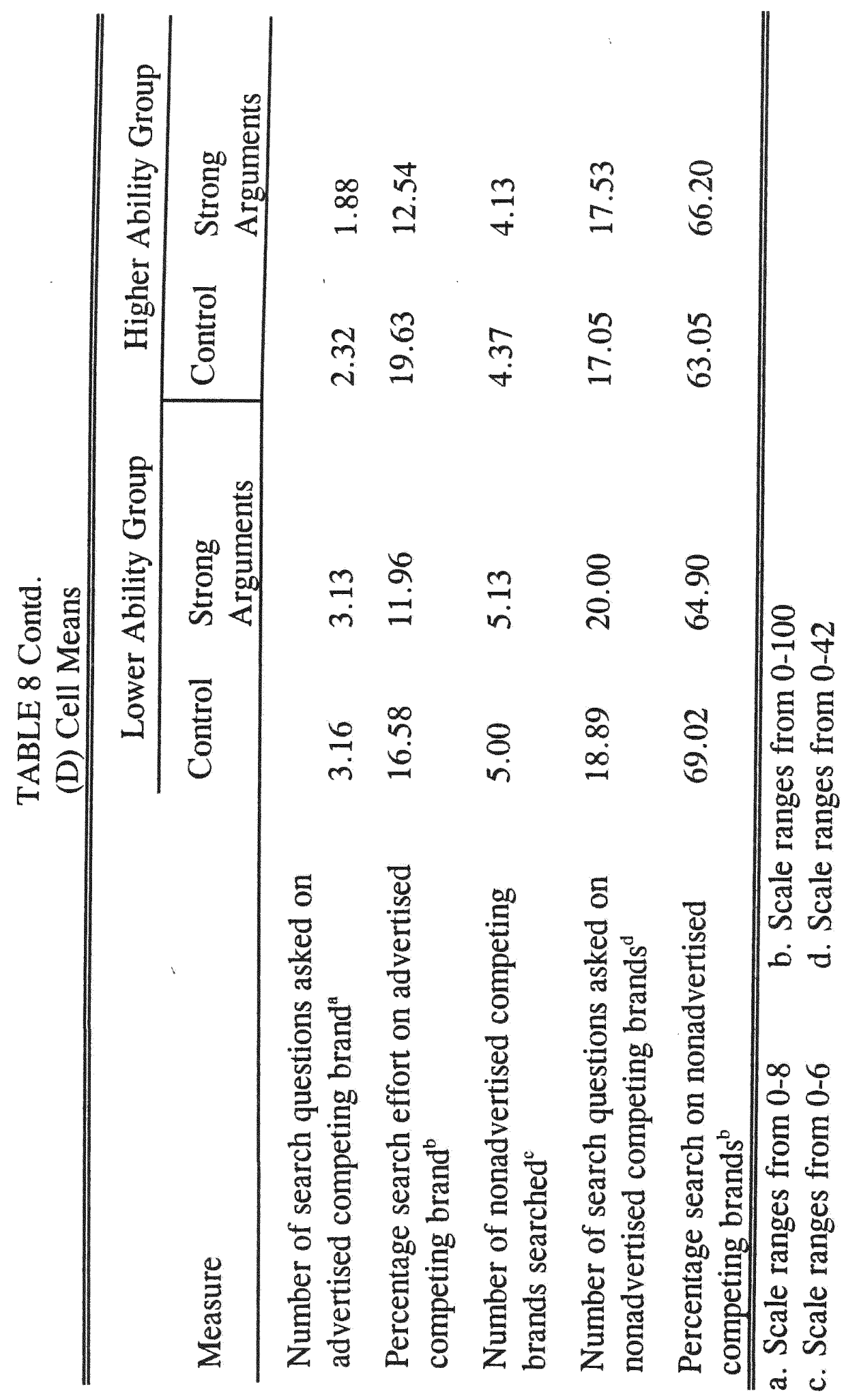




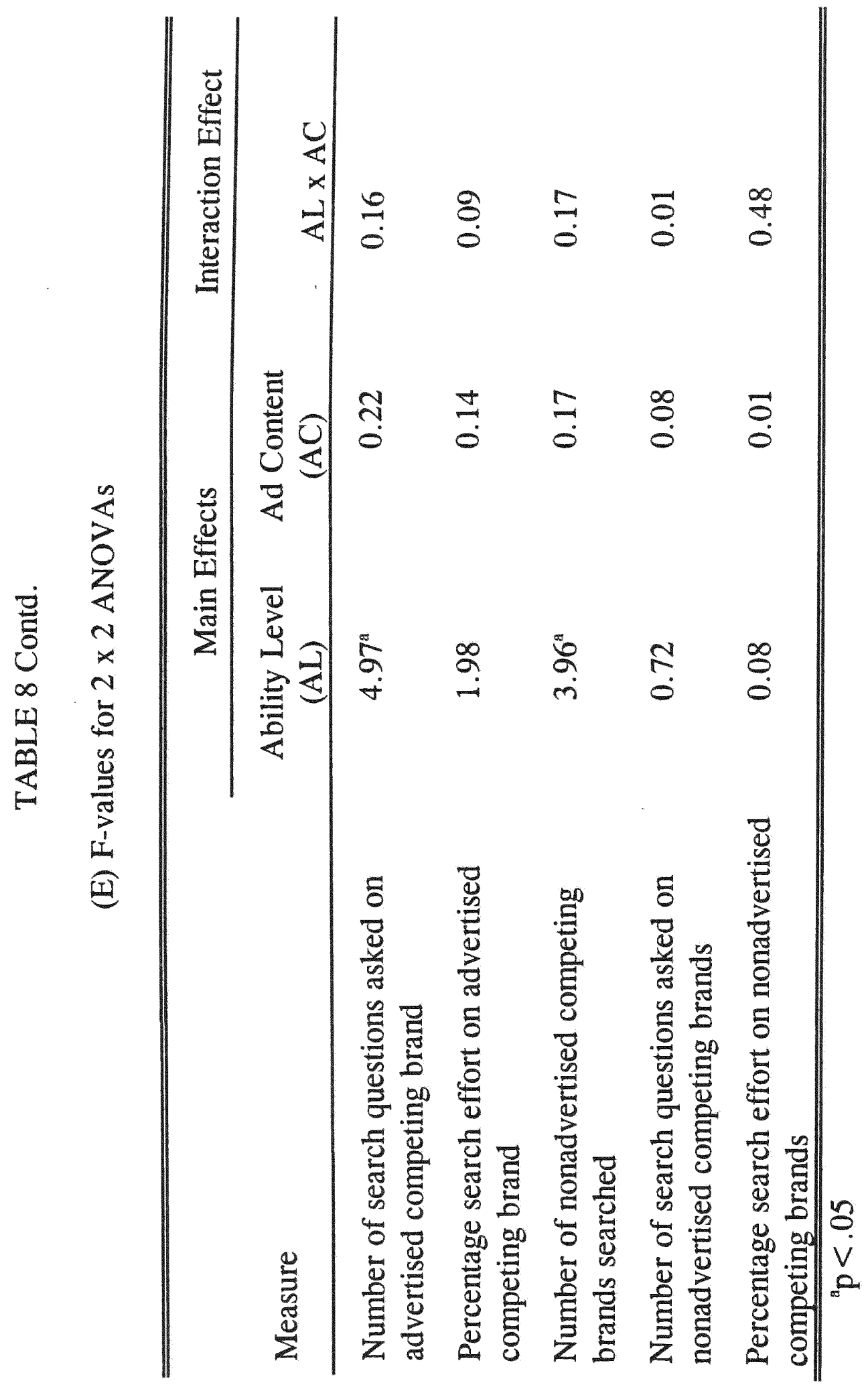

$\stackrel{9}{9}$ 


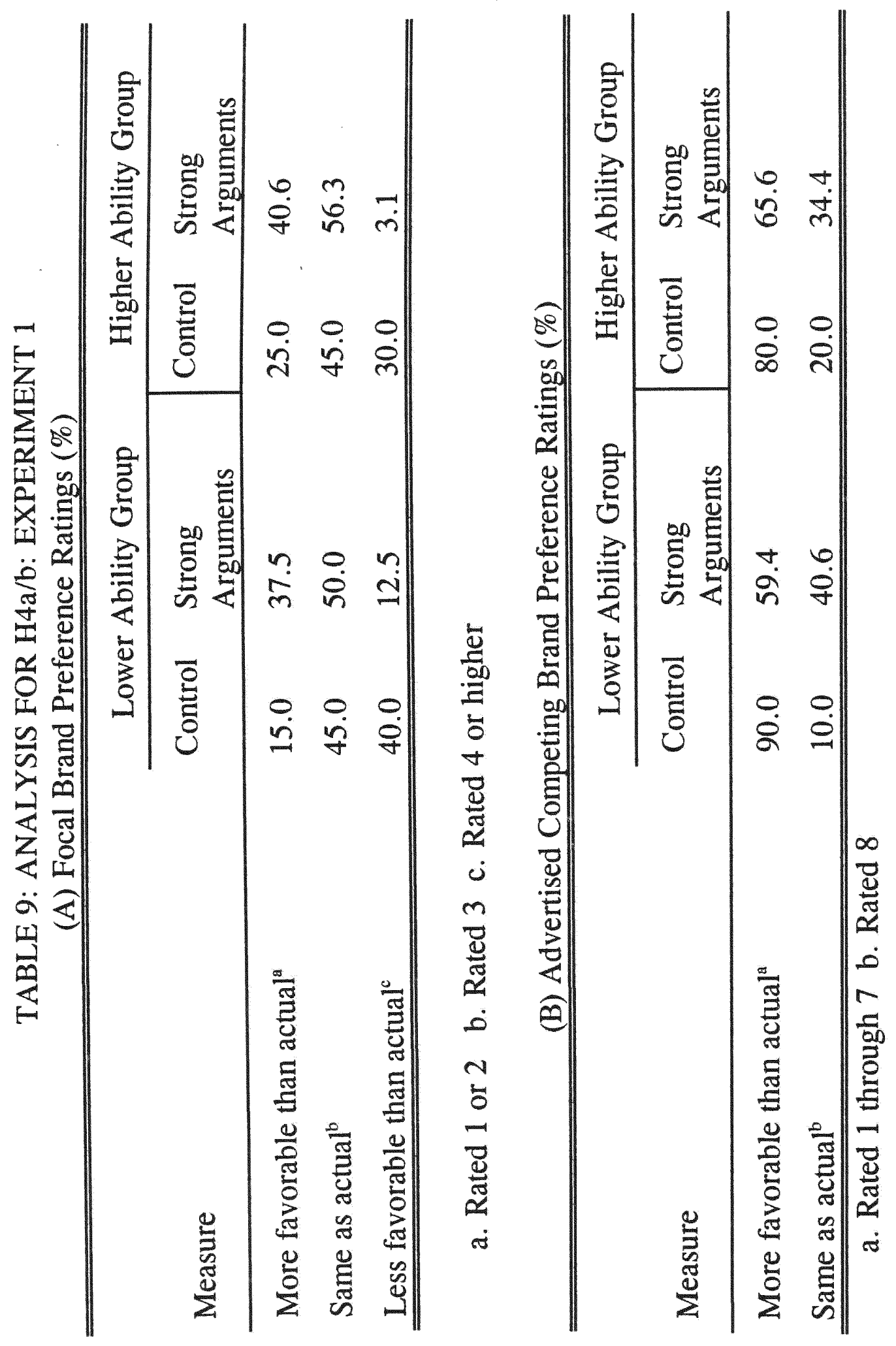

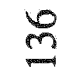




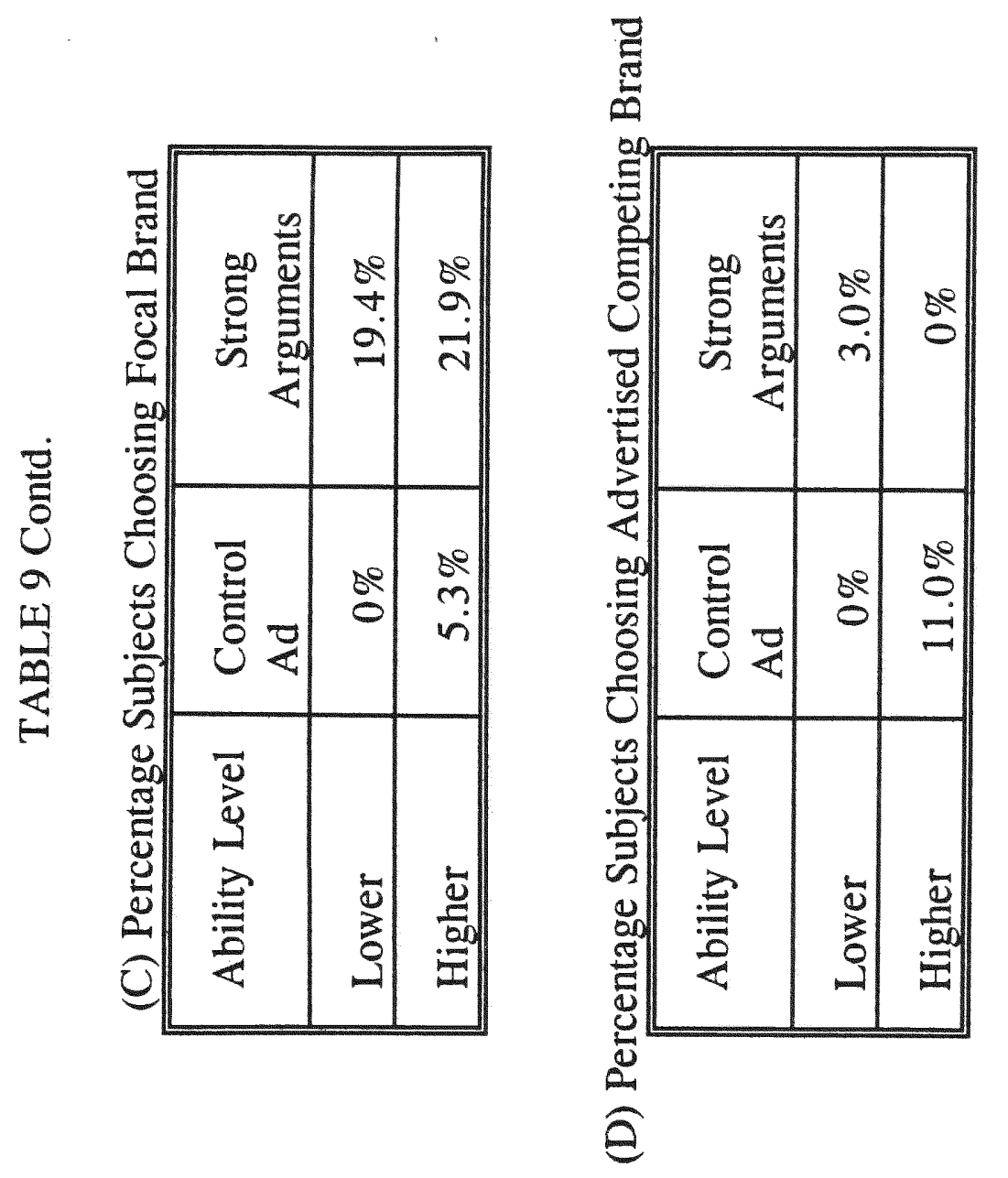




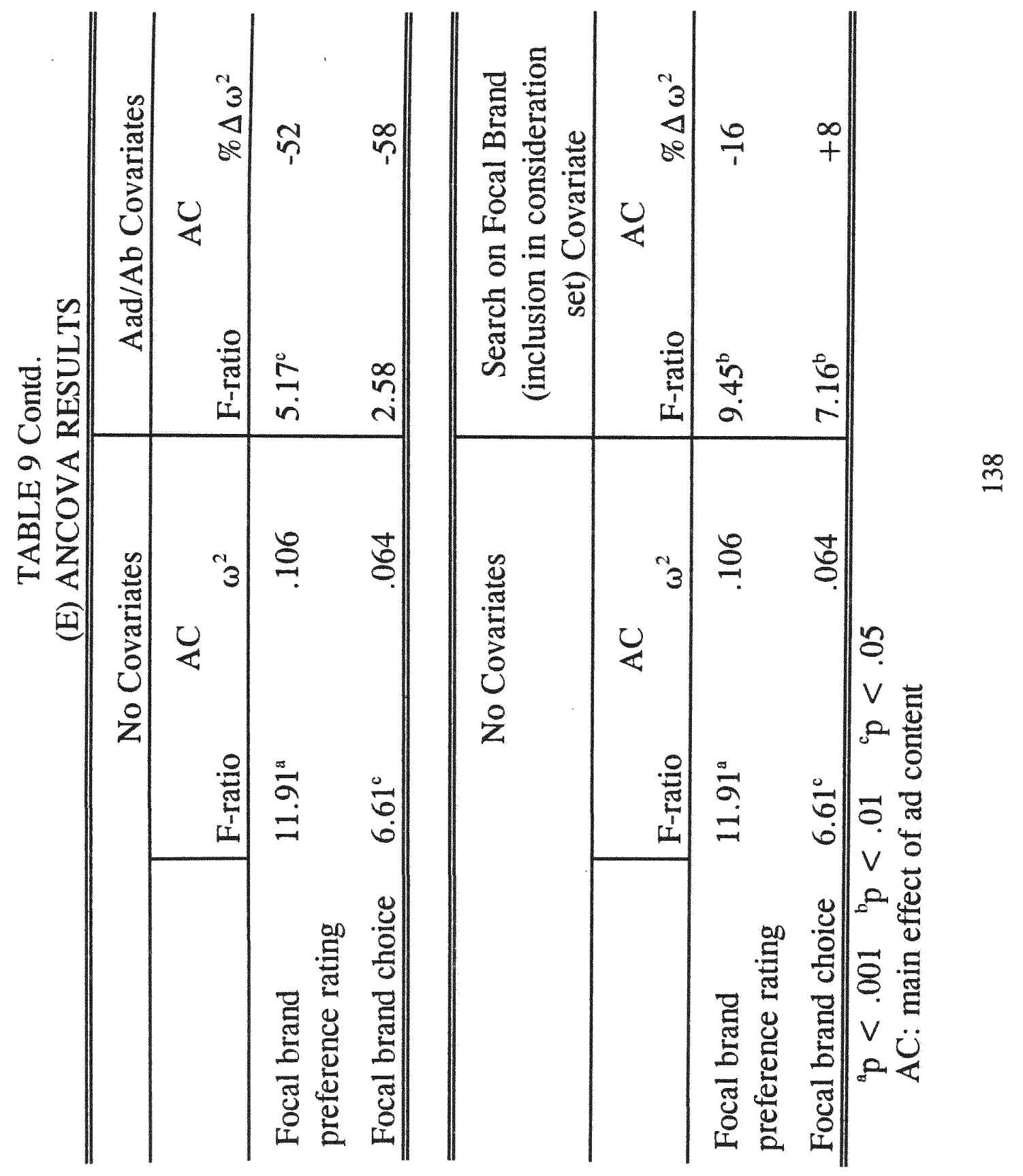


TABLE 10: CELL MEANS FOR MANIPULATION AND INDUCTION CHECKS: EXPERIMENT 2

\begin{tabular}{|c|c|c|c|c|}
\hline \multirow[b]{2}{*}{ Measures } & \multicolumn{2}{|c|}{ Lower Ability Group } & \multicolumn{2}{|c|}{ Higher Ability Group } \\
\hline & Control & Peripheral & Control & Peripheral \\
\hline \multicolumn{5}{|c|}{ ABILITY TO PROCESS MANIPULATION } \\
\hline Subjective knowledge $\mathrm{e}^{\mathrm{a}}$ & 3.20 & 3.35 & 4.39 & 4.50 \\
\hline Ability to process ${ }^{b}$ & 1.15 & 1.00 & 4.19 & 3.88 \\
\hline \multicolumn{5}{|c|}{ TASK INVOLVEMENT INDUCTION } \\
\hline Care vs paper towels & 7.06 & 6.44 & 7.28 & 7.61 \\
\hline $\begin{array}{l}\text { Care vs electronic } \\
\text { products }\end{array}$ & 5.15 & 4.91 & 5.66 & 5.94 \\
\hline $\begin{array}{l}\text { Importance of choosing } \\
\text { the best model }\end{array}$ & 6.33 & 7.00 & 6.38 & 6.87 \\
\hline \multicolumn{5}{|c|}{ AD CONTENT MANIPULATION } \\
\hline Picture quality ${ }^{\mathrm{c}}$ & 5.21 & 4.76 & 4.44 & 4.53 \\
\hline $\begin{array}{l}\text { Technical } \\
\text { sophistication }^{\mathrm{c}}\end{array}$ & 4.73 & 4.58 & 4.28 & 4.91 \\
\hline User friendliness $^{\mathrm{c}}$ & 6.27 & 6.39 & 6.00 & 6.78 \\
\hline $\begin{array}{l}\text { a. Scale ranges from 1-7 } \\
\text { c. Scale ranges from 1-9 }\end{array}$ & \multicolumn{4}{|c|}{ b. Scale ranges from $0-5$} \\
\hline
\end{tabular}


TABLE 11: MANIPULATION AND INDUCTION CHECKS:

EXPERIMENT 2 (F-values for $2 \times 2$ ANOVAs)

\begin{tabular}{|c|c|c|c|}
\hline \multirow[b]{2}{*}{ Measure } & \multicolumn{2}{|c|}{ Main Effects } & $\begin{array}{l}\text { Interaction } \\
\text { Effect }\end{array}$ \\
\hline & $\begin{array}{c}\text { Ability } \\
\text { Level } \\
(\mathrm{AL}) \\
\end{array}$ & $\begin{array}{l}\text { Ad Content } \\
\text { (AC) }\end{array}$ & $\mathrm{AL} \times \mathrm{AC}$ \\
\hline \multicolumn{4}{|c|}{ ABILITY TO PROCESS MANIPULATION } \\
\hline Subjective knowledge & $37.89^{a}$ & 0.47 & 0.01 \\
\hline Objective knowledge & $152.42^{\mathrm{a}}$ & 0.93 & 0.11 \\
\hline \multicolumn{4}{|c|}{ TASK INVOLVEMENT INDUCTION } \\
\hline Care vs paper towels & $5.24^{\mathrm{c}}$ & 0.27 & 2.45 \\
\hline $\begin{array}{l}\text { Care vs electronic } \\
\text { products }\end{array}$ & $7.15^{\mathrm{b}}$ & 0.00 & 0.82 \\
\hline $\begin{array}{l}\text { Importance of } \\
\text { choosing the best } \\
\text { model }\end{array}$ & 0.01 & 2.57 & 0.06 \\
\hline \multicolumn{4}{|c|}{ AD CONTENT MANIPULATION } \\
\hline Picture quality & 2.47 & 0.34 & 0.74 \\
\hline $\begin{array}{l}\text { Technical } \\
\text { sophistication }\end{array}$ & 0.02 & 0.35 & 0.98 \\
\hline User friendliness & 0.03 & 1.68 & 0.92 \\
\hline
\end{tabular}




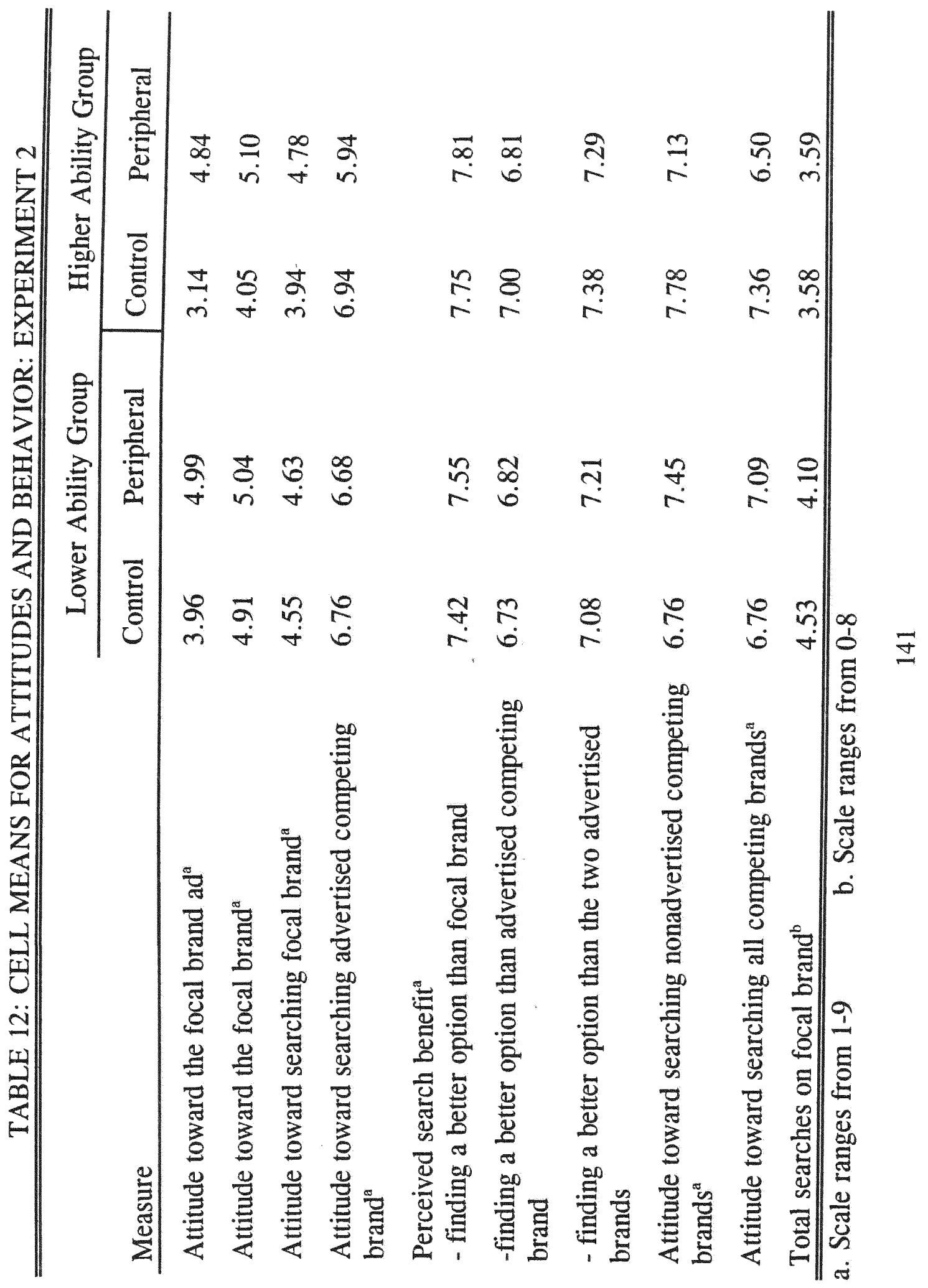




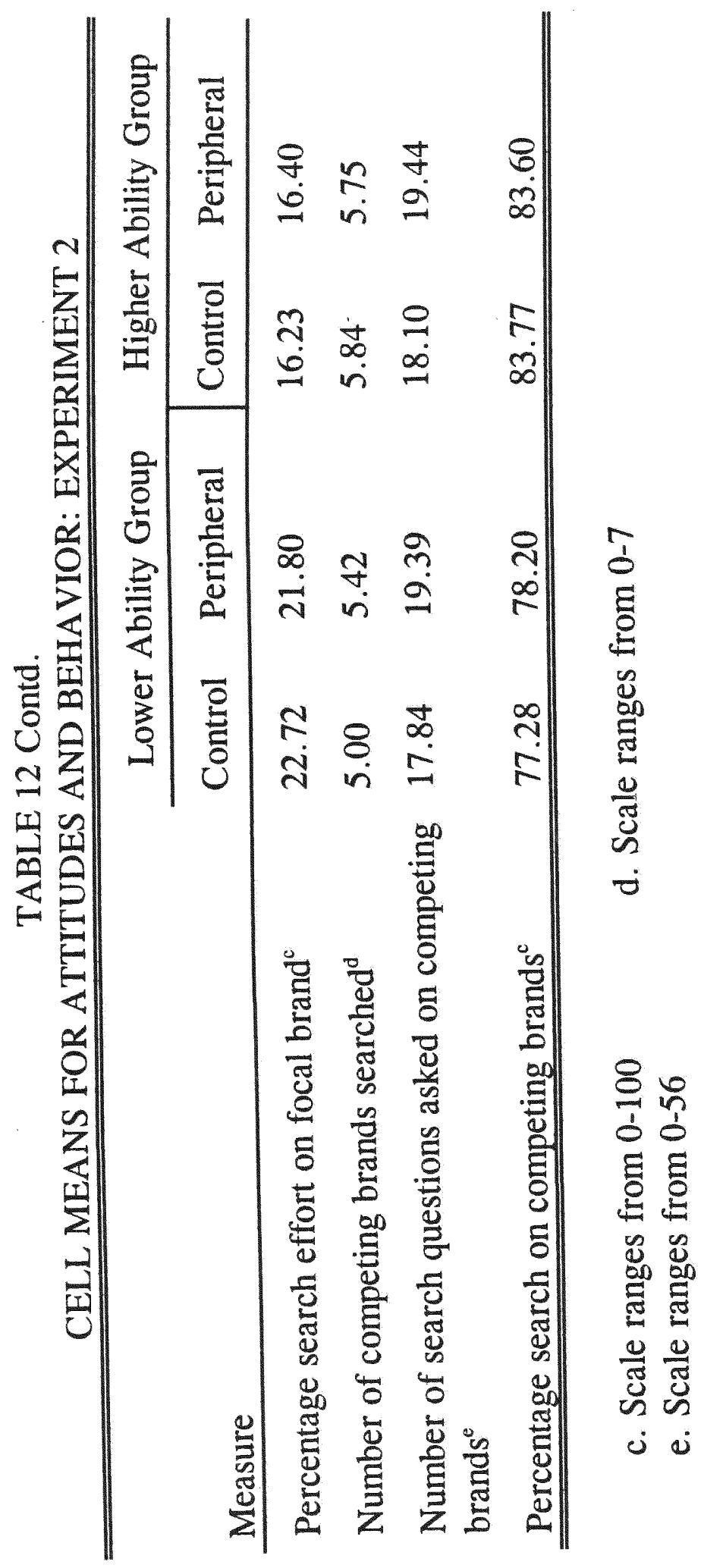


TABLE 13: SEARCH ATTITUDES AND BEHAVIOR: EXPERIMENT 2 (Fvalues for $2 \times 2$ ANOVAs)

\begin{tabular}{|c|c|c|c|}
\hline \multirow[b]{2}{*}{ Measure } & \multicolumn{2}{|c|}{ Main Effects } & \multirow{2}{*}{$\begin{array}{l}\text { Interaction Effect } \\
\mathrm{AL} \times \mathrm{AC} \\
\end{array}$} \\
\hline & $\begin{array}{l}\text { Ability Level } \\
\text { (AL) }\end{array}$ & $\begin{array}{l}\text { Ad Content } \\
\text { (AC) }\end{array}$ & \\
\hline $\begin{array}{l}\text { Attitude toward focal } \\
\text { brand ad }\end{array}$ & 1.86 & $14.68^{\mathrm{a}}$ & 0.91 \\
\hline $\begin{array}{l}\text { Attitude toward focal } \\
\text { brand }\end{array}$ & 1.43 & $3.24^{c}$ & 1.96 \\
\hline $\begin{array}{l}\text { Attitude toward searching } \\
\text { focal brand }\end{array}$ & 0.28 & 1.14 & 0.79 \\
\hline $\begin{array}{l}\text { Attitude toward searching } \\
\text { the advertised competing } \\
\text { brand }\end{array}$ & 0.49 & 1.72 & 1.31 \\
\hline $\begin{array}{l}\text { Perceived search benefit } \\
\text { - finding a better option } \\
\text { than focal brand }\end{array}$ & 1.01 & 0.10 & 0.01 \\
\hline $\begin{array}{l}\text {-finding a better option } \\
\text { than advertised competing } \\
\text { brand }\end{array}$ & 0.14 & 0.02 & 0.18 \\
\hline $\begin{array}{l}\text { - finding a better option } \\
\text { than the two advertised } \\
\text { brands }\end{array}$ & 0.48 & 0.01 & 0.15 \\
\hline $\begin{array}{l}\text { Attitude toward searching } \\
\text { nonadvertised competing } \\
\text { brands }\end{array}$ & 1.12 & 0.01 & $4.25^{\mathrm{b}}$ \\
\hline $\begin{array}{l}\text { Attitude toward searching } \\
\text { all competing brands }\end{array}$ & 0.00 & 0.99 & $5.81^{b}$ \\
\hline $\begin{array}{l}\text { Total searches on focal } \\
\text { brand }\end{array}$ & 1.89 & 0.16 & 0.18 \\
\hline
\end{tabular}




\section{TABLE 13 Contd}

F-values for $2 \times 2$ ANOVAs

\begin{tabular}{lccc}
\hline & \multicolumn{2}{c}{ Main Effects } & $\begin{array}{c}\text { Interaction } \\
\text { Effect }\end{array}$ \\
\cline { 2 - 4 } Measure & $\begin{array}{c}\text { Ability } \\
\text { Level (AL) }\end{array}$ & $\begin{array}{c}\text { Ad Content } \\
\text { (AC) }\end{array}$ & AL X AC \\
\hline $\begin{array}{l}\text { Percentage search } \\
\text { effort on focal brand }\end{array}$ & $4.72^{b}$ & 0.02 & 0.09 \\
$\begin{array}{l}\text { Number of competing } \\
\text { brands searched }\end{array}$ & & & \\
$\begin{array}{l}\text { Number of search } \\
\text { questions asked on } \\
\text { competing brands } \\
\begin{array}{l}\text { Percentage search } \\
\text { effort on competing } \\
\text { brands }\end{array}\end{array}$ \\
\begin{tabular}{l} 
Focal brand rating \\
\hline \hline
\end{tabular}
\end{tabular}




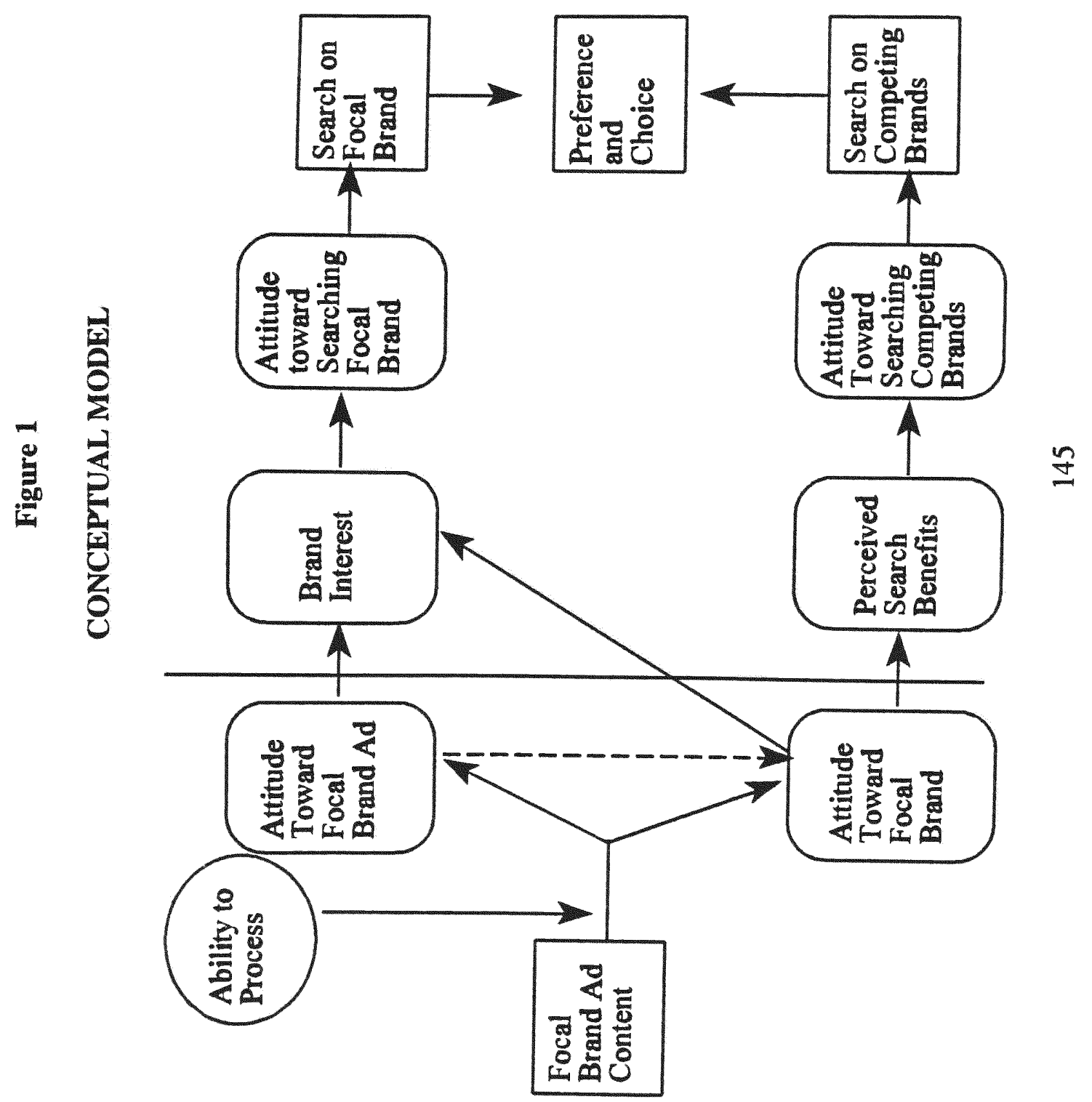


June 19, 1964

1984

1986

1986-1988

1988-1992

1990

1991

1991

1993-1995
Born, Moradabad, India

B.A.(Honors), Economics

Lady Sriram College, Delhi Univ Delhi, India

M.B.A. (Marketing major)

Faculty of Management Studies, Delhi Univ., India

Research Trainee

Feedback Management Services

Delhi, India

Project Director

Indian Market Research Bureau

Delhi, India

Guest Lecturer

Management Development Institute

Gurgaon, India

Visiting Faculty

Institute of Management Technology

Ghaziabad, India

Guest Lecturer

Times School of Management

Delhi, India

Instructor

Florida International University Miami, Florida 


\section{ACADEMIC HONORS AND AWARDS}

Recipient of the Citation of Excellence in 1997 by ANBAR Electronic Intelligence for the paper titled "India and the USA: The Relationship Between Situational Variables and Purchasing" published in the International Marketing Review, Vol 13 (6).

Recipient of the First Prize in 1997 Graduate Students Association (Florida International University) Annual Paper Competition: Business Category. Paper titled "Marketing on the Worldwide Web: An Exploratory Study".

Recipient of the Best-in-Track Paper (Research Methodology Track) in 1996 Academy of Marketing Science Conference. Paper titled "The Impact of Respondent Accountability on Carry-Over Effects in Marketing Research."

Recipient of the Second Place in 1996 Academy of Marketing Science Conference, Jane K. Fenyo Student Paper Competition. Paper titled "Shopping Behavior: A Cross-Cultural Comparison."

American Marketing Association Doctoral Consortium Fellow (1995).

Recipient of the First Prize in 1995 Graduate Students Association (Florida International University) Annual Paper Competition: Business Category. Paper titled "Shopping Behavior: A Cross-Cultural Analysis".

Recipient of the Second Prize in 1994 Graduate Students Association (Florida International University) Annual Paper Competition: Humanities Category. Paper titled "The Impact of Respondent Accountability on Carryover Effects in Marketing Research". 


\section{PUBLICATIONS AND PRESENTATIONS}

\section{Journals}

Zanakis, F, Solomon A. Anthony, Sandipa Dublish, and Nicole Wishart (1997), "Multi-Attribute Decision Making: A Comparison of Select Methods," forthcoming in the European Journal of Operational Research.

Nicholls, J.A:F, Sydney Roslow, and Sandipa Dublish (1997), "Time and Companionship: Key Factors in Hispanic Shopping Behaviors," Journal of Consumer Marketing, 14 (3), 194-205.

Nicholls, J.A.F, Sydney Roslow, and Sandipa Dublish (1997), "Hispanic and Non-Hispanic Mall Shoppers: Segmentation by Situational Variables and Purchase Behaviors," Journal of Segmentation in Marketing, 1 (1), 57-74.

Nicholls, J.A.F, Sydney Roslow, Sandipa Dublish, and Lucette B. Comer (1996), "Situational Influences on Shoppers: Exploratory Research in India and the United States," Journal of International Consumer Marketing, 9 (2), 21-39.

Nicholls, J.A.F, Sydney Roslow, and Sandipa Dublish (1996), "Interaction Between Situational Variables and Purchasing in India and the United States" International Marketing Review, 13(6), 6-21.

\section{Conference Proceedings}

Dublish, Sandipa, F. B. Seaton, and H. Laskey (1998), "Effects of English versus Spanish Ads on Bilingual Hispanics: Moderating Role of Language Dominance," forthcoming in Developments in Marketing Science, proceedings of the Annual Conference of the Academy of Marketing Science, Vol 21.

Miniard, P.W., Mary Jane Burns, Kimberly A. Taylor, Sandipa Dublish, and Mahatapa Palit (1997), "The Impact of Choice Sets on Postconsumption Evaluations," in the proceedings of the Society for Consumer Psychology Conference, St. Petersburg, Florida (February 13-15), pp.55-56 (abstract). 
Dublish, Sandipa, Mary Jane Burns, and A.V. Muthukrishnan (1996), "The Impact of Respondent Accountability on Carry-Over Effects in Marketing Research, " in Developments in Marketing Science, proceedings of the Annual Conference of the Academy of Marketing Science, Vol 19, 105-108.

Dublish, Sandipa (1996), "Shopping Behavior: A Cross-Cultural Comparison," in Developments in Marketing Science, proceedings of the Annual Conference of the Academy of Marketing Science, Vol 19, p.198 (abstract).

Nicholls, J.A.F., Sydney Roslow, and Sandipa Dublish (1996), "Hispanic and Non-Hispanic Mall Shoppers," in the proceedings of the National convention of Hispanic and Latino Studies, Houston, Texas (February 13-17), pp. 231250.

Nicholls, J.A.F., S.Roslow, L.B.Comer, and Sandipa Dublish (1995), "Shopper Situation Attributes in India and the United States,", in Developments in Marketing Science, proceedings of the Annual Conference of the Academy of Marketing Science, Vol 18, p.33 (abstract).

Nicholls, J.A.F., S.Roslow, L.B. Comer, and Sandipa Dublish (1995), "Interaction Between Situational Variables and Shopping in India and United States," in the proceedings of the 1995 American Marketing Association: Winter Educators Conference, Vol. 6, p.358 (abstract).

\section{Paper presentations}

"Effects of English versus Spanish Ads on Bilingual Hispanics: Moderating Role of Language Dominance," (with F.B. Seaton and H. Laskey) to be presented at the 1998 Academy of Marketing Science Conference, Norfolk, Virginia (May).

"Hispanic Shoppers in the United States and Turkish Shoppers in Cyprus: Similarities and Differences in Situational Attributes and Purchase Behavior," (with J.A.F. Nicholls and S. Roslow) presented at the 1997 National Convention of the National Association of Hispanic \& Latino Studies, Houston, Texas (February). 
"Hispanics by Degree of Language Compared with Non-Hispanic Mall Shoppers," (with J.A.F. Nicholls and S. Roslow), presented at the 1996 International Conference of the Academy of Business Administration, Athens, Greece (July).

"Shopping Behavior: A Cross-Cultural Comparison," presented at the $\underline{1996}$ Academy of Marketing Science Annual Conference, Phoenix, Arizona (May).

"The Impact of Respondent Accountability on Carryover-Effects in Marketing Research," (with M.J.Burns and A.V.Muthukrishnan), presented at the 1996 Academy of Marketing Science Annual Conference, Phoenix, Arizona (May).

"Top-of-Mind Brand Awareness: Spectators at Golf and Tennis Tournaments," (with J.A.F.Nicholls and S.Roslow), presented at the 1996 American Marketing Association: Winter Educators Conference, Hilton Head, South Carolina (February).

"Hispanic and Non-Hispanic Mall Shopping," (with J.A.F.Nicholls and S.Roslow), presented at the 1996 National Convention of the National Association of Hispanic and Latino Studies, Houston, Texas (February).

"Shopper Situation Attributes in India and the United States," (with J.A.F.Nicholls, S.Roslow, and L.B.Comer), presented at the 1995 Academy of Marketing Science Conference, Orlando, Florida (May).

"Interaction Between Situational Variables and Shopping in India and United States," (with J.A.F.Nicholls, S.Roslow and L.B. Comer), presented at the 1995 American Marketing Association: Winter Educators Conference, La Jolla, San Diego (February). 